
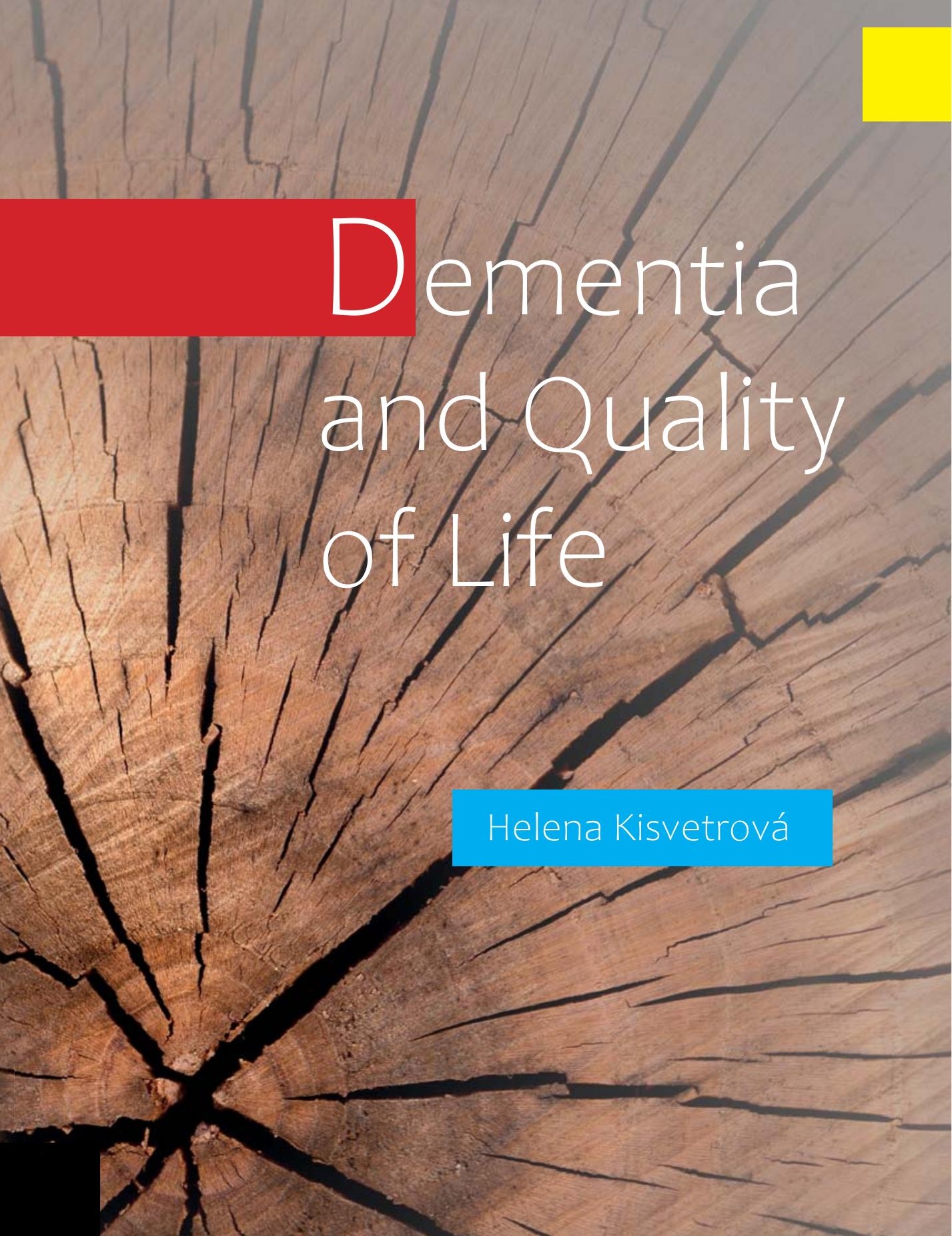
PALACKÝ UNIVERSITY OLOMOUC

FACULTY OF HEALTH SCIENCES

\section{DEMENTIA \\ AND QUALITY OF LIFE}

Helena Kisvetrová 
Reviewers: prof. MUDr. David Školoudík, Ph.D., FESO, FEAN

MUDr. Milena Bretšnajdrová, Ph.D.

\section{(ㄷ)(1) $(8$}

This work is subject to the Creative Commons Licence:

Quote the source - do not use the work commercially observe the 4.0 International Licence.

To see the licence conditions, go to http://creativecommons.org/licenses/by-nc/4.0/

This work has been supported by the programme projects of the Ministry of Health of the Czech Republic with the registered number 16-28628A and NU20-07-00100.

Unauthorized use of the work is a breach of copyright and may be subject to civil, administrative or criminal liability.

First edition

(c) Helena Kisvetrová, 2020

(c) Palacký University Olomouc, 2020

Translation @ Helena Tylšarová, 2020

DOI: $10.5507 / f z v .20 .24457772$

ISBN 978-80-244-5777-2 (print)

ISBN 978-80-244-5778-9 (online: PDF) 


\section{Contents}

List of abbreviations

Preface

Introduction

1/ Dementia

1.1 Definition of dementia

1.1.1 Risk factors for the development of dementia

1.2 Basic classification of dementias

1.2.1 Atrophic-degenerative dementias

1.2.2 Secondary dementias

20

1.3 Disorders in the cognitive functions and dementia stages

1.4 Screening tools to assess cognitive functions

1.4.1 Mini-Mental State Examination

1.4.2 Other screening tools 
2.1 Definition of quality of life 32

2.2 Quality of life in people with dementia 36

2.3 Assessment of quality of life 37

2.4 Assessment tools $\quad 40$

2.4.1 Quality of Life - Alzheimer's Disease Questionnaire 42

3/Determinants of quality of life $\quad 46$

3.1 Demographic characteristics 47

$\begin{array}{ll}3.2 & \text { Health }\end{array}$

3.2.1 Physical fitness $\quad 48$

3.2.1.1 Short Physical Performance Battery $\quad 48$

3.2.2 Self-sufficiency in activities of daily living 50

3.2.2.1 Bristol Activities of Daily Living Scale 50

3.2.3 Cognition $\quad 52$

3.2.4 Pain $\quad 52$

3.3 Psychological and emotional area 53

3.3.1 Depression $\quad 54$

3.3.1.1 Geriatric Depression Scale $\quad 55$

3.3.2 Attitudes to old age and ageing 57

3.3.2.1 Attitude to Ageing Questionnaire 58

3.3.3 Dignity 60

3.3.3.1 Patient Dignity Inventory $\quad 65$

$\begin{array}{ll}3.3 .4 \text { Fear of falling } & 71\end{array}$

3·3.4.1 Falls Efficacy Scale-International $\quad 71$

$\begin{array}{ll}3.4 & \text { Social and relationship area } \\ \end{array}$ 
4/ Trajectory of quality of life

4.1 Theoretical background and aims of the study 76

4.2 Sample and methodology 79

4.3 Results

82

Conclusion

Summary

List of tables

Name index 98

Subject index

References

102 



\section{List of abbreviations}

a alpha

7MST 7 Minute Screen Test

AAQ Attitudes to Ageing Questionnaire

AC1 Gwet's Coefficient

ACE Addenbrooke's Cognitive Examination

ADI Alzheimer's Disease International

ADL Activities of Daily Living

ADRQL Alzheimer's Disease-Related Quality of Life

ALBA Amnesia Light and Brief Assessment

ARS Affect Rating Scale

ATOA Attitude toward Own Aging

AZV CR Czech Health Research Council

BADLS Bristol Activities of Daily Living Scale

BDI-II Beck Depression Inventory

BV Brief Version

CDT Clock Drawing Test

CR Czech Republic

CZSO Czech Statistical Office

EFA Exploratory Factor Analysis

e.g. For example

EV Expanded Version

FES-I Falls Efficacy Scale-International 
G8 Group of Eight (association of the most economically advanced countries in the world)

GDS Geriatric Depression Scale

HAMD Hamilton Scale of Depression

HRQOL Health-related Quality of Life

HVAS Horizontal Visual Analogue Scale

ICC Intraclass Correlation Coefficient

ICD International Statistical Classification of Diseases and Related Health Problems

i.e. That is

IGA UP Internal Grant Agency of Palacký University Olomouc

IHIS CR The Institute of Health Information and Statistics of the Czech Republic

KMO Kaiser-Meyer-Olkin Measure

$\mathrm{MCl} \quad$ Mild Cognitive Impairment

MMS Mini-Mental State

MMSE Mini-Mental State Examination

MoCA Montreal Cognitive Assessment

NIA The National Institute on Aging

NIH The National Institutes of Health

NINDS The National Institute of Neurological Disorders and Stroke

p Statistical significance

PCA Principal Component Analysis

PDI Patient Dignity Inventory

ProFaNe Prevention of Falls Network Europe

QOL-AD Quality of life-Alzheimer's Disease Questionnaire

SCD Subjective Cognitive Decline

SPPB Short Physical Performance Battery

SV Standard Version

UN United Nations

UNPF United Nations Population Fund

VAS Visual Analogue Scale

VIF Variance Inflation Factor

WHO World Health Organisation 


\section{Preface}

Dementia presents a worldwide challenge in the $21^{\text {st }}$ century. It is a global phenomenon in the field of health and society and it affects the whole population. The Alzheimer Europe Organisation (2019) states that in 2018 the estimated prevalence of dementia in Europe was around 9.8 million people and by 2050 they expect this to grow up to 12.3 million people. Thus, according to the WHO, dementia presents one of the most significant global problems that the health system is dealing with at the beginning of the $21^{\text {st }}$ century. Therefore, the treatment to support or increase the life quality of patients with dementia is among the key aims of the health services. In order to be able to provide such care, it is necessary to know how the patients with dementia themselves evaluate their own quality of life, which factors influence dementia and how the patients' evaluation of the quality of life changes in the long run. That was the reason to conduct a study whose theoretical sources and results are presented in this work.

The aim of this monograph is to bring a basic overview of information on dementia, the quality of life and the results of the longitudinal multicentre prospective study focusing on the trajectory of quality of life in older adults in the early stage of dementia, which was conducted in 2016-2019 in three regions of the Czech Republic (Olomouc, Hradec Králové, and Ostrava). The book is divided into three chapters. The first one deals with dementia, its definition, classification and potential screening assessment needed to create theoretical sources for the study. For this 
reason, the text does not include information about pharmacotherapy or non-pharmacological treatment used for the patients with dementia. The second chapter deals with the quality of life, both in general terms and in people with dementia. It also informs about the assessment tools for the life quality field. The focus of the third chapter is on the individual determinants of the quality of life and the tools that can be used to assess it. Greater attention is paid to the assessment tools that have been used in the study. The last chapter describes the evaluation of the quality of life by people in the early stage of dementia and compares it to the quality of life in older adults with no cognitive deficit. In the conclusion, we can read about the predictors of change of life quality in people with dementia that were detected within the two years.

I believe that this monograph and the study results it presents may contribute to a better understanding of the life quality in older adults in the early stage of dementia in the long-term perspective, including the identified predictors indicating its change.

Helena Kisvetrová 


\section{Introduction}

The ageing of the population is one of the most significant and important demographic challenges of the $21^{\text {st }}$ century. It has a wide impact on the whole society. In almost all the regions of the world, the number of inhabitants over the age of 60 is growing faster than does the whole population. In 1950 this category consisted of 205 million people. In 2017 the number grew to 962 million and according to the population prognoses, in 2050 there will be more than two billion people aged over 60 which will correspond to approximately $22 \%$ of the global population (UNPF, 2012; UN, 2017).

Due to the increasing geriatrisation in population, older people represent a much larger part of all the inhabitants than they have ever done in the past. Globally, the number of people over the age of 80 is growing much faster than any other category of the elderly population. In the Czech Republic, the demographic evolution is similar and our population has been ageing since the end of the 1980s. Recently, there has been an exceptional acceleration in the growth of the category of people aged 80 and over (CZSO, 2018).

At present, there are about 47 million people with dementia in the whole world. Local estimates of the dementia prevalence in people aged 60 and over range from $4.6 \%$ in central Europe to $8.7 \%$ in North Africa and in the Middle East. There is an estimate that by 2050 there will be up to 131 million people with dementia in the world (ADI, 2016; ADI, 2018). By this, dementia is becoming one of the most frequent diseases in the 
current society. In the Czech Republic about 156 thousand people suffer from it and this number is expected to grow up to 383 thousand by 2050 (Mátl et al., 2016). Dementia not only affects the patients, it also has a significant impact on their caregivers, families and the whole society. Therefore, it presents a global problem with crucial health and social consequences and is becoming a great challenge for the health and social policies of individual countries (Moniz-Cook et al., 2008).

In 2013 the Summit of Group of Eight (G8, an association of the most economically advanced countries in the world) dealt with the topic of dementia research. It gave a recommendation that a research priority to focus on should be the maximisation of the quality of life and social well-being of people with dementia (Shah et al., 2016). The quality of life as a subjective multidimensional construct includes both the individual experience and evaluation regarding the mental well-being and physical fitness, one's social and cognitive competence, as well as one's interaction with the surroundings (Whitehouse, Rabins, 1992). From a long-term perspective, observing the quality of life in people with dementia, the knowledge of factors influencing it and the identification of the predictors that might change it can be a significant source for the definition of optimal intervention to support the protection and maximisation of the quality of life in older adults with dementia. 


\section{$1 /$ Dementia}

Dementia is a global medical and social challenge that affects the whole society. On average, people with dementia have a chance to live seven to ten years after they are diagnosed (Mátl et al., 2016) and the number of people dying of dementia is gradually growing. In the period of 2000-2016 the number of deaths caused by dementia more than doubled and in 2016 dementia became the fifth main cause of death. This was a big shift from the year 2000 when it occupied only the fourteenth position worldwide (Fymat, 2018).

\subsection{Definition of dementia}

In its report "Dementia: A public health priority" the WHO defines dementia as "a syndrome caused by a brain disease which is mostly of chronical and progressive character. It causes the failure of advanced brain functions including memory, thinking, orientation, understanding, counting, learning, language and judgement. The consciousness is usually not affected. The decrease in the cognitive functions is usually accompanied by a worsened emotional control, social behaviour or motivation, which in some cases can precede the worsening of the cognitive function" (IHIS CR, 2012, p. 1-2). The dementia syndrome appears with various diseases affecting the brain in a primary or secondary way. This progressive irreversible organic mental illness originates after an 
individual's development of cognitive functions is completed and it can be affected by a number of factors (Pereira et al., 2015).

The basic areas that are affected by advanced dementia include both the cognitive and the non-cognitive functions (behavioural and psychological symptoms, associated psychotic symptoms and deliria) and activities of daily living (failures in executive functions) (Jirák, 2004; Dijkstra et al., 2004). Therefore, dementia presents the main cause of the loss of selfsufficiency, of dependence on the provision of care and of disability in elderly people (IHIS CR, 2012). This means that individuals will live about $12 \%$ of their lifetime with a disability caused by this chronic incurable disease.

According to the World Health Organisation (WHO), the term of dementia is therefore an overall term for more diseases affecting the memory, other cognitive skills and behaviour by which they significantly disturb the individual's ability to keep their self-sufficiency in activities of daily living ( $A D L)$. Although age is the best known risk factor for dementia, dementia is not a common part of normal ageing (WHO, 2017).

The National Institute of Neurological Disorders and Stroke (NINDS) and the National Institute on Aging (NIA), which are part of the National Institutes of Health (NIH), state that dementia is a group of symptoms caused by failures that affect the brain. It brings the loss of cognitive functions, which disturbs the individual's everyday life and activities. The functions that are affected by dementia include memory, language skills, visual perception, problem solving, and the ability to concentrate and pay attention to something. Although memory loss is a typical dementia syndrome, the memory loss itself does not indicate dementia. Dementia cannot be mistaken for the age-related deterioration of cognitive functions when performance is slower in the areas of thinking, memory and information processing but the level of intelligence does not change. Even though it is normal for older adults to be forgetful from time to time, many elderly people live without any symptoms of dementia even at a very high age (NIH, 2017). 


\subsubsection{Risk factors for the development of dementia}

Factors that can increase the risk in individuals for the development of a type of dementia include both those that cannot be influenced (e.g. age, sex, genetic predisposition) and those that can be influenced, such as the cardiovascular risk factors (e.g. the arterial hypertension, Diabetes Mellitus, dyslipidaemia, obesity), psycho-social factors (depression), health manners (low amount of physical or mental activity, smoking, alcohol consumption), head trauma (brain injuries) and the level of education (Hanyu, 2018; Livingston et al., 2017; National Academies of Sciences, Engineering, and Medicine, et al., 2017). In older patients, dementia risk factors also include the loss of weight connected with the frailty and sarcopenia, hearing impairment and social isolation (Kuiper et al., 2015; NICE, 2015).

Basic information on the selected factors is listed below:

Age - This is the best known primary risk factor for the development of dementia (NIH, 2017). For this reason, the demographic shift in the society is connected with a higher occurrence and prevalence of dementia which increases exponentially with age (in Western and middle Europe the occurrence of dementia doubles when age increases by 6.5 years).

? Sex - Women occur more frequently among older patients with dementia. This is connected to their higher life expectancy as compared to men. ADI (2015) states that in some regions there has been noted an independent influence of sex on the prevalence of dementia. In regions such as East Asia, the Caribbean, Western Europe and Latin America the presumed prevalence of dementia was $14-32 \%$ lower in men than that in women. However, this effect has not been proven as statistically significant in other regions.

- Genetic predisposition - The risk of developing a genetically-caused form of dementia increases if it has occurred in more than one family member.

? Down syndrome - In middle-aged individuals with Down syndrome we are more likely to encounter the symptoms of Alzheimer's disease. 
I Atherosclerosis - This means building up fat and cholesterol together with changes in the artery structure, infectious processes, bleeding in the atheroma, gradual narrowing of arteries, necrosis in the atheroma, thrombosis and subsequent decrease in blood circulation in the brain and the risk of brain infarct in these veins. These factors increase not only the risk of vascular dementia but also other dementia types including Alzheimer's disease.

- Arterial hypertension - It is connected with the dementia types that damage the white brain matter; it is a risk factor both for the onset of vascular dementia and for Alzheimer's disease.

Stroke - This increases the risk of developing vascular dementia, in some cases it is its sole cause.

D Diabetes Mellitus - In patients with the compensated but mainly in patients with decompensated Diabetes Mellitus, the risk of dementia is higher, especially that of the vascular dementia.

OParkinson's disease - Degeneration and dying of brain cells in patients with this disease often leads to a significant loss of memory and other cognitive functions and to the development of dementia; similarly, in patients with Alzheimer's disease, this leads to the increased risk of parkinsonian symptoms.

$\rightarrow$ Education - It is assumed that a low level of education makes people prone to cognitive decreases. This results in a smaller cognitive reserve (Valenzuela, Sachde, 2006) which enables the individual to keep the cognitive functions in spite of the brain pathology (Valenzuela, 2008).

$\rightarrow$ Head injury - This can cause trauma to the brain and lead to the onset of dementia and other serious cognitive problems.

? Alcohol abuse - Regular consumption of excessive amounts of alcohol increases the risk of a specific dementia (Wernicke-Korsakoff syndrome).

Smoking - This increases the risk of a cardiovascular disease which slows or blocks the blood flow into the brain and can thus contribute to the development of dementia. 
- Social isolation - This can cause lack of cognitive activities which is connected to the faster decrease in cognitive functions and therefore it is a risk factor for dementia.

- Movement - The lack of regular physical activity is also considered a risk factor for the onset of dementia (Livingston et al., 2017). In this respect, some authors state that physical activity can help slow down the worsening of the cognitive deficit in individuals with dementia (Dishman et al., 2006; Rockwood, Middleton, 2007; Vaughan et al., 2014; Leckie et al., 2014). On the contrary, Sabia et al. (2017) have not found any proof of a neuroprotective effect that physical activity would have. They assume that the results of the previous studies showing lower risks of dementia in physically active people can be assigned to the reverse causality, specifically to the result of the decrease in physical activity in the pre-clinical phase of dementia.

\subsection{Basic classification of dementias}

There are more criteria to classify dementias upon. The basic classification includes classification based on the cause into two basic groups, i. e. primarily degenerative dementias, originating due to atrophic-degenerative processes and secondary (symptomatic) dementias.

\subsubsection{Atrophic-degenerative dementias}

In atrophic-degenerative impairment, dementia originates due to processes leading to the decrease in the number of neurons, to a disruption in the function of neurons and neuroglia (supporting nerve cells) and to the reduction of the number of neuron synapses. This kind of dementia creates over $60 \%$ of all dementias. It is characterised by the creation and storage of pathological protein with many other degenerative processes. Neurodegeneration then results in a brain malfunction and a subsequent onset of the dementia syndrome (Jirák et al., 2009). 
The most frequent atrophic-degenerative dementia is Alzheimer's disease.

O Alzheimer's disease accounts for almost $70 \%$ of all dementias. It usually affects individuals over the age of 65 and its incidence and prevalence rises with age. A higher occurrence has been proven in women; in women aged 85 and over its incidence is almost 50\%. Similarly to other neurogenerative dementias, Alzheimer's disease has a typical slow onset with memory impairment and gradual deterioration of cognitive functions. This leads to the complete loss of self-sufficiency and ability to have meaningful communication with others (Krombholz, 2011).

$\rightarrow$ Lewy body dementia is the second most frequent neurogenerative dementia, following Alzheimer's disease. Besides the basic dementia symptoms it is characteristic for its fluctuating impairments in cognitive functions, recurring visual hallucinations, extrapyramidal syndrome and occasional delusions (Maj, Sartorius, 2003; Sanford, 2018). The prevalence of Lewy body dementia in people aged 85 and over is more than $20 \%$ (Krombholz, 2011).

- Parkinson's disease dementia is characterised by the damage in all kinds of memory (especially the explicit and procedural one), as well as by an executive dysfunction (disability to plan and manage more complex motoric chains) and by the visuo-spatial impairment causing problems with orientation and visual analysis. Speech impairment is less marked in this kind of dementia than it is in Alzheimer's disease (Aarsland et al., 2017). In contrary to Lewy body dementia, delusions in Parkinson's disease dementia occur only as a result of pharmacotherapy. There can also occur, as well as in Lewy body dementia, delusional contents in thinking. These are usually paranoidly persecutional and often systematised. We also often encounter emulational (jealousy) bizarre delusions (Krombholz, 2011).

Frontotemporal dementia represents a heterogeneous group of neurodegenerative diseases which are characterised by clinically dominating behavioural impairments, changes in executive functions and personality changes. This is a so-called behavioural variant fronto- 
temporal dementia. There are also linguistic variants characterised by speech impairments, which include the semantic variant of the primary progressive aphasia and the nonfluent variant primary progressive aphasia (Vyhnálek, 2017). Frontotemporal dementias are typical with their selective degeneration of frontal and temporal cortices. They are seen in the progressive deterioration in the areas of behaviour, executive functions and speech. By their behavioural symptoms they can imitate some psychiatric diseases. These dementia types occur mainly in people under the age of 65 (Bang et al., 2015; Olney et al., 2017). The deficit of cognitive functions in frontotemporal dementias is often connected with motoric comorbidities (Vyhnálek, 2017).

$\checkmark$ The best known frontotemporal dementia is Pick's disease, which progresses slowly and often affects personality characteristics. At its onset, the memory is usually not impaired and the deficit lies in the area of recalling in combination with a relatively preserved ability to imprint. Executive functions are usually impaired significantly; there is a deterioration of attention, planning and visuo-spatial function. Social behaviour is often impaired and we encounter emotional numbness. Other symptoms include fixed thinking, utilitarian behaviour, and stereotypy (Krombholz, 2011).

$\checkmark$ Frontotemporal dementias also include Huntington's disease dementia, typical for its progressive motoric, behavioural, and cognitive deficit. Psychiatric symptoms occurring in this dementia include depression and anxiety. Huntington's disease dementia starts before the older age rather than in the older age itself (Wyant, Ridder, Dayalu, 2017).

$\checkmark$ Another frontotemporal dementia is Steele-Richardson-Olszewski syndrome (progressive supranuclear palsy), which is connected with the cognitive deficit and dementia of the subcortical type. Progressive supranuclear palsy is characterised by the parkinsonian syndrome, axial rigidity, postural instability with frequent falls, and disruption of eye movement (Williams et al., 2005). 


\subsubsection{Secondary dementias}

Secondary or symptomatic dementias originate when the brain function is damaged e.g. by a system disease chronic intoxication, trauma or infection. They can be further classified as vascular dementias and other symptomatic dementias (Jirák, 2004).

- Vascular dementia (vessel-related dementia) is the second most common dementia after Alzheimer's disease and it accounts for up to $20 \%$ of all dementias (Krombholz, 2011). It is characterised by the loss of cognitive functions resulting from ischaemic, haemorrhagic or hypoperfusion brain lesions caused by cerebrovascular or cardiovascular diseases. Dementia symptoms usually occur within three months of the incidence of a haemorrhagic stroke (Pidrman, 2007). Vascular dementia consists of three basic groups: strategic infarct dementia, multi-infarct dementia, and Biswanger's dementia (subcortical ischaemic leukoencephalopathy) (O’Brien, Thomas, 2015).

$\rightarrow$ Other symptomatic dementias include infectious dementia, whose incidence is rather rare (e.g. progressive paralysis and other forms of brain luetic infection), dementia caused by prion diseases (CreutzfeldtJakob disease), metabolic dementias with a hereditary basis (Wilson's disease) or without a hereditary basis (resulting from liver encephalopathy, uremic encephalopathy or with a metabolic damage), dementia caused by intoxication (alcohol dementia [Wernicke-Korsakoff syndrome]; dementia after exposure to carbon monoxide), dementia caused by tumours (primary brain tumour, metastasis in the brain, paraneoplastic dementias), and dementias after excessive brain traumas (Jirák, 2004).

\subsection{Disorders in the cognitive functions and dementia stages}

Cognitive functions can be defined as all mental processes that enable the individual to distinguish, recall, learn and adapt to permanently changing conditions of the environment. These functions include mem- 
ory, thinking, learning, receptive functions (perception of stimuli, their remembering and sorting), and expressive functions (speech, writing, drawing, expressive skills) (Raboch et al., 2008). These functions can be weakened or disturbed by various causes.

Subjective cognitive decline (SCD) is characterised by a very light cognitive decrease which appears before the incidence of an objective cognitive impairment. SCD is considered to be a pre-clinical manifestation of Alzheimer's disease (Lin et al., 2019). The state in which all dementia criteria are not fulfilled but the individual has an objectifiable cognitive deficit is called mild cognitive impairment $(\mathrm{MCl})$. Memory impairment with a parallel presence of at least one cognitive function impairment is called dementia syndrome and it can be divided into a couple of stages (Fymat, 2018).

To assess the cognitive functions, the Mini-Mental State Examination (MMSE) is most commonly used. Some studies state that the cognition impairment is diagnosed at the MMSE score of 24 and lower (Folstein et al., 1983; Folstein et al., 2001). However, the classification of impairments based on the total MMSE score is not completely unified in specialised literature. The division based on the individual authors is seen in the Tables $1-3$.

Tombaugh and Mclntyre (1992) consider the number of 24 points in the MMSE score to be the limit for individuals without cognitive impairment. However, they recommend the assessment with the MMSE to be performed in individuals who have been through at least eight years of schooling.

Table 1 Cognition assessment (Tombaugh, Mclntyre, 1992)

\begin{tabular}{lc} 
& MMSE score \\
\hline no cognitive impairment & $24-30$ points \\
mild cognitive impairment & $18-23$ points \\
\hline serious cognitive impairment & $0-17$ points \\
\hline
\end{tabular}


The MMSE scores for the individual dementia stages, as defined by Fymat (2018), are presented in Table 2.

Table 2 MMSE scores for individual dementia stages (Fymat, 2018)

\begin{tabular}{lc|}
\hline & MMSE score \\
\hline mild cognitive impairment & $27-30$ points (normal value) \\
\hline early dementia stage & $20-25$ points \\
middle dementia & $6-17$ points \\
\hline late dementia & lower than 6 points \\
\hline
\end{tabular}

In the Czech Republic, the MMSE has been used for a number of years. The division of the amount of cognitive impairment according to the MMSE score, as presented by Jirák and Koukolík (2004), is shown in Table 3. However, Štěpánková et al. (2015) have proven in a Czech normative MMSE study that the assessment of the cognition with the MMSE in healthy older adults depends on their age and education. Therefore, in an older adult with a university degree, the MMSE score of 30 points does not have to clearly indicate the absence of a cognitive deficit.

Table 3 Cognitive impairment assessment (Jirák, Koukolík, 2004)

\begin{tabular}{lc}
\hline & MMSE score \\
\hline no cognitive impairment & $27-30$ points \\
limit value (suggesting a mild cognitive impairment) & $25-26$ points \\
early stage of dementia & $24-18$ points \\
middle dementia & $6-17$ points \\
late dementia & lower than 6 points \\
\hline
\end{tabular}

\section{O Subjective cognitive decline (SCD)}

The concept of the subjective cognitive decline (SCD) was introduced by Reisberg et al. (1982). Jessen et al. (2014) describe the SCD as the patient's subjective feeling of a permanent deterioration of cognitive 
skills compared to the normal state. At the same time, there are no abnormalities in objective neuropsychological assessments. The subjective cognitive decline is considered to be a pre-clinical manifestation of Alzheimer's disease (Lin et al., 2019). While being a prodromal stage of the mild cognitive impairment $(\mathrm{MCl})$, the subjective cognitive decline can affect the individual's emotional and social functioning as well as the overall quality of life (Jenkins et al., 2015). Therefore, recently there has been an increase in studies dealing with the subjective cognitive decline (Rabin et al., 2017; Molinuevo et al., 2017; Lin et al., 2019). Yet, there is no consensus on how to assess or classify the subjective cognitive impairment and the approaches that have been used show a great amount of heterogeneity (Rabin et al., 2017).

\section{Mild cognitive impairment $(\mathrm{MCl})$}

This is a state in which the individual does not fulfil the dementia criteria but has an objectifiable cognitive deficit. It is a transition phase between the cognitive changes connected with normal ageing and the early dementia stage (Bartoš, Hasalíková, 2010). Mild cognitive impairment is characterised by memory problems which are not serious enough to affect the individual's ability to perform the activities of daily living. Other cognitive functions are within the normal range (speech, executive functions, cognition). People with a mild cognitive impairment are clinically and neuropathologically heterogeneous (DeCarli, 2003). A simple way to test the memory takes only three minutes and is called Amnesia Light and Brief Assessment (ALBA; Bartoš, 2019).

As soon as mild cognitive impairment is diagnosed, it is important to evaluate the reversible causes. At present, there is no pharmacological treatment that would be proven to slow down or cure the progression of mild cognitive impairment to prevent it from developing into dementia. However, there has been evidence that modification of one's lifestyle including diet, exercise, and cognitive stimulation can be effective in this respect (Tangalos, Petersen, 2018). The estimated prevalence of mild cognitive impairment varies from 4 to 
$19 \%$ in people aged 65 or over. This depends on the definition and its interpretation used (Livingston et al., 2017). Most commonly, in the progress of about five to eight years, mild cognitive impairment gradually develops into dementia in $50-70 \%$ of people suffering from $\mathrm{MCl}$ (Fymat, 2018).

\section{Early stage of dementia (mild dementia)}

In the early stage of dementia, patients experience a decrease in memory, problems with communication (fluent expression is becoming more difficult), impairment in executive functions, personality changes, changes of moods (depression, anxiety), and apathy (Fymat, 2018). In the early stage of dementia, individuals are still able to acknowledge their disease. In this respect, they experience fear, sadness, but also anger and refusal. Security can be established by providing order, regular daily routine and keeping rituals which help the patient with time orientation. Any changes are very confusing for them (Ritter-Rauch, 2016). In order to support the quality of life and protect the patients' dignity in this phase, it is necessary to provide them with as much information as they are able to understand. If this is not done, patients feel insecure and become suspicious and distrustful.

\section{Middle stage of dementia (developed dementia)}

Dementia at this stage is typical for increasing trouble with problem solving, worsening of social judgement, disorientation in time and space, gradual reduction of vocabulary, and lack of self-sufficiency in self-care and hygiene. Besides, patients show changes in behaviour and accentuation of negative personality characteristics (e.g. egocentrism) (Fymat, 2018). Patients forget a lot, including important events from their own past. They need a permanents caregiver's assistance in activities of daily living and hygienic care. There is also deterioration in the ability to express oneself clearly and communicate meaningfully. The spatial disorientation worsens even in familiar 
surroundings and as regards orientation in time patients cease to be able to distinguish the seasons of the year. Patients experience hallucinations, unease, and aimless wandering. This stage can take rather long and it is very demanding for family caregivers as the patient's dependence on the provided care grows. Most commonly, patients are able to move outdoors. In relation to the patient's personal dignity, it is necessary to save them in public from any mockery by the surrounding people due to their behaviour or imperfections in clothing. It is also necessary to provide the patient with the opportunity to make their own decisions in simple matters (Ritter-Rauch, 2016).

\section{$\rightarrow$ Late (severe) stage of dementia}

This stage is characterised by serious impairments to long-term memory; patients do not recognise even their closest family and friends. Speech is reduced to a couple of simple words, patients depend on the care of others, there are big changes in behaviour and both time and space orientation deepen (Fymat, 2018). Patients are more prone to infections and these are the most frequent causes of death. There are serious problems with eating and drinking (troubled chewing, swallowing, fits of cough), the risk of aspiration increases and causes the risk of aspiration pneumonia. The patient's mobility decreases, unsteady walking often leads to falling and immobility due to accidents. This stage is typical for its gradual withering away (frailty syndrome in older people). If dementia keeps progressing, permanent institutional care is usually inevitable. That presents patients with further burdens and stress. They need to cope with a transfer to an unfamiliar environment, which makes them very insecure. In order to maximise the quality of life and to protect the patients' dignity in this phase of dementia, it is necessary to provide them with social contacts in their surroundings and with manifestation of respect. 


\subsection{Screening tools to assess cognitive functions}

Assessing cognitive functions with various screening tools focuses on memory, speech, visuo-spatial, executive (performance) and cognitive functions, emotional and psychological adaptation. Falk et al. (2018) state that in case of suspected dementia there can be used short screening tests such as the Mini-Cog. If the results are worse, it is necessary to use more detailed tools for further assessment. These include the MiniMental State Examination (MMSE) or Montreal Cognitive Assessment (MoCA). The most commonly used screening test worldwide is the MiniMental State Examination (Velayudhan et al., 2014) and it is therefore described below in detail.

\subsubsection{Mini-Mental State Examination}

The Mini-Mental State (MMS), later called the Mini-Mental State Examination (MMSE), has been used since its creation and publication in 1975 in clinical practice as a screening method to detect the dementia syndrome, especially in relation to the identification of individuals with middle to serious cognitive deficit (Folstein et al., 1975; Tombaugh, McIntyre, 1992). The test is valid for psychiatric, neurological and older patients. The MMSE is also used in research studies to confirm the normal level of cognition of people taking part in the research. The MMSE provides the assessment of global cognitive functions and the level of impairment. It covers five assessment domains that focus on:

(1) Orientation (by the person, in time and space);

(2) Memory (immediate remembering and repetition of three words);

(3) Attention and counting (subtracting the number 7 from the number 100 , five times in a row);

(4) Short-term memory (recalling - repeating three objects named earlier);

(5) Speech, communication and construction abilities. 
The test is administered in about ten minutes, so it is not too demanding on the patient. The maximum score is 30 points; the better the score, the better the cognitive performance.

The tasks contained in the test are relatively simple and for this reason this test cannot be reliable as a tool to assess a mild cognitive impairment in a patient. However, the MMSE makes is possible to differentiate a middle dementia stage from normal ageing. The MMSE is a screening tool, therefore its most important psychometric characteristics is its sensitivity that makes it possible to correctly identify individuals with dementia (Lezak et al., 2012). To detect dementia, the required sensitivity is $89 \%$ and the specificity of $81 \%$ (Lin et al., 2013). Low sensitivity in the MMSE in patients with mild cognitive impairment is affected by the relative simplicity of the test in terms of memory and by a low representation of items testing the memory and also by the absence of tasks testing functions such as planning (Wind et al., 1997). The criteria for screening tests to detect the mild cognitive impairment in patients aged over 60 are better met by the Montreal Cognitive Assessment (MoCa; Nasreddine et al., 2005; Ciesielska et al., 2016). Based on a vast analysis of studies that have used the MMSE, Creavin et al. (2016) support the usage of the MMSE as a part of the decision making process about the individual's having or not having dementia. However, the test results should be interpreted in a wider context of the specific patient (personality, behaviour, and the way they perform activities of daily living). There has also been confirmed the dependence of the MMSE results on age, education and literacy (Mitchell, 2009; Štěpánková et al., 2015).

In the second half of 1990s, a Czech version of the MMSE (Brázdil et al., 1995) was created. A validation study was conducted and pilot normative data was obtained without the stratification according to education and age (Tošnerová, Bahbouh, 1998). Later, Czech norms were set for the MMSE. These were based on the percentile and standard deviations of 650 older adults with unimpaired cognitive functions (aged $69 \pm 8$ years; with the MMSE score of $28 \pm 2$ points). The norms are divided based on education and age. In patients with dementia, there was noted a significantly lower score than in those with mild cognitive impairment. Both groups of patients had a significantly lower MMSE score than the older 
people with unimpaired cognitive functions. An optimal limit value was assigned ( $\leq 27$ points) with the sensitivity of $86 \%$ and specificity of $79 \%$ for the timely detection of patients with dementia (Bartoš, Raisová, 2016). The dependence of the MMSE assessment on age and education was confirmed in a study of healthy Czech older adults by Štěpánková et al. (2015). At present, the MMSE is still the most commonly used tool in the Czech Republic for the assessment of cognitive functions. This is because its performance is required by health insurance companies to start and monitor the cognitive therapy. Since 2001, copyright laws have been applied to the MMSE and there is a fee to pay for its usage. For this reason, a sample of the questionnaire is not included in this work. Authorised translations of individual language versions of the MMSE, including the Czech one, are available at https://www.parinc.com/products/pkey/237.

At present, there is also a MMSE-2 test with its standard, brief, and expanded version. Thanks to the three different MMSE-2 versions, the examiner can choose a variant that corresponds best to the specific patient's needs.

$\checkmark$ Standard version (MMSE-2: SV) keeps the structure and scoring of the original MMSE. Its completion takes about 10-15 minutes. The scores of the MMSE and MMSE-2: SV are comparable.

$\checkmark$ Brief version (MMSE-2: BV) consists of 16 points. It can be used in clinical or research situations where fast cognitive screening is needed.

$\checkmark$ Expanded version (MMSE-2: EV) consists of 90 points. It is more sensitive to subcortical dementia and changes connected with ageing. This version includes two new tasks assessing story recalling and speed of processing.

The Czech translation of the MMSE-2 has not been done yet. Information on the MMSE-2 is available at https://www.parinc.com/products/ pkey/238. 


\subsubsection{Other screening tools}

In a brief overview below, you can find a selection of screening tools used for the assessment of cognitive functions in elderly patients.

\section{F Addenbrooke's Cognitive Examination}

The Addenbrooke's Cognitive Examination (ACE; Mathuranath et al., 2000) and its revised version ACE-R (Mioshi et al., 2006) enable the assessment of all cognitive domains including the memory, speech, executive and visuo-spatial functions. As the ACE-R version included also some MMSE items and these have been charged for copyright since 2001 (Seshadri, Mazi-Kotwal, 2012), the usage of ACE and ACE-R has become more complicated (Newman, 2015). Therefore, the authors of the original ACE test created a new version, Addenbrooke's Cognitive Examination - III (ACE III; Hsieh et al., 2013) without the MMSE items. The ACE-III has been translated to several languages and validated for various cultural environments (Mirza et al., 2017; Bruno et al., 2019). At present the ACE-III is available for example in Portuguese (Machado et al., 2015), Spanish (Matias-Guiu et al., 2015), Chinese (Wang et al., 2017) or Japanese (Takenoshita et al., 2019). The test takes about 25-30 minutes to administer, so it is more timedemanding than the MMSE.

\section{Montreal Cognitive Assessment}

The Montreal Cognitive Assessment (MoCA; Nasreddine et al., 2005) consists of 11 tasks for the assessment in five cognitive domains. It enables an earlier recognition of a mild cognitive impairment (Damian et al., 2011). The test takes about 10-15 minutes to administer. The total score is 30 points, the higher the score, the better the cognition. 


\section{O 7 Minute Screen Test}

The 7 Minute Screen Test (7MST; Solomon et al., 1998) consists of test sets dealing with:

$\checkmark$ Assessment of detailed orientation in time (Benton Temporal Orientation);

$\checkmark$ Assessment of memory (Grober and Buschke's enhanced cued recall);

$\checkmark$ Assessment of executive and visuo-spatial functions (Clock Drawing);

$\checkmark$ Assessment of speech (Verbal Fluency).

The 7 MST is designed to identify mild cognitive impairment and early stages of Alzheimer's disease (Meulen et al., 2004). The test takes longer to administer than the seven minutes suggested in its name (Rektorová, 2011).

\section{$\rightarrow$ Mini-Cog}

The Mini-Cog (Borson et al., 2000) is a brief test to examine the memory and visuo-spatial functions - remembering three words, Clock Drawing Test and recalling three words (Galvin et al., 2012). The test is very brief: it takes only about three minutes. To detect a cognitive impairment, the patient must have the specificity between $54-85 \%$ and sensitivity of 76-100\% (Lin et al., 2013).

\section{Clock Drawing Test}

The Clock Drawing Test (CDT; Sunderland et al., 1989) is an orientation simple test focusing on a couple of cognitive functions at the same time: space memory, visuo-spatial coordination, executive functions, semantic memory, ability to plan and concentrate (Shulman et al., 2000; Shulman et al., 2006). Due to its simplicity and briefness, it is 
very frequently used (Amodeo et al., 2015; Kim, Chey, 2010; SouillardMandar et al., 2016; Sugawara et al., 2010). The tested person is asked to draw a circular clock face with numbers where the hands are supposed to show the time of 2:45. The result is assessed on the scale from 1 to 10 points. There are a couple of assessment systems to interpret the score (Mainland et al., 2014; Ricci et al., 2016; SouillardMandar et al., 2016). Each of the systems uses different methods and instructions for the clock drawing. Based on the meta-analysis they have conducted, Park et al. (2018) recommend the Shulman's system. 


\section{2/Quality of life}

The quality of life is an important indicator of the level of care for older people. The Second International Plan of Action on Ageing by the United Nations (UN) stresses the importance of the support of active ageing, well-being, and the quality of life of older adults (Fernandez-Ballesteros et al., 2007). Due to the increasing geriatrisation of population worldwide, it is therefore crucial that research focuses on the quality of life of the ageing population.

\subsection{Definition of quality of life}

The quality of life is an individual and very personal concept as every individual has a unique standard of what they perceive as values creating the quality of their life (Fayers, Machin, 2016). This concept includes not only objective indicators of well-being assessed according to socionormative criteria but also subjective perception by the people during the individual periods of life. The quality of life includes both objective determinants such as health or function abilities and subjective factors such as satisfaction (Selai, Trimble, 1999). Therefore, the quality of life presents a multidimensional and complex approach connected with the individual's aims, expectations, and concerns which include both the physical and psychological area, independence, social interaction, environment, and spiritual aspects (Birren, Dieckermann 1991). 
According to the World Health Organisation's definition, the quality of life is the way individuals perceive their place in life with respect to the culture and value system they live in and in relation to their own aims, standards, expectations, and concerns (The WHOQOL Group, 1993; 1995). Such understanding of the quality of life presumes that individuals have the intellectual ability to make complex subjective judgements about their lives.

The quality of life is defined and assessed in various ways depending on the context in which the term is used and on the conceptual focus of the researcher. The term of the quality of life can also denote "how good or bad something is" or "how high the level of the value or excellence is" in relation to the individual's life. In this sense the quality of life in older age is not a simply neutral description of an older adult, but rather a complex assessment of their level of life and conditions that affect it. In literature dealing with the quality of life in older age such assessment is commonly used (Sirgy et al., 2006; Rokne, Wahl, 2011). If an older person suffers from a chronic impairment, they must gradually adapt to changes and cope with physical, emotional, and social challenges which arise from their impairment. For this reason, patients often revise their aims and expectations related to the quality of life (Huber et al., 2011). However, older adults do not consider the quality of life to reflect only good health. As has already been seen in past researches, older adults consider social contacts to be equally important for their quality of life as is their health (Farquhar, 1995a).

Therefore, the definition of the quality of life in older age often varies author by author. For example, Halvorsrud and Kalfoss (2007) state that in the specialised literature we can find more than 100 various definitions of the quality of life in older age. Walker (2005) notes that there has been no consensus in the way of defining and measuring the quality of life. Rosenberg (1995) includes a couple of constructs into the term of the quality of life: the physical, functional, emotional, social, and cognitive domains. On the other hand, some authors believe that these domains represent various dimensions of a single phenomenon (Bowling et al., 2003; Walker, 2010; Rokne, Wahl, 2011). 
Due to the large number of existing definitions of the quality of life in older people, there have been created a couple of taxonomies that divide the definitions based on various aspects. These include the Farquhar's taxonomy (Farquhar, 1995b) and the typology of the quality of life in old age based on the contents of the definitions (Brown et al., 2004). In the latter, however, authors do not mention the method used for the development of their classification system. In relation to the classification of definitions of quality of life in old age, Boggatz (2016) has described basic concepts that are most appropriate for the assessment of results of the care provided to older people.

\section{Farquhar's taxonomy}

Farquhar (1995b) created a taxonomy that sorts out definitions of the quality of life in old age based on formal aspects. However, it is less informative as regards the contents of the definitions. This taxonomy distinguishes four basic types:

$\checkmark$ Global definitions which refer to the general satisfaction with one's life or luck;

$\checkmark$ Component definitions which specify subjective or objective aspects of the quality of life;

$\checkmark$ Focused definitions which are limited to a single aspect, such as functional capacity;

$\checkmark$ Combination definitions which consist of both general satisfaction and individual aspects.

\section{Brown's taxonomy of models of quality of life in the old age based on their contents}

Brown recommends that models should be classified based on their contents in relation to the categories that the models focus on (Brown et al., 2004). These categories are divided into: 
$\checkmark$ Objective indicators;

$\checkmark$ Subjective indicators;

$\checkmark$ Human needs satisfaction;

$\checkmark$ Psychological models;

$\checkmark$ Health and functioning models;

$\checkmark$ Social health models;

$\checkmark$ Social cohesion and social capital;

$\checkmark$ Environmental models;

$\checkmark$ Idiographic or individualised hermeneutic models.

Some of the categories above may partly overlap each other. For example the objective indicators include aspects that are also part of health models and environmental models. On the other hand, other categories do not refer to different contents but rather to different ways of approaching them, e.g. subjective indicators and idiographic approaches (Brown et al., 2004).

\section{Boggatz's classification of definitions based on the basic concepts of quality of life in old age}

Boggatz (2016) identified three basic concepts of the quality of life in old age as related to the nursing care:

$\checkmark$ Fulfilment of life conditions;

$\checkmark$ Subjective general well-being;

$\checkmark$ Subjective satisfaction of human needs.

Out of the concepts above, the satisfaction of human needs is the most relevant one to evaluate the nursing care, as it includes several dimen- 
sions that can alter when the older person's life conditions change. In this respect, these dimensions can enable the assessment whether the nursing interventions increase or decrease the overall quality of life (or its individual dimensions) of older adults who receive nursing care (Boggatz, 2016).

\subsection{Quality of life in people with dementia}

More and more, the quality of life is considered to be a significant factor in assessing the clinical progression of an illness and the effectiveness of assigned interventions. Also in patients with dementia the quality of life is an important indicator to assess the effectiveness of interventions. Therefore, the research dealing with the quality of life in patients with dementia has an increasing clinical significance. This is caused by the fact that due to growing life expectancy dementia incidence has also grown in the population and dementia has therefore become one of the main challenges in the sphere of public health care (WHO, 2012). However, conducting a research of quality of life in patients with dementia is quite limited by the existence and level of cognitive deficit of the research subjects. It has been stated that people with mild to moderate dementia (Brod et al., 1999; Logsdon et al., 1999; Schölzel-Dorenbos et al., 2007; Trigg et al., 2007; Arlt et al., 2008; Banerjee et al., 2009) and sometimes even patients with the more severe dementia level (Thorgrimsen et al., 2003; Hurt et al., 2008) are able to provide a meaningful assessment of their quality of life and to speak about their needs in a relevant way (Orrell et al., 2008).

The quality of life also significantly correlates with the individual's health and thus it presents a multi-dimensional concept which includes the perception of mental, physical, emotional and social functioning in relation to various dementia stages in a patient with dementia (Ettema et al., 2005). Health-related quality of life is also affected by the level of selfsufficiency and functional fitness, comorbidity, sex, and the depression level (Setiati et al., 2011; Garrido-Abejar et al., 2012). Patients with dementia therefore have to adapt to the changes caused by their disease and 
cope with physical, emotional, and social challenges presented by their disease (Huber et al., 2011).

Lawton (1983; 1991; 1997) suggested that understanding and conceptualisation of the quality of life by a patient with dementia should consist of both subjective and objective factors categorised into four dimensions:

$\checkmark$ Behavioural capability;

$\checkmark$ Mental well-being;

$\checkmark$ Objective environment;

$\checkmark$ Perceiving the quality of life.

The most commonly used definition of the quality of life was suggested by Whitehouse and Rabins (1992). They considered the quality of life to be a combination of cognitive functioning, activities of daily life (ADL), social interaction, mental well-being, and subjective perception of one's own position in life.

\subsection{Assessment of quality of life}

Assessing the quality of life is a very complicated process of introspection and evaluation consisting of a couple of cognitive components including implicit and explicit memory. Therefore, in case the cognitive functions drop below a certain level, the self-rating of the quality of life is considered too difficult for the patient and also rather invalid (Selai et al., 2001).

In recent decades the usage of the quality of life assessment has increased both in clinical practice and research (Rabins, Black, 2007). More methods can be used for the assessment of quality of life in patients with dementia (Logsdon et al., 2002; Naglie, 2007; Vogel et al., 2012). Each of these methods has its positive and negative aspects when used for older adults with cognitive impairments. These aspects usually depend on how serious the disease is (Whitehouse et al., 1997). 
In order to assess the quality of life, we can use three basic approaches or their combination. These include the direct observation, self-rating of the quality of life by the patient with dementia, and assessment of the quality of life in a patient with dementia from the caregiver's perspective.

\section{$\checkmark$ Direct observation}

Direct observation of behaviour and activities, which supposedly relate to the quality of life, has the advantage that it can be considered "more objective". The presumption is based on the fact that such an assessment can be based on pre-defined behaviour manifestations and can be continuously assessed in a longer time span. The assessment of the observed influences (Lawton et al., 1996; 1999) and events (Logsdon, Teri, 1997; Teri, Logsdon, 1991) has been suggested for the measurement of observable attributes of the quality of life (Albert et al., 1999).

The limitations of the approach described above include the uncertainty whether we really observe what the individual with dementia considers significant for the quality of their life. Direct observation can also be subject to many stereotypes connected with the assessment of the quality of life in people with dementia from the family or professional caregiver's perspective. It is therefore vital that before the observation starts, the observer is trained in using observation strategies to assess the quality of life in patients with dementia (Lawton et al., 1999).

\section{$\checkmark$ Self-rating the quality of life by patients with dementia}

A couple of studies have proven that in the early stages of dementia patients can provide a reliable assessment of their quality of life (Buckley et al., 2012; Gómez-Gallego et al., 2012b). As the subjective dimension of the quality of life is very important, the patient's assessment of the quality of life should be preferred with the exception of patients with severe dementia (Brod et al., 1999). On the other hand, some authors emphasise that the subjective element in the perception of the quality of life makes it doubtful whether patients with dementia can give a reliable assessment of the quality of their 
life. This can be due to their decreased ability to make decisions, to understand complex problems; they can have impaired memory and a communication deficit, which are common dementia symptoms (Rabins, 2000). Besides, the patients' assessment of quality of life can also be affected by behavioural or non-cognitive dementia symptoms including depression, agitation or psychosis (Logsdon et al., 2002).

\section{$\checkmark$ Assessment of quality of life by a relative or caregiver}

Assessment of the quality of life by a caregiver or relative is often used in patients in advanced stages of dementia (Clare, Quinn et al., 2014). Caregivers usually assess the dementia patient's quality of life less positively in comparison with the patient's own assessment (Thorgrimsen et al., 2003; Cahill et al., 2004; Vogel et al., 2006; Arlt et al., 2008; Hurt et al., 2008). The factors that can have a negative influence on the caregiver's interpretation of the quality of life in a patient with dementia include for example the caregiver's burden and depression (Naglie, 2007; Orgeta et al., 2014). There is sometimes also a discrepancy between the assessment of people with greater limitation in activities of daily living, which has a greater influence on the assessment by family and caregivers but not on the subjective assessment of the quality of life by the patient (Moyle et al., 2011a). Also the patients' adaptation to the cognitive impairment (similarly to other chronic states) and the loss of insight may increase the quality of life perceived by the patient as opposed to the caregiver's view (Naglie, 2007).

\section{$\checkmark$ Combination of assessment methods}

According to Banerjee et al. (2009), when comparing assessments of the quality of life done by patients with dementia and by their caregivers, research has repeatedly shown differences. The discrepancy in the assessment can be for example in the patients with dementia who have greater limitations in ADL. According to Moyle et al. (2012), the degree of self-sufficiency affected only the caregiver's assessment but it was not reflected in the self-rating by patients with dementia. Therefore, the usage of a combined assessment by the patient as well as by the caregiver has its positives. It enables wider 
and complementary views on the quality of life among patients with dementia and the realisation of more effective interventions to support or improve the quality of their lives (Logsdon et al., 2007; Bosboom et al., 2012; Gómez-Gallego et al., 2012b). However, in case of patients with more advanced dementia, their self-rating of the quality of life can be unreliable due to their worsened speech skills, understanding, and the level of consciousness (Albert et al., 1996; Ready et al., 2006). In such cases, the caregivers' assessment can provide important and meaningful complementary information to assess the quality of life in patients with dementia (Buckley et al., 2012).

\subsection{Assessment tools}

A couple of assessment tools have been developed and validated to assess the quality of life in patients with dementia. The choice of the tool for a specific research is guided by the degree of dementia as well as by the type and organisation of the care for the patient with dementia (Schölzel-Dorenbos et al., 2007). Assessment tools can be divided into three groups according to whose perspective guides the assessment of quality of life in the patient with dementia.

\section{$\checkmark$ Objective observation}

This group consists of tools based only on the objective observation of a patient with dementia by the assessor. Objective observation of emotional behaviour of the patients with dementia makes it easier to understand their preferences and aversions, which can help to assess their quality of life better. One of the tools in this group is for example the 6-point Affect Rating Scale (ARS) questionnaire. It evaluates the positive (pleasure, interest, contentment) or negative feelings (sadness, fear/anxiety, anger) of the person with dementia based on the direct observation of their face expressions, body language, and other non-verbal signals. This assessment is independent of the patient's own self-rating of the quality of life (Lawton et al., 1996). 


\section{$\checkmark$ Caregiver's assessment}

This group consists of tools which are only based on the assessment by a family or professional caregiver. A representative of this category is the Alzheimer's Disease-Related Quality of Life (ADRQL) questionnaire. The tool assesses five domains of the quality of life (social interaction; awareness of self; feelings and mood; enjoyment of activities; response to surroundings) and it includes preferences that reflect the caregiver's idea about the benefits of the individual items to the health-related quality of life (Rabins et al., 1999). In 2009 the ADRQL was revised (Kasper et al., 2009). The questionnaire is available upon registration in the Mapi Research Trust (https://eprovide.mapi-trust.org/instruments/alzheimer-s-disease-related-qualityof-life).

$\checkmark$ Combination of self-rating by the patient with dementia and caregiver's assessment

The assessment tools in this group include both the subjective view on the quality of life by the patient with dementia and the caregiver's assessment. Accessing the quality of life from both of these perspectives is very important because not paying attention to the patients' subjective individual experience can lead us to measuring such aspects of the quality of life that are not meaningful for the people with dementia (Russell, 1996). As has earlier been pointed out by Walker et al. (1998), aspects of the quality of life of people with dementia are affected by various sociocultural influences and factors which are different from factors affecting the quality of life of people without cognitive impairment. The most commonly used tool in this group is the Quality of Life - Alzheimer's Disease Questionnaire (QOL-AD; Logsdon et al., 2002). Since the QOL-AD was used in the study dealing with the trajectory of quality of life in older adults in the early dementia stage, whose results are presented in this work, the questionnaire is described below in detail. 


\subsubsection{Quality of Life - Alzheimer's Disease Questionnaire}

The QOL-AD is an assessment tool developed specifically for patients with dementia (Logsdon et al., 1999; 2002). It is based on Lawton's model that defines the concept of quality of life in patients with dementia as a multidimensional one consisting of both subjective (e.g. perceiving the quality of life and psychological well-being) and objective components (e.g. behavioural competence and the environment) (Lawton, 1991). Even though the QOL-AD questionnaire was originally designed as a selfrating tool for individuals with dementia living in a community, it has also often been used as an assessment tool by caregivers in long-term care institutions and nursing homes (Dichter et al., 2015; Beerens et al., 2016; Nielsen et al., 2016).

Another variant of the questionnaire is the QOL-AD version for patient and caregiver (Logsdon, et al., 2002), which is the most frequently used tool to assess the quality of life related to health in people with dementia (Edelman et al., 2005; Hylla et al., 2016; Barrios et al., 2013). It includes the assessment of quality of life both from the position of the patient and of the caregiver. It has been proven that the QOL-AD is reliable and valid for people with the MMSE score above 10 points, so it cannot be used to assess the quality of life in patients with mild or moderate dementia (Logsdon et al., 1999; 2002; Thorgrimsen et al., 2003; Wolak et al., 2009; Novelli et al., 2010). In comparison with other questionnaires which assess the quality of life in patients with dementia, the QOL-AD has a couple of advantages.

$\checkmark$ First -it is relatively brief (the questionnaire completion takes about 10-15 minutes on average) and the items are easy to understand (Bowling et al., 2015).

$\checkmark$ Second - the reliability of patients' and caregivers' responses was evaluated as excellent ( $\alpha=0.88$ [patient] and 0.87 [caregiver]), which shows that the items really measure the cohesive construct. Also the correlation between the items is good (ICC $=0.76$ [patient] and 0.92 [caregiver]) (Logsdon et al., 1999). 
The QOL-AD version for the patient with dementia has 13 items identical to the version for the caregiver. They are assessed with respect to the current quality of life of the patient. Simple and easy-to-understand formulations are used for the individual items. Every item has a fourgrade Likert scale ( 1 = poor; 2 = fair; 3 =good; 4 = excellent) to assess the degree of agreement with the specific statement. The list of items is shown in Table 4.

Table 4 QOL-AD questionnaire items

\section{QOL-AD questionnaire items}

1. Physical health

2. Energy

3. Mood

4. Living situation

5. Memory

6. Family

7. Marriage / closest personal relationship

8. Friends

9. Self as a whole

10. Ability to do chores around the house

11. Ability to do things for fun

12. Money

13. Life as a whole

The parallel forms validity of the QOL-AD has strong correlations with questionnaires measuring activities of daily living and the degree of depression (Logsdon et al., 1999; Longsdon et al., 2002; Bruvik et al., 2012; Klapwijk et al., 2016). Intercultural validity of the QOL-AD has been confirmed in countries with various cultures, including the Czech Republic (Matsui et al., 2006; Wolak et al., 2009; Novelli et al., 2010; Gómez-Gallego et al., 2012a; Akpinar et al., 2012; Bárrios et al., 2013; Buasi, Permsuwan, 2014; Kisvetrová et al., 2018a). 
The QOL-AD has been used in studies conducted in various environments, both in communities (Novelli et al., 2010) and in acute (Sheehan et al., 2012) and long-term care (Hoe et al., 2006). The assessors included both family caregivers (Léon-Salas et al., 2011) and professional caregivers (Gómez-Gallego et al., 2012b). The QOL-AD is used with patients with mild cognitive impairment (Teng et al., 2012) and with various types of dementia who scored above 10 points in the MMSE (Wolak et al., 2009; Novelli et al., 2010).

In case one or two items of the QOL-AD are not filled-in, the recommended procedure is to replace them by an average score of other items. In case more than two items are missing (are not filled-in), the questionnaire is no longer valid and the patient is considered "unable or unwilling to complete the assessment" (Logsdon et al., 2002). The total QOL-AD score is obtained by adding points of the individual items, so it could be interpreted as a global rate of the perceived quality of life (Lawton, 1991). The score can be calculated as two separate results for the patient with dementia and for the caregiver or as a weighted composite score. As the patient's assessment is considered to be more significant, the weighted composite score is calculated in the following way: the patient's score is doubled, the caregiver's score is added and the result is divided by three. The total QOL-AD score is within the range of 13-52 points. Higher values of the total score indicate a better quality of life. Lower values of the QOL-AD score are often connected with the incidence of depression, a certain level of cognitive impairment, degree of self-sufficiency in activities of daily living, and a higher comorbidity (Logsdon et al., 1999; 2002; Bárrios et al., 2013; Conde-Sala et al., 2009; Bosboom et al., 2012).

\section{$\checkmark$ Czech version of the QOL-AD (version for the patient and family)}

The Czech translation of the QOL-AD is available upon registration with the official distributor Mapi Research Trust (PROQOLID. Quality of Life in Alzheimer's Disease [QOL-AD], accessible at https://eprovide.mapi-trust.org/).

Due to the non-existence of a psychometric validation of this Czech translation, after the official Czech versions of the QOL-AD were ob- 
tained for the patient and family, including the translated instructions for examiners by Mapi Research Trust, a psychometric validation was realised in Czech patients in the early dementia stage. This study was part of the first phase of the Czech Health Research Council grant (No. 16-28628A).

The study of the psychometric validation of the Czech version of the QOL-AD involved 212 patients in the early stage of dementia (with the MMSE score of $22.6 \pm 1.7$ points; ranging from 20 to 25 points) and their family caregivers. The study was part of a multicentre longitudinal study dealing with the trajectory of quality of life in older adults in the early stage of dementia which was supported by the Czech Health Research Council (grant No. 16-28628A).

The reliability of the Czech version of the QOL-AD for patients and caregivers was good (Cronbach's $\alpha=0.85$; ICC $=0.25-0.54$ ). When evaluating the convergent validity, a positive correlation was proven between the QOL-AD and physical fitness (SPPB; $r=.45, p<0.0001$ for the patients' assessment; $r=0.37, p<0.0001$ for the caregivers' assessment and $r=0.48, p<0.0001$ for the composite score). Negative correlation existed between the QOL-AD and the level of selfsufficiency (BADLS; $r=-0.47, p<0.0001$ for the patients' assessment; $r=-0.61, p<0.0001$ for the caregivers' assessment and $r=-0.59$, $p<0.0001$ for the composite score). Negative correlation was also proven between QOL-AD and depression (GDS): $r=-0.67, p<0.0001$ for the patients' assessment; $r=-0.40, p<0.0001$ for the caregivers' assessment and $r=-0.66, p<0.0001$ for the composite score). In construct validity the results of the factor analysis have confirmed the three-factor solution (factors: Physical and mental health; Family life; Social security). Cronbach's alpha was calculated for each factor. The alpha values were in the range of 0.86 to 0.44 . Lower alpha values in the factors of Family life and Social security were caused by a low number of items contained in these factors. The results of the study have confirmed that the Czech version of the QOL-AD has good psychometric characteristics which are in compliance with the international recommendation (Kisvetrová et al., 2018a). 


\section{3/ Determinants of quality of life}

At present the quality of life in older adults with dementia is one of the priorities of health policies in individual countries (Department of Health, 2011). Therefore, there has been an increased interest in research dealing with the quality of life in people with dementia and in interventions that can improve it (Kane, 2001; Rabins, Black, 2007; Kisvetrová et al., 2019a). There is a presumption that in older people with dementia the quality of life will change due to the progression of the cognitive deficit. However, Beerens et al. (2015) suggest that the natural progression of dementia does not necessarily have to be connected with the decrease in the quality of life. In order to preserve or improve the quality of life in people with dementia, it is necessary to have more knowledge about the determinants of quality of life and about the factors that they include. Their identification in the individual stages of dementia can contribute to a better understanding of the quality of life and the dementia progression.

Determinants of the quality of life present independent variables consisting of sets of factors which affect the specific individual's quality of life. These factors can be divided into a couple of groups corresponding to the determinants of the quality of life. 
$\checkmark$ Demographic characteristics;

$\checkmark$ Health;

$\checkmark$ Psychological and emotional factors;

$\checkmark$ Social and relationship factors.

\subsection{Demographic characteristics}

Basic demographic factors, including age, sex, education, and marital status, are often among the examined variables in research dealing with the quality of life. Study results confirm that the degree of education, sex, marital status, and age affect the individual's quality of life. Studies that have dealt with the individual factors are outlined in Table 5.

Table 5 Demographic characteristics

\begin{tabular}{ll}
\hline Factor & Source \\
\hline age & $\begin{array}{l}\text { Banerjee et al., 2006; Mjørud et al., 2014; Song et al., 2019; } \\
\text { Bilgili, Arpacı, 2014 }\end{array}$ \\
\hline sex & Barca et al., 2011; Woods et al., 2014; Bilgili, Arpacı, 2013 \\
education & Li et al., 2012; Marventano et al., 2015; Mjørud et al., 2014; \\
Bilgili, Arpacl, 2013 \\
marital status & Samus et al., 2005 \\
\hline
\end{tabular}

\subsection{Health}

Health as the determinant of quality of life in people with dementia includes factors focusing mainly on physical health, independence in ADL, cognitive functions, and physical symptoms (pain), as outlined in Table 6 . 


\section{Table 6 Health factors}

\begin{tabular}{|c|c|}
\hline Factor & Source \\
\hline $\begin{array}{l}\text { physical fitness / } \\
\text { self-sufficiency in ADL }\end{array}$ & $\begin{array}{l}\text { Beerens et al., 2015; León-Salas et al., 2015; } \\
\text { Orpwood et al., 2007; Potter et al., 2011; } \\
\text { Silberfeld et al., 2002; Giebel et al., 2015 }\end{array}$ \\
\hline cognitive state & $\begin{array}{l}\text { Sloane et al., 2005; Wetzels et al., 2010; } \\
\text { Winzelberg et al., 2005; Black et al., 2012; } \\
\text { Marventano et al., 2015; Mjørud et al., 2014; } \\
\text { Samus et al., 2005; Barca et al., 2011; Beerens et al., 2013; } \\
\text { Beer et al., 2010; Beerens et al., 2015; Garre-Olmo et al., 2012; } \\
\text { Hodgson et al., 2014; León-Salas et al., 2015; } \\
\text { Missotten et al., 2007; González-Salvador et al., 2000; } \\
\text { Oudman, Veurink, } 2014\end{array}$ \\
\hline $\begin{array}{l}\text { physical symptoms } \\
\text { (pain) }\end{array}$ & $\begin{array}{l}\text { Beer et al., 2010; Hendriks et al., 2014; Hodgson et al., 2014; } \\
\text { Tan et al., } 2014\end{array}$ \\
\hline
\end{tabular}

\subsubsection{Physical fitness}

Decreasing physical fitness is typical for the older age. To assess the old adult's physical fitness, we can use the tool Short Physical Performance Battery (SPPB; Guralnik et al., 1994; Berková et al., 2013). The SPPB is easy to use also for patients with dementia (Pitkälä et al., 2013).

\subsubsection{Short Physical Performance Battery}

The Short Physical Performance Battery (SPPB) consists of three tested areas that are described in Table 7. 
Table 7 Areas tested in SPPB

\section{Test}

Test of balance

\section{Activity}

1. Standing with feet together.

2. Standing with feet in a semi-tandem position.

3. Standing with feet in a full tandem position.

The maximum score for this part is 4 points.

$\begin{array}{ll}\begin{array}{l}\text { Test of walking } \\ \text { speed }\end{array} & \begin{array}{l}\text { Walking four metres in an ordinary way - two tries. } \\ \text { We measure the time the individual needs to make a specified } \\ \text { distance. There are two tries, the better one is recorded. } \\ \text { The maximum score for this part is } 4 \text { points. }\end{array} \\ \begin{array}{ll}\text { Test of repeated } \\ \text { chair stands }\end{array} & \begin{array}{l}\text { Tested individuals are sitting on a chair with their arms folded } \\ \text { across the chest. Then they are asked to stand up five times } \\ \text { without using their arms (i. e. getting from the sitting position to } \\ \text { the upright position as fast as possible without using their arms). } \\ \text { The total time is measured in seconds. We record how much time } \\ \text { the individual needs to perform five chair stands in a row as fast as } \\ \text { possible without using their arms. } \\ \text { The maximum score for this part is } 4 \text { points. }\end{array}\end{array}$

The maximum score for this part is 4 points.

The total SPPB score is calculated by adding points in the individual tests and it comes in the range of 0-12 points (Berková et al., 2013; Guralnik et al., 1995).

$\checkmark$ The score of 10-12 points represents good physical fitness.

$\checkmark$ The score of 7-9 points indicates deteriorated physical fitness.

$\checkmark$ In case the score is 6 points or lower, the older adult is assessed as frail and there is a high risk of lack of self-sufficiency in the future.

Li et al. (2020) confirm the correlation in older people of the parallel incidence of frailty, cognitive impairment, and health-related quality of life. Therefore, we identify frailty as one of the significant factors of the quality of life in the early stages of a cognitive impairment (Mhaoláin et al., 2012). 


\subsubsection{Self-sufficiency in activities of daily living}

The lack of self-sufficiency in performing activities of daily living (ADL), which include activities such as mobility, personal hygiene, dressing, eating and using the toilet, significantly influences the quality of life in people with dementia. To assess the self-sufficiency in ADL a number of tools have been developed but only a few of them have been designed specifically for individuals with mild dementia living in a community. In such a case, the assessment is performed by a caregiver (Bucks, Haworth, 2002). At present the Bristol Activities of Daily Living Scale (BADLS) standardised questionnaire is often used to assess the selfsufficiency in older adults with dementia.

\subsubsection{Bristol Activities of Daily Living Scale}

The Bristol Activities of Daily Living Scale (BADLS) contains both basic and instrumental $A D L$ and covers a wide spectre of activities ranging from completely independent ones to completely dependent ones. This aspect is especially significant in dementia. The questionnaire is completed by a close person who assesses the performance of the examined person in twenty basic activities of daily living within the recent two weeks.

The BADLS has a good sensitivity in relation to the changes in the disease progression (Byrne et al., 2000), good psychometric features (Bucks et al., 1996; Sikkes et al., 2009) and its results do not depend on the basic demographic characteristics of the assessed person (age, sex, education), as stated by Bartoš and Hasalíková (2010).

Bucks et al. (1996) confirmed that the BADLS has a good convergent validity $(r=0.65, p<0.001)$. The tool correlates well with the MMSE $(r=-0.67, p<0.001)$ and shows excellent test-retest reliability $(r=0.95$, $p<0.001)$. When using the Cohen's kappa coefficients, seven items reached a lower kappa score (0.30-0.59) and 13 items reached a good or very good kappa score (0.62-0.94). The analysis of the main components has confirmed four factors with their own values higher than 1 , which explained $65 \%$ of the total variability (Instrumental activities of daily life; Self-care; Orientation; Mobility). 


\section{$\rightarrow$ Czech version of BADLS}

In 2010 a Czech version of the questionnaire was created - BADLS-CZ (Bartoš et al., 2010; Bartoš, Hasalíková, 2010). It is available at https:// www.nudz.cz/adcentrum/dotazniky.html\#BADLS. The list of activities assessed by the test is shown in Table 8 .

Table 8 BADLS-CZ questionnaire items

\begin{tabular}{|rlcl|}
\hline & & Assessed activities \\
\hline $\mathbf{1}$ & Preparing meals & $\mathbf{1 1}$ & Walking \\
\hline $\mathbf{2}$ & Eating & $\mathbf{1 2}$ & Orientation in time \\
\hline $\mathbf{3}$ & Preparing drinks & $\mathbf{1 3}$ & Orientation in space \\
\hline $\mathbf{4}$ & Drinking & $\mathbf{1 4}$ & Communication \\
\hline $\mathbf{5}$ & Dressing & $\mathbf{1 5}$ & Telephone usage \\
\hline $\mathbf{6}$ & Hygiene & $\mathbf{1 6}$ & Household chores, DIY \\
\hline $\mathbf{7}$ & Caring for own or false teeth & $\mathbf{1 7}$ & Shopping \\
\hline $\mathbf{8}$ & Taking a bath/shower & $\mathbf{1 8}$ & Money \\
\hline $\mathbf{9}$ & Toilet hygiene & $\mathbf{1 9}$ & Hobbies and games \\
\hline $\mathbf{1 0}$ & Basic movement & $\mathbf{2 0}$ & Transport \\
\hline
\end{tabular}

There are five assessment statements assigned to each questionnaire item, each assessed by $0-3$ points or " $X$ " = irrelevant. The score of "o points" means that the patient performs the specific activity without any limitations. If they have any trouble with performing the specific activity, the assessment is in the range from 1 to 3 points. A larger deficit in self-sufficiency in the performed activity is manifested by a higher number of points. The total score of the questionnaire is in the range of $o$ (completely self-sufficient) up to 60 points (completely dependent). In the Czech version (BADLS-CZ) the score is also expressed as a percentage (0-100\%). This value shows the self-sufficiency in percent. The result of $0 \%$ means a complete lack of self-sufficiency of the assessed person. 


\subsubsection{Cognition}

The correlation between the level of the cognitive state (or cognitive impairment) and the quality of life in people with dementia is suggested by results of a couple of studies. Marventano et al. (2015) and Mjørud et al. (2014) state that the quality of life in patients with dementia has a tendency to decrease with the increasing seriousness of dementia. This is confirmed by the correlation between the levels of cognitive functions and the quality of life in patients with dementia mentioned for example in the work by Lužný (2013). On the contrary, Beerens et al. (2015) believe that the natural progression of dementia does not necessarily have to cause the decrease in an individual's quality of life. Also Oudman and Veurink (2014) state that the quality of life in patients with severe dementia can be stable in spite of the global cognitive deterioration; especially in the later dementia stages. In the Czech clinical practice, the most frequently used tool to assess the cognitive functions is the Mini-Mental State Examination (MMSE) that is described in detail in Chapter 1.4.1.

\subsubsection{Pain}

Pain is a physical symptom that negatively affects the quality of life in older adults with dementia (Hendriks et al., 2014; Hodgson et al., 2014). Corbett et al. (2012) point out that the incidence of chronic painful states in older patients with dementia can be comparable to that in individuals without dementia. However, as regards the assessment of pain, a great majority of patients with moderate to severe dementia may not be able to assess their pain with an assessment tool and therefore the pain is rather reported by informal caregivers than by the patients themselves (Bullock et al., 2019). The incidence of pain in older adults with cognitive impairment is often underestimated and that has a negative effect on their independence in ADL and on their quality of life. The correlation between pain and the quality of life in patients with dementia has been confirmed in past as well as contemporary studies (Katz, 2002; Wróblewska et al., 2019). 
Self-rating tools for pain assessment are relevant for people with mild to middle cognitive impairment. Patients in the middle dementia stage (with the MMSE score of 10-19 points) manifest a good correlation between all the used scales to assess pain (Álvaro González, 2015). In case of patients with severe dementia, it is better when caregivers observe the non-verbal expressions in order to assess the pain (Cravello et al., 2019).

When patients communicate, we can use a simple visual scale - descriptive verbal scale, visual analogue scale (VAS), and a numeric scale. Using these assessment tools, the intensity of the subjectively perceived pain can be quantified in the following ways:

$\checkmark$ matching the score to the individual verbal assessments (ranging from "no pain" to "the worst possible pain");

$\checkmark$ marking the numeral value from 0 to 10 by numbers;

$\checkmark$ making a graphic mark on a horizontal line (e.g. in VAS).

The Horizontal Visual Analogue Scale (HVAS) consists of a 10-centimetre line where the patient marks the level of the subjectively perceived pain (ranging from no pain to extreme pain). The HVAS can be successfully used in most elderly patients with mild to moderate dementia (Pautex et al., 2005).

\subsection{Psychological and emotional area}

In the subjective assessment of quality of life by older patients with dementia, psychological and emotional factors play a significant role. This group includes mainly depression, fear and mood (Beerens et al., 2016), autonomy, dignity, and self-confidence. The list of studies dealing with the specific factors is shown in Table 9. 
Table 9 Psychological and emotional factors

\begin{tabular}{|c|c|}
\hline Factor & Source \\
\hline depression & $\begin{array}{l}\text { Beerens et al., 2013; Winzelberg et al., 2005; } \\
\text { Black et al., 2012; Li et al., 2012; Marventano et al., 2015; } \\
\text { Barca et al., 2011; Beerens et al., 2015; Byrne-Davis et al., 2006; } \\
\text { Heggie et al., 2011; González-Salvador et al., 2000; } \\
\text { Sivertsen et al., 2015; Song et al., } 2019\end{array}$ \\
\hline fear of falling & Uemura et al., 2014; Akosile et al., 2014 \\
\hline $\begin{array}{l}\text { satisfaction } \\
\text { with life }\end{array}$ & Byrne-Davis et al., 2006 \\
\hline $\begin{array}{l}\text { attitude to old age } \\
\text { and ageing }\end{array}$ & Yamada et al., 2015; Trigg et al., 2012; Kisvetrová et al., 2019a \\
\hline $\begin{array}{l}\text { feeling of usefulness } \\
\text { to the society }\end{array}$ & $\begin{array}{l}\text { Byrne-Davis et al., 2006; Moyle et al., 2011a; } \\
\text { O'Rourke et al., 2015; Silberfeld et al., 2002; }\end{array}$ \\
\hline $\begin{array}{l}\text { control over one's } \\
\text { own life }\end{array}$ & Moyle et al., $2011 a$ \\
\hline autonomy & Crespo et al., 2011; O’Rourke et al., 2015 \\
\hline dignity and respect & $\begin{array}{l}\text { Manthorpe et al., 2010; Russell et al., 2008; Venturato, 2010; } \\
\text { Tranvag et al., 2015, } 2016\end{array}$ \\
\hline
\end{tabular}

Research results suggest that the positive mood, being useful to others, and life satisfaction correlate with a better quality of life (Byrne-Davis et al., 2006; Clare, Woods et al., 2014). Also one's autonomy (Crespo et al., 2011; O'Rourke et al., 2015), positive perception of one's dignity (Tranvag et al., 2015; Tranvag et al., 2016), and control over one's life (Moyle et al., 2011a; Moyle et al., 2015) have been confirmed as positive predictors of the quality of life. Other factors affecting the quality of life in older patients with dementia include the fear of falling (Uemura et al., 2014; Akosile et al., 2014) and the attitude to one's own age and ageing (Yamada et al., 2015; Trigg et al., 2012).

\subsubsection{Depression}

Epidemiological studies confirm that the incidence of depression is more and more common in the general population and it increases with age and has an invalidating effect (Naismith et al., 2012). There is an estimate that up to $50 \%$ of people with dementia suffer from depression and the 
persistence of depressive symptoms is high. The incidence and persistence of clinically significant depression symptoms is connected with the type of provided care. There is high incidence for example in older people in institutional care (Barca et al., 2010). Depression is considered to be a risk factor for all dementia types (Diniz et al., 2013, Deckers et al., 2015) and the trajectory of depression symptoms is related to the speed of the dementia progression (Barca et al., 2017). Depression significantly influences the quality of life both in terms of psychological well-being and of the self-perception of the individuals (health, personal performance, abilities) and their other personal and environmental needs (Houtjes et al., 2011).

In institutions, correlation has been proven to exist between serious depression and the deterioration of the quality of life in older patients with dementia (Barca et al., 2011). Depression is therefore considered to be the main predictor for the quality of life at all dementia stages as has been suggested by cross-sectional as well as longitudinal studies (Gómez-Gallego et al., 2012b; Hoe et al., 2009; Missotten et al., 2007; Naglie et al., 2011; Tatsumi et al., 2009).

Several tools are used to assess the number of depressive symptoms. The most frequently used ones include the Hamilton Scale of Depression (HAMD; Hamilton, 1960), the Beck Depression Inventory-II (BDI-II; Beck, 1996; Preiss, Vacíř, 1999; Filip, 1997) or the Geriatric Depression Scale (GDS; Yesavage et al., 1983). As the brief version of the Geriatric Depression Scale (GDS-15; Yesavage, Sheikh, 1986) was used in the research on the trajectory of quality of life in older adults in the early stage of dementia, which is described in this work, the GDS-15 is described in detail below.

\subsubsection{Geriatric Depression Scale}

In order to detect the incidence of depression symptoms in older adults, we often use the Geriatric Depression Scale (GDS; Yesavage et al., 1983) consisting of 30 items. In the clinical environment it presents a useful screening tool that makes the depression assessment in older people easier. The GDS can be administered either verbally, which means that 
the assessor asks the individual questions and records the answers into a form, or the older adults can complete the questionnaire by themselves. The GDS can be used both in healthy and ill older people including patients with mild to middle impairment of cognitive functions. However, some authors point out that the GDS completed by patients with cognitive impairment has a lower validity (Kørner et al., 2006). The GDS has a sensitivity of $92 \%$ and the specificity of $89 \%$ when assessment is based on diagnostic criteria. In a validation study comparing the usage of the long version (GDS) and the brief version (GDS-15) for self-rating of depression symptoms, both the versions proved the ability to successfully distinguish depression patients from non-depression individuals with a high correlation $(r=0.84, p<0.001)$ (Sheikh, Yesavage, 1986).

The GDS-15 (Yesavage et al., 1986; Tošnerová, Bahbouh, 1999) consists of 15 self-rating items (yes/no answers) in which older people themselves rate their mood in the recent week (the items are listed in Table 10). Each answer is evaluated with o or 1 point. The total GDS-15 score ranges from 0 to 15 points. Scores up to 5 points are evaluated as "no depression". The growing number of points means a growing seriousness of depression (Yesavage, Sheikh, 1986). Conradsson et al. (2013) state that the GDS-15 is a brief, valid instrument for depression screening and is relevant to use in individuals with mild to moderate dementia.

Table 10 GDS-15 questionnaire items

\section{GDS-15 questionnaire items}

01 Are you basically satisfied with your life?

02 Have you dropped many of your activities and interests recently?

03 Do you feel that your life is empty?

04 Do you often feel sad and bored?

05 Are you in good spirits most of the time?

06 Are you afraid that something bad is going to happen to you?

07 Do you feel happy most of the time?

08 Do you often feel helpless?

09 Do you prefer to stay at home rather than go out and do new things?

10 Do you think you have more problems with memory than your peers? 


\section{GDS-15 questionnaire items}

11 Do you think it is wonderful to be alive now?

12 Do you feel pretty worthless the way you are now?

13 Do you feel full of energy?

14 Do you feel your situation is hopeless?

15 Do you think that most people are better off than you are?

\subsubsection{Attitudes to old age and ageing}

Attitudes represent stable and integrative judgements which summarise the individual's ideas, feelings, and memories about objects or situations (Low et al., 2013). They derive from observation or from direct experience and consist of three main elements - cognition, influence, and behaviour (Ibrahim, Bayen, 2019). Attitudes to ageing differ across cultures and are formed by tradition, religion, as well as socio-cultural belief (Kickbusch, 2005; Moberg, 2005). Therefore, they present social constructs set in cultural and historical contexts which are interpreted individually. In older people, positive approaches to ageing contribute to the support of mental and physical health (Bryant et al., 2012). They can influence the older adults' view of their own health (Beyer et al., 2015), level of well-being and life satisfaction (Faudzi et al., 2019), physical performance (Gale, Cooper, 2018), and self-sufficiency in ADL (Moser et al., 2011). The perception of one's own ageing affects the older adults' psychological and physical health (Robertson et al., 2016) and the attitude to one's own ageing therefore significantly reflects the subjective assessment of one's own quality of life (Trigg et al., 2012; Yamada et al., 2015; Low et al., 2013; Chachamovich et al., 2008a; Top et al., 2012). Results of studies dealing with attitudes toward the old age in older people confirm that their attitudes toward psychosocial changes are more positive than attitudes toward physical changes (Top, Dikmetas, 2015; Korkmaz Aslan et al., 2017). Older people also connect positive attitudes toward their own ageing with the social support and participation in the community (Lu et al., 2010).

In comparison with individuals without any cognitive deficit, patients with dementia often show tendency to a more negative attitude to ageing as to the time of psychosocial loss. A negative attitude to ageing in 
the early stage of dementia is usually connected to the acknowledgement of a gradual decrease in cognitive abilities (Siebert et al., 2018).

A frequently used tool to assess one's own ageing is the subscale called the Attitude Toward Own Aging (ATOA) derived from the Philadelphia Geriatric Morale Scale consisting of five statements to assess the general attitude to ageing (Lawton, 1975; Liang, Bollen, 1983). Due to some opinions that the ATOA as a general instrument is insufficient to an overall assessment of attitudes toward one's own ageing, there has been an effort to create a tool that would make it possible to assess the process of ageing as an individual experience viewed by older adults. The resulting product is the Attitude to Ageing Questionnaire (AAQ). The methods used by the WHOQOL have provided a unique approach to develop an instrument that ensures intercultural validity in the assessment of attitudes to ageing and lowers the risk of cultural distortion (Laidlaw et al., 2007).

\subsubsection{Attitude to Ageing Questionnaire}

The Attitude to Ageing Questionnaire (AAQ) constitutes a multidimensional conception usable in various cultures. The final version of the questionnaire was made with focus on three different aspects of ageing which create three subcategories (domains) of the AAQ. The first domain focuses on psychosocial losses related to the older adults who perceive age as a negative experience connected with the losses in the psychological and social area. The second domain deals with the physical area of ageing including aspects such as health, exercise, and one's own experience of ageing. The third domain is connected to the wisdom and growth in old age. It shows the perceived positive aspects in relation to the individual and others (Laidlaw et al., 2007). In total, the AAQ consists of 24 items divided into three domains which are seen in Tables 11-13.

The AAQ questionnaire has shown very good psychometric features across cultures. The psychometric analysis of the AAQ was conducted for example in Spain, Brazil, Scotland, Norway, Canada and Iran (LucasCarrasco et al., 2013; Kalfoss et al., 2010; Chachamovich et al., 2008b; Shenkin et al., 2014; Rejeh et al., 2017). It has been proven that the AAQ has a corresponding validity and reliability. 
It has also been confirmed that older people with dementia are able to give valid answers to questions about their attitudes to ageing (Trigg et al., 2007).

Table 11 Domain I

\begin{tabular}{|c|c|c|}
\hline & \multicolumn{2}{|c|}{ Contents } \\
\hline \multirow{10}{*}{$\begin{array}{l}\text { Psychosocial } \\
\text { loss }\end{array}$} & \multicolumn{2}{|c|}{$\begin{array}{l}\text { Feelings of loneliness, social exclusion, seclusion, and gradual loss } \\
\text { of self-sufficiency. }\end{array}$} \\
\hline & \multicolumn{2}{|l|}{ Items } \\
\hline & 03 & Old age is a time of loneliness. \\
\hline & 06 & Old age is a depressing time of life. \\
\hline & 09 & $\begin{array}{l}\text { I find it more difficult to talk about my feelings as I get } \\
\text { older. }\end{array}$ \\
\hline & 12 & I see old age mainly as a time of loss. \\
\hline & 15 & I am losing my physical independence as I get older. \\
\hline & 17 & As I get older I find it more difficult to make new friends. \\
\hline & 20 & I don't feel involved in society now that I am older. \\
\hline & 22 & I feel excluded from things because of my age. \\
\hline
\end{tabular}

Table 12 Domain II

\begin{tabular}{|c|c|c|}
\hline & \multicolumn{2}{|c|}{ Contents } \\
\hline \multirow{10}{*}{$\begin{array}{l}\text { Physical } \\
\text { change }\end{array}$} & \multicolumn{2}{|c|}{$\begin{array}{l}\text { Assessment of physical health, condition, exercise and the overall } \\
\text { reflection on ageing. }\end{array}$} \\
\hline & \multicolumn{2}{|l|}{ Items } \\
\hline & 07 & It is important to do exercise at any age. \\
\hline & 08 & Growing older has been easier than I thought. \\
\hline & 11 & I don't feel old. \\
\hline & 13 & My identity is not defined by age. \\
\hline & 14 & I have more energy now than I expected for my age. \\
\hline & 16 & $\begin{array}{l}\text { Problems with physical health do not hold me back } \\
\text { from doing what I want to do. }\end{array}$ \\
\hline & 23 & My health is better than I expected for my age. \\
\hline & 24 & I keep myself as fit and active as possible by exercising. \\
\hline
\end{tabular}




\begin{tabular}{|c|c|c|}
\hline & \multicolumn{2}{|c|}{ Contents } \\
\hline \multirow{10}{*}{$\begin{array}{l}\text { Psychological } \\
\text { growth }\end{array}$} & \multicolumn{2}{|c|}{$\begin{array}{l}\text { Positive experience, positive attitude to oneself and to the world } \\
\text { around in relation to one's own ageing. }\end{array}$} \\
\hline & \multicolumn{2}{|c|}{ Items } \\
\hline & 01 & As people get older they are better able to cope with life. \\
\hline & 02 & It is a privilege to grow old. \\
\hline & 04 & Wisdom comes with age. \\
\hline & 05 & There are many pleasant things about growing older. \\
\hline & 10 & I am more accepting of myself as I have grown older. \\
\hline & 18 & $\begin{array}{l}\text { It is important to pass on the benefits of my experience } \\
\text { to younger people. }\end{array}$ \\
\hline & 19 & I believe my life has made a difference. \\
\hline & 21 & I want to give a good example to younger people. \\
\hline
\end{tabular}

(Processed according to Dragomirecká, Prajsová, 2009)

The individual items in the AAQ domains, as shown in Tables 11-13, are completed with a 5-point Likert scale (ranging from 1 = strongly disagree to $5=$ strongly agree). Every domain has eight items, the minimum score per domain is 8 points, and the maximum is 40 points. The total questionnaire score is calculated by adding all the domain scores and it comes between 24 and 120 points. A higher score indicates a more positive attitude to one's own ageing and old age (Laidlaw et al., 2007). The creation and psychometric validation of the Czech version is described by Dragomirecká and Prajsová (2009). Their book contains the psychometric characteristics of the questionnaire, orientation Czech norms, and a detailed scoring manual.

\subsubsection{Dignity}

We can describe dignity as a multidimensional concept that includes perception, cognition, and emotions related both to the feeling of one's value and respect and to the respect and esteem shown by other people to the individual (Manthorpe et al., 2010). Jacelon (2004) describes it as inherent characteristics of a human being which can be perceived as an 
attribute of one's own "self" and is manifested by behaviour demonstrating respect to oneself and others. Dignity can also be understood as a dual concept including absolute and relative dignity (Edlund et al., 2013), objective and subjective dignity (Gallagher, 2004), human, also called basic, and social, also called personal, dignity (Jacobson, 2007; Jacobson, 2009).

Human dignity is an abstract universal value belonging to all human beings due to the fact they are human.

$\checkmark$ Spiritual concept of human dignity is based on the belief that human beings have a privileged position among God's creations (Quante, 2005).

$\checkmark$ Secular concept of human dignity is based on the belief that the meaning of dignity is rooted in the rationality of human beings and their ability to behave as moral individuals (Nordenfelt, 2004).

Therefore, it is impossible to measure, create or destroy human dignity.

Social dignity of individuals originates based on their interactions with other people, groups, and society. It can be classified as dignity which:

$\checkmark$ Individuals attribute to themselves (manifesting self-respect and pride).

$\checkmark$ Is attributed to individuals by others (including the ways of showing value and respect to individuals by individual and collective behaviour).

As social dignity arises due to social interaction, it can be measured, violated or improved. In old age, this form of dignity is easy to be influenced either in the positive or negative way when care is provided.

The terms of absolute and relative dignity give rise to four dignity categories that have been described by Lennart Nordenfelt (2004).

$\checkmark$ The first category is dignity as a human right (Menschenwürde in German), which represents an absolute value. All people have the same 
amount of this dignity due to the fact that they are human. It is therefore inborn (internal) and belongs to all people regardless their sex, age, race, education, status or religion.

Menschenwürde creates the basis for the moral commitment to respect other people and for the experience of dignity or humiliation in three more categories. These include the dignity of credit, dignity of moral strength, and dignity of personal identity.

These three categories represent dignity as a relative value. It depends on the behaviour, autonomy, and integrity of the individual and the people one is in contact with. It provides a base for the individual's self-esteem.

$\checkmark$ Dignity of merit is identified by the individual's formal and informal status in the society. It is attributed to people due to the roles they play, due to their functions or credits for their action.

$\checkmark$ Dignity of moral stature is based on the moral integrity and stresses the individual's ability to live in compliance with the moral principles.

$\checkmark$ Dignity of identity is related to the identity of a specific person, to the self-esteem, and to the terms of integrity, independence, and inclusion. This dignity can be endangered and violated if older adults are offended and treated as things. Regarding the older adults, this is the most significant type of dignity.

While Nordenfelt (2004) describes four positive categories of dignity, Jonathan Mann (1998) has created the taxonomy of four categories of dignity violation.

\section{Mann's taxonomy}

$\checkmark$ The first category can be called not being seen. This is the situation when an individual has a feeling of being ignored and not respected. For example an older patient in the nursing care is trying to attract the attention of the nurse who is taking care of them. But the nurse is avoiding eye contact with the patient and ignores them. 
$\checkmark$ The second category can be described as being subsumed into a group identity. This is a situation when older adults are only stereotypically perceived as members of specific groups (e.g. pensioners or the demented). In this respect, Mann (1998) emphasises that the group classification can cause pride but in this case the perception of the older adult only as a member of a group is rather pejorative.

$\checkmark$ The third category can be defined as dignity violation via invasion of personal space. This can happen while performing personal hygiene if the older people do not have enough privacy.

$\checkmark$ The fourth category is humiliation. It is seen in situations when the older people are excluded, differentiated or separated from a group or society and are subjects of criticism or mockery.

The model of dignity in illness has been presented by Oosterveld-Vlug et al. (2014). In this model they describe how an illness can affect the patient's personal (social) dignity.

According to this two-level model, the illness does not have a direct effect on the patient's dignity. It influences it indirectly in the way the patient is perceived via three elements forming the self-concept: individual self, relational self, and societal self.

\section{Dignity from the older adults' view}

When assessing their dignity, older adults connect the idea of dignity especially with esteem (to themselves [self-esteem] as well as toward others and by others) and participation, i. e. the possibility to join in activities. Older adults most often connect the dignity endangerment in care provision with:

$\checkmark$ Dependence on the care provided by others;

$\checkmark$ Wrong communication;

$\checkmark$ Depersonalisation of care. 
From the older adults' view, preserving dignity means that they have their lives under control and are treated with respect to their autonomy and personal identity. In order to achieve this, older people must be perceived by others as unique human beings as well as integrated and respected society members. Older adults who are aware of the deterioration of their cognitive abilities often perceive this as a stigma lowering their self-esteem (Burgener et al., 2015) and the consequent personal dignity which is negatively reflected in their assessment of the quality of life.

Understanding problems that could endanger the older adults' dignity enables the medical staff to protect older people from losing their personal dignity. Relevant tools to assess the dignity in the old age, including that of patients with dementia, include for example the Jacelon Attributed Dignity Scale (JADS) or the Patient Dignity Inventory (PDI).

\section{ᄀ Jacelon Attributed Dignity Scale}

The Jacelon Attributed Dignity Scale (JADS) has been created specifically for the population of older adults. It consists of 18 positively formulated statements focusing on the degree of the older person's attributed dignity. A high value of the attributed dignity indicates a protective factor in relation to health, self-sufficiency, independence, quality of life, and successful ageing (Jacelon et al., 2009). Psychometric validation has shown that the JADS has four factors with high internal consistence for each of the factors as well as for the questionnaire as a whole. Construct validity has been determined based on the JADS correlation with the self-esteem assessment tools - the Rosenberg Self-Esteem Scale (SES; Rosenberg, 1965), and social desirability assessment tools - the Crowne and Marlow Social Desirability Scale (SDS; Crowne, Marlow, 1960). The results have confirmed the validity of the JADS and have shown that the attributed dignity is a unique concept that is stable over time (Jacelon, Choi, 2014). 
Another relevant questionnaire to assess dignity is the Patient Dignity Inventory (PDI). As the PDI was used in the research on the trajectory of quality of life in older adults in the early dementia stage, whose results are presented in this work, the questionnaire is described below in detail.

\subsubsection{Patient Dignity Inventory}

The Patient Dignity Inventory (PDI) is a screening tool providing the medical staff with a rather easy way to identify a wide spectre of problems that can cause anxiety and concerns in an individual related to the endangerment of their dignity (Chochinov et al., 2008). Although it was primarily designed as an assessment tool for terminally ill oncological patients, it is now used also with patients in the early dementia stage (Johnston et al., 2016) and with older adults who are not in a terminal stage of an illness but are experiencing the final phase of their life (Kisvetrová et al., 2019a).

The PDI has 25 items with a 5-point Likert scale which describes how problematic or concerning the specific situation has been for the individual in recent days ( $1=$ no problem; 2 =slight problem; 3 =problem; 4 = serious problem; $5=$ overwhelming problem). The total questionnaire score is in the range of 25 to 125 points. A higher score indicates a higher endangerment of dignity (Chochinov et al., 2008).

\section{O Patient Dignity Inventory in Czech (PDI-CZ)}

Creating a Czech version of the PDI questionnaire (Patient Dignity Inventory in (zech; PDI-CZ) and its linguistic and psychometric validation were part of the first phase of the longitudinal multicentre study (Czech Health Research Council; grant No. 16-28628A) where the PDI-CZ was used to assess the perception of dignity by older adults with and without dementia.

Having received the approval by Professor H. Chochinov (Manitoba Palliative Care Research Unit, CancerCare Manitoba, Canada), the author of the original PDI English version, the questionnaire was 
translated to Czech. The transformation of the PDI English version was done according to the process suggested by Beaton et al. (2000; 2007) and Guillemin et al. (1993). The suggested methodology is based on the needs of the medical, psychological, and sociological research and the creation of assessment tools for the HRQOL concept (health-related quality of life). A five-phase process has been recommended (A-E phases).

\section{A) Translation to the mother tongue}

The translation of the PDI original English version into Czech was done by two translators (a clinical and a professional one), both Czech natives. The criteria for the selection of a clinical translator were: medical specialist with an excellent knowledge of the English language (living in an English speaking environment or permanently using English in their profession in the (zech Republic). The resulting translation versions were marked $\mathrm{T} 1$ and $\mathrm{T} 2$.

B) Translation synthesis

The synthesis was done by an independent professional translator with the participation of the T1 and T2 translators. Comparing the two versions and the original PDI, a common version called T12 was created.

C) Reverse translation to the original (English) language

In this phase, the T12 version was translated back to the English language by two translators who did not take part in the first phase of the translation. The criteria for the selection of translators were: native English speakers with an excellent knowledge of the Czech language, one of the translators was a medical specialist. The new translation versions were called $\mathrm{BT} 1$ and $\mathrm{BT} 2$. The aim of this phase was to find out whether the presented $\mathrm{T} 12$ version reflected exactly the contents of the items of the original PDI version. 
D) Translation review by a board of specialists in the specific field

A board of specialists was selected based on the following criteria: knowledge of English, medical profession (doctor, nurse) in the field of nursing the incurable and patients in the final phase of their life, and a professional translator. The task was for the committee to judge any differences between the translated versions ( $T 1, T 2, T 12$, $\mathrm{BT} 1$, and $\mathrm{BT} 2$ ) and verify that the translations correspond by using semantic, idiomatic, expressive, and conceptual equivalence. The translation compliance was judged based on the work by de Vijver, Tanzer (2004), and Beaton et al. (2000; 2007). The discussion resulted in a pre-final Czech version of the questionnaire to be used in the pretest. The abbreviation for the Czech version was preserved as PDI with a CZ index so that the original resource and translation into Czech would be clear also in the international context (PDI-CZ).

E) Questionnaire pre-test

The pre-test method was used in order to evaluate the clarity of the pre-final questionnaire version. The sample of respondents consisted of 40 patients. The inclusion criteria were: 1) age: over 18 years old; 2) suffering from an incurable disease in an advanced or terminal stage; 3) consent with the research participation; 4) ability to complete the questionnaire by oneself or with a researcher. The exclusion criterion was: a serious cognitive deficit. Having been informed about the pre-test aim, the respondents were asked to fill in the questionnaire. With every item, the researcher asked the respondent how they understood it. This made it possible to find out whether the translated version of the questionnaire preserved the meaning of the original English items (Beaton et al., 2007).

Based on the pre-test results a board of specialists adapted the final Czech version of the PDI-CZ questionnaire. Two items were modified in order to be better understandable for the Czech environment. In item 22 the expression "health care provider" was replaced with the expression "health care professional". Most respondents matched the term 
of health care provider with an image of an institution where care is provided and not with a caregiver as a person. In item 23 the term "challenge" was changed for "obstacles" as respondents often said that they do not consider the illness to be a challenge but that they perceive it as an obstacle in their life.

The psychometric validation of the PDI-CZ was conducted with a sample of 239 incurable patients (136 [56.9\%] with oncological and 103 [43.1\%] with non-oncological diagnoses). The average age of respondents was $72.2 \pm 11.5$, ranging from 25 to 96 years old; 144 (60.3\%) of the respondents were female. Regarding the questionnaire validity, the internal structure of the PDI-CZ was assessed together with its internal consistence and test-retest reliability. The internal structure of the questionnaire was assessed by the factor analysis using the principal component method with the Varimax rotation. The overall KMO (Kaiser-Meyer-Olkin Measure) score (for all items) was good (0.88) and confirmed, together with the Bartlett's test of sphericity, the relevance of the factor analysis by the Principal Component Analysis method (PCA). The factor analysis resulted in a four-factor solution that presented $56.3 \%$ of the total variability. The PDI-CZ reliability was very good. The internal consistency expressed by Cronbach's alpha for the whole PDI-CZ questionnaire was 0.92. The individual factors had the following alpha values: Loss of purpose of life $=0.90$; Loss of autonomy $=0.84$; Loss of confidence $=0.67$; Loss of social support $=0.58$. The lowest value of Cronbach's alpha in the last factor was due to the low number of items. Test-retest reliability was assessed by the Gwet's coefficient (AC1 in the range of 0.58-1.00). There was also proven a significant correlation among all the factors (subscales). The individual correlations are shown in Table 14. The study has shown that the PDI-CZ Czech version has good psychometric features and is therefore appropriate to use also in international studies (Kisvetrová et al., 2018b). 
Table 14 Correlation of factors (subscales) in PDI-CZ

\begin{tabular}{|c|c|c|c|c|}
\hline & $\begin{array}{c}\text { Loss of purpose } \\
\text { of life } \\
r\end{array}$ & $\begin{array}{c}\text { Loss } \\
\text { of autonomy } \\
r\end{array}$ & $\begin{array}{c}\text { Loss } \\
\text { of confidence } \\
r\end{array}$ & $\begin{array}{l}\text { Loss of social } \\
\text { support } \\
\mathbf{r}\end{array}$ \\
\hline $\begin{array}{l}\text { Loss of purpose } \\
\text { of life }\end{array}$ & 1 & & & \\
\hline $\begin{array}{l}\text { Loss } \\
\text { of autonomy }\end{array}$ & $0.517^{*}$ & 1 & & \\
\hline $\begin{array}{l}\text { Loss of } \\
\text { confidence }\end{array}$ & $0.582 *$ & $0.350 *$ & 1 & \\
\hline $\begin{array}{l}\text { Loss of social } \\
\text { support }\end{array}$ & $0.302 *$ & $0.210 *$ & $0.187^{*}$ & 1 \\
\hline
\end{tabular}

$r=$ Pearson's correlation coefficient; * $p<0.01$

In the Czech version of the PDI-CZ, items are divided into four subscales corresponding to the four factors determined based on the result of the factor analysis (Kisvetrová et al., 2018b). The classification of items in the individual subscales is seen in Table 15.

\section{PDI-CZ subscales}

$\checkmark$ Loss of purpose of life - this includes the items dealing with the loss of the purpose of life in relation to the illness, self-rating, and the future.

$\checkmark$ Loss of autonomy - consists of items focused on dependence, selfcare, and community reactions.

$\checkmark$ Loss of confidence - includes items related to mental and existential insecurity.

$\checkmark$ Loss of social support - consists of items reflecting social support by friends, nursing staff, and care provided with respect. 


\section{Table 15 Structure of subscales in PDI-CZ}

\section{Loss of purpose of life}

12 Not feeling worthwhile or valued

24 Not being able to accept the way things are

15 Feeling that I have not made a meaningful and lasting contribution during my lifetime

13 Not being able to carry out important roles (e.g., spouse, parent)

11 Feeling like I am no longer who I was

19 Feeling that I don't have control over my life

23 Feeling like I am no longer able to mentally 'fight' the challenges of my illness

16 Feeling I have 'unfinished business' (e.g., things left unsaid, or incomplete)

08 Worrying about my future

18 Feeling that I am a burden to others

03 Experiencing physically distressing symptoms (such as pain, shortness of breath, nausea)

14 Feeling that life no longer has meaning or purpose

07 Feeling uncertain about my illness and treatment

\section{Loss of autonomy}

$01 \quad$ Not being able to carry out tasks associated with daily living (e.g. washing myself, getting dressed)

02 Not being able to attend to my bodily functions independently (e.g. needing assistance with toileting-related activities)

10 Not being able to continue with my usual routines

20 Feeling that my illness and care needs have reduced my privacy

04 Feeling that how I look to others has changed significantly

\section{Loss of confidence}

05 Feeling depressed

06 Feeling anxious

17 Concern that my spiritual life is not meaningful

09 Not being able to think clearly

\section{Loss of social support}

21 Not feeling supported by my community of friends and family

22 Not feeling supported by my health care providers

25 Not being treated with respect or understanding by others 


\subsubsection{Fear of falling}

The fear of falling can be defined as permanent concerns about falling which result in the individual's avoiding activities they would otherwise be able to perform. People therefore lose the self-sufficiency in such activities even though no real fall has happened (Tinetti, Powell, 1993). The fear of falling is considered to be a multifactorial (Katsumata et al., 2011; Kumar et al., 2014; Liu, 2015) and multidimensional construct (Boyd, Steven, 2009). Research shows that it occurs more frequently in women (Scheffer et al., 2008; Donoghue et al., 2013; Zijlstra et al., 2007a; Le Bouthillier et al., 2013; Friedman et al., 2002; Kurková et al., 2020) and older adults (Zijlstra et al., 2007b). The fear of falling is connected with a deteriorated functional fitness (Yardley, Smith, 2002; Dias et al., 2011), geriatric frailty (Kurková et al., 2020), cognitive capacity (Yardley, Smith, 2002), and with depression (Austin et al., 2007). The prevalence of the fear of falling in older adults is also related to the occurrence of falling in the anamnesis, polypragmasia, hearing impairment, functional dependence in the ADL, lower walking speed, and depression symptoms (Malini et al., 2016). The fear of falling therefore represents a significant psychological factor connected with the limited living space of older people (Auais et al., 2017) which increases the risk of falling and worsens the quality of life (Esbrí-Víctor et al., 2017; Trombetti et al., 2016).

At present, the fear of falling is a factor often occurring in the assessment of older adults. The nursing staff providing care to older patients should not only make a routine evaluation of the previous fall anamnesis in them but also assess their fear of falling and the related factors (Lavedán et al., 2018). The most common tool to measure various levels of the fear of falling is the Falls Efficacy Scale-International (FES-I; Yardley et al., 2005).

\subsubsection{Falls Efficacy Scale-International}

The Falls Efficacy Scale-International (FES-I) was created and verified within the Prevention of Falls Network Europe (ProFaNE; Yardley et al., 2005). The previous studies have confirmed that the FES-I is a valid tool to assess the fear of falling in older people across cultures (Ruggiero 
et al., 2009; Baharlouei et al., 2013; Billis et al., 2011; Ulus et al., 2012; Camargos et al., 2010; Figueiredo et al., 2018; Halaweh et al., 2016; Kempen et al., 2007; Kovács et al., 2017; Kwan, 2013; Kisvetrová et al., 2019b). FES-I has been used in various groups of older adults, for example in older adults living in a community (Kovács et al., 2017; Ulus et al., 2012), in day care centres for older people (Figueiredo et al., 2017), and in older adults staying in hospitals (Denkinger et al., 2009). However, only a couple of studies focused also on people with cognitive impairment (Hauer et al., 2010; Hauer et al., 2011).

FES-I consists of 16 items providing information about the degree of concerns of falling for a number of activities of daily living (Yardley et al., 2005). Out of the 16 items, ten items assess basic activities and the other six items assess the more demanding physical and social activities. On a 4-item Likert scale, each item assesses the degree of the fear of falling when performing a specific activity ( $1=$ not concerned at all, 2 = slightly concerned; 3 = quite concerned; 4 = seriously concerned). The overall score ranges between 16 points (no fear at all) and 64 points (greatest fear). The score between 16 and 19 points indicates low fear of falling, the score between 20 and 27 points reflects mild fear, and the score over 27 points shows serious fear of falling (Delbaere et al., 2010).

\section{Fear of Falling (Czech translation of the FES-I)}

The Czech translation of the FES-I (Reguli, Svobodová, 2011) has not been validated yet. Therefore, in the first phase of the Czech Health Research Council grant (No. 16-28628A) its psychometric validation was conducted with a sample of patients in the early stage of dementia.

The sample consisted of 282 respondents who were diagnosed with any type of dementia in its early stage (their average age was $80.0 \pm 7.7$, ranging from 60 to 97; the number of women was 177 [62.8\%]; the MMSE score $=22.7 \pm 1.7$ points). The internal reliability of the questionnaire was measured by Cronbach's alpha $(\alpha=0.98)$. The item-total correlation was between 0.81 and 0.93 which shows strong to very strong correlation. The ICC coefficients were used to 
evaluate the test-retest reliability. The ICC for the total scale was 0.90 ( $95 \% \mathrm{Cl} 0.83-0.94)$. The ICC for the individual items ranged from 0.71 to 0.90 which indicates good to very good reliability.

The internal structure of the scale was examined by the exploratory factor analysis (EFA). The number of factors was determined by the Principal component method with the Varimax rotation. Sixteen items of the Czech version of the FES-I were divided into two factors which explained the $83.7 \%$ of the overall variability. The first factor was called Basic activities and consisted of the first nine items. The second factor was called Risky activities and included items 10-16 as shown in Table 16. The convergent validity was checked by the correlation of the overall score of the Czech version of the FES-I with the SPPB scales (physical fitness), GDS-15 (depression), QOL-AD (quality of life), and BADLS-CZ (self-sufficiency). This showed a medium negative correlation with the SPPB $(r=-0.639, p<0.0001)$ and the BADLS-CZ ( $r=-0.637, p<0.0001)$, weak negative correlation with the QOL-AD $(r=-0.358, p<0.0001)$, and a medium positive correlation with the GDS-15 $(r=0.419, p<0.0001)$.

The results of the validation study have proven excellent internal reliability of the Czech version of the FES-I and have confirmed its relevance to be used with patients in the early dementia stage (Kisvetrová et al., 2019b).

Table 16 Classification of FES-I items (Kisvetrová et al., 2019b)

\section{Factor l: Basic activities}

1 Cleaning the house (e.g. sweeping, vacuuming, dusting)

$2 \quad$ Getting dressed or undressed

3 Preparing simple meals

4 Taking a bath or shower

5 Going to the shop

6 Getting in or out of a chair

7 Going up or down stairs

8 Walking around in the neighbourhood

9 Reaching for something above your head or on the ground 


\section{Factor II: Risky activities}

10 Going fast to answer the phone before it stops ringing

11 Walking on a slippery surface (e.g. wet or icy)

12 Visiting a friend or relative

13 Walking in a place with crowds

14 Walking on an uneven surface

(e.g. rocky ground, poorly maintained pavement)

15 Walking up or down a slope

16 Going out to a social event

(e.g. religious service, family gathering or club meeting)

\subsection{Social and relationship area}

Relationships, communication, social inclusion, and volunteering represent important factors of the quality of life in older adults with dementia. Results of several studies (Clare, Woods et al., 2014; Moyle et al., 2011a; Moyle et al., 2015; Nikmat et al., 2015; O’Rourke et al., 2015; Orpwood et al., 2007) confirm that quality relationships with family, friends, neighbours, and caregivers are connected with a better quality of life in older patients with dementia. Also the participation in social events contributes to the higher quality of life in older adults with dementia (Moyle et al., 2015; Orpwood et al., 2007; Silberfeld et al., 2002). Inclusion in the life of a religious community can also keep patients with dementia in touch with their social network and this social support helps to lower their sadness, anxiety, and depression (McNamara, 2002).

As regards the location of the permanent residence, older people living in their own social environment usually assess the quality of their life as better than older adults living in residential institutions (Kuo et al., 2010; Nikmat et al., 2015; González-Salvador et al., 2000; Winzelberg et al., 2005).

The gradual progression of the worsening of cognitive functions, which is common in dementia, also has a significant effect on the social relationships and interactions. Older adults in the early dementia stage are sensitive to the feelings of loneliness which lead to social isolation. It is therefore necessary to consider and support social relationships of 
patients with dementia in order to keep up their personal well-being as well as the well-being of their family members (Moyle et al., 2011b).

Social relationships include the interactions with family, friends, and professional care providers (O'Rourke et al., 2015; Orpwood et al., 2007; Beerens et al., 2016; Gräske et al., 2015). Relationships characterised by closeness, kindness, esteem, and respect improve the quality of life in older people (Sorrell et al., 2006; Cahill, Diaz-Ponce, 2011). If older patients with dementia feel connected to others, they assess their quality of life better. On the other hand, missing or negative social interactions, experience of distrust, conflicts or manifestations of ignorance and disdain by the others cause loneliness and worsen the quality of life. The overview of selected studies dealing with the individual factors of the social and relationship field is shown in Table 17.

Table 17 Social and relationship factors

\section{Factor}

quality of relationship

with care providers

social interaction,

partner, family, friends

family visits

relationships with children

loneliness, social isolation

involvement in community /

social activities

contact with volunteers

ability to communicate

permanent residence location /

environment

\section{Source}

Woods et al., 2014; Clare, Woods et al., 2014;

Moyle et al., 2011a

Byrne-Davis et al., 2006; O'Rourke et al., 2015;

Orpwood et al., 2007; Beerens et al., 2016

Gräske et al., 2015; Moyle et al., 2011a

Nikmat et al., 2015

Moyle et al., 2011b

Castillo et al., 2010; Orpwood et al., 2007;

Silberfeld et al., 2002; Burgener et al., 2015

George, 2010; León-Salas et al., 2015

Young et al., 2011; Moyle et al., 2011a

Kuo et al., 2010; Nikmat et al., 2015;

Wolf-Ostermann et al., 2014; Moyle et al., 2014 


\section{4 / Trajectory of quality of life}

The results of a vast research conducted by the Alzheimer's Disease International organisation (ADI, 2019) have shown that almost $80 \%$ of the population are afraid of dementia at some point in life. In this respect, one out of four people believe that there is nothing that could be done at present to prevent dementia. In order to be able to realise programmes aimed at patients with dementia (dementia-friendly programmes), to protect and support their quality of life, it is necessary to know how the individuals with dementia themselves perceive and assess the quality of their life and what factors affect it (ADI, 2019). The significance assigned to the self-rating of the quality of life is based on the fact that the quality of life is a multidimensional construct based on both the personal experience of the individuals with their own lives and on objective criteria in the context of culture and values in the society where the individuals live (The WHOQOL Group, 1995).

\subsection{Theoretical background and aims of the study}

At present, the awareness about dementia and the quality of life of patients with dementia is increasing in many countries. However, it is still true that the dementia diagnosis brings the patients stigma, social isolation, and worsening of the quality of life (ADI, 2015). This is because older adults suffering from dementia in the early stage acknowledge 
their illness and this often causes insecurity, changes of mood, depression, and anxiety (Kalvach et al., 2011). On the other hand, security is provided by a regular daily routine and keeping the personal rituals. Lowering the performance of complex cognition-directed daily activities of the individuals therefore has negative effects on the quality of their lives. Therefore, the support of the quality of life of older adults in the early dementia stage has become one of the key aims of medical care (Moniz-Cook et al., 2008; Rodakowski et al., 2014) and the importance of research focusing on self-rating of the quality of life of these people has been stressed (Woods et al., 2014).

Cross-sectional studies and observation studies aimed mainly at longterm observation of the trajectory of quality of life in patients with early dementia are very important as foreign literature points out at the fact that the quality of life in older adults has not been researched enough; especially from a long-term perspective (Clare, Woods et al., 2014; Vogel et al., 2012). Even though in the past Selwood et al. (2005) recommended watching the changes in the quality of life in people with early dementia in the long run and in bigger groups of respondents, the quality of life in these people was usually observed in connection to the relatively limited number of factors, in a short-term perspective, and in smaller groups of patients (St John, Montgomery, 2010; Bowling et al., 2015). Therefore, research has recently started to focus on the trajectory of self-rating of the quality of life and on the factors that affect it in older patients with dementia and to compare it with the quality of life in older adults without any impairment of the cognitive functions (Goyal et al., 2018; van de Beek et al., 2019; Joanovič et al., 2019; Kožený et al., 2019).

Factors directly affecting the assessment of quality of life of older adults in the early stage of dementia include the level of functional ability and self-sufficiency in the activities of daily living (ADL). Worsening in the cognitive functions in older adults leads to a progressive loss of their selfsufficiency in ADL and in the ability to get involved in social activities. All this then negatively influences the older adult's quality of life (Giebel et al., 2015; Barbe et al., 2017). A significant factor connected with age is physical fitness, as the geriatric frailty lowers the ability of the individual's organism to react to stressors and therefore affects their quality of life. 
For this reason, the correlation between the frailty and the cognitive impairment is studied at present (Robertson et al., 2013). Another factor is the chronic pain (Tan et al., 2014; 2016). In patients with dementia, pain often causes discomfort and distress (Herr, 2011; Scherder et al., 2009), which consequently influences their self-rating of the quality of life (Corbett et al., 2012; Cordner et al., 2010).

One of the significant psychological factors is the attitude to ageing (Trigg et al., 2012). Ageist attitudes lead to the worsening of the quality of life, to the limited access to medical or rehabilitation services, and also to frequent indecent treatment of older adults with dementia (ADI, 2019). In older people with mild cognitive impairment and in early dementia stages the quality of life is also significantly affected by the fear of falling (Akosile et al., 2014; Uemura et al., 2014). Other factors include the depression, which often occurs in older people and is considered to be a variable with a significant effect on the quality of life in patients with dementia (Selwood et al., 2005, Banerjee et al., 2009; Gómez-Gallego et al., 2012b).

Social and interpersonal characteristics of an individual represent another factor with an important role in the subjective perception of the quality of life (Burgener, Twigg, 2002; Fukushima et al., 2005). This area includes a deteriorated ability to communicate which secondarily deepens the limitation of social participation in patients in the early dementia stage which is then negatively reflected in the subjectively perceived quality of their lives (Moyle et al., 2011a; Burgener et al., 2015). These factors affecting the quality of life often occur not only in patients with dementia but also in people without a cognitive deficit (Gobbens, Van Assen, 2014). However, the older adult's dignity has not been included among the variables in examining the quality of life of older people with dementia and its changes in a long-term perspective. Yet, the results of several studies show that even the dignity can affect the quality of life (Tranvag et al., 2015; Tranvag et al., 2016).

Therefore, the aim of the longitudinal prospective study called "Trajectory of Quality of Life in Older Adults in Early Stage of Dementia" was to determine how older people in the early dementia stage asses their 
quality of life and what factors affect it. Later on, the results in the patients with dementia were compared with a comparative sample of older adults without any cognitive deficit and predictors were defined of the changes of the quality of life within two years (Kisvetrová et al., 2020).

\subsection{Sample and methodology}

The research sample of the multicentre study consisted of two groups of older adults. One contained people who were diagnosed with dementia and the other were individuals without dementia.

The first group (patient group) included patients in the early stage of dementia who complied with the inclusion criteria below:

(1) Is 60 years old or over;

(2) Lives in one's own social environment;

(3) Has been diagnosed in recent 12 months with any dementia type at its early stage (diagnosed by MKN-10 (2020): Foo, F01-F03; MMSE score of 20-25 points);

(4) Is in touch with a family caregiver at least once a week;

(5) Has signed an informed consent for the participation in the study.

The researchers engaged in the study addressed patients and their family caregivers via neurological and geriatric clinics where the patients with dementia were treated.

The other (control) group consisted of older adults without dementia who complied with the inclusion criteria below:

(1) Is 60 years old or over;

(2) Lives in one's own social environment;

(3) Has not been diagnosed with any dementia type (MMSE score of 26-30 points). 
These older adults were addressed by the research team via adult general practitioners' offices.

Exclusion criteria for both the groups of respondents were:

(1) Permanent institutional care (old people's home);

(2) Complete immobility;

(3) Serious mental disease (bipolar disorder, schizophrenia);

(4) Terminal stage of an oncological or non-oncological disease.

The sample size calculation was based on the expected difference of 0.5 point in the QOL-AD tests (quality of life) within 24 months between the patients with dementia and the respondents without dementia (control group), $\alpha=0.05$ (two-tailed) and $\beta=0.8$. Supposing that $30 \%$ respondents do not complete the study, it was necessary to screen at least 290 respondents for every group.

\section{Realisation of the research}

The study was approved by the Ethical boards of the institutions involved in the realisation of the research (Faculty of Health Sciences at Palacký University Olomouc, University Hospital Hradec Králové, University Hospital Ostrava) and before the first patient was involved in the study, it was registered at: www.clinicaltrials.gov (Identified: NCT02845830).

The research was conducted in three regions of the Czech Republic (Olomouc, Ostrava, and Hradec Králové) in 2016-2019. To conduct the research, we used a prospective longitudinal design. The research consisted of three phases of measurements in which the older people completed a set of questionnaires either by themselves or in structured interviews with the researchers - first when they were involved in the study, then 12 months later and 24 months later. All respondents signed an informed consent for the participation in the study and were exam- 
ined by a medical doctor (general practitioner, neurologist or geriatrist) upon the entry into the study. The doctors performed a basic examination of the vision and hearing and recorded the socio-demographic characteristics of the respondents (age, sex, education, social situation [who the respondent lives with], frequency of involvement in social activities, visits and telephone contacts with friends/relatives, and time spent alone during the day).

The questionnaire battery consisted of a set of Czech versions of the standardised tools to assess the quality of life (Quality of Life-Alzheimer's Disease; QOL-AD), depression (Geriatric Depression Scale; GDS-15), dignity (Patient Dignity Inventory; PDI-CZ), attitudes to ageing (Attitude to Ageing Questionnaire; AAQ), fear of falling (Falls Efficacy Scale International; FES-I), physical fitness (Short Physical Performance Battery; SPPB), self-sufficiency in ADL (Bristol Activities of Daily Living Scale; BADLS-CZ), and pain (Horizontal Visual Analogue Scale; HVAS).

\section{Statistical data processing}

The sample of respondents was described with absolute and relative frequencies (mean, standard deviation [SD], and median). Comparing the two respondent groups (patients diagnosed with dementia and individuals without dementia) in quantitative traits was done by a $t$-test for independent samples. The comparison of quantitative values of the first (entry) and third (24 months later) measurement was done by a pair t-test. In qualitative values the groups were compared by a chi-square test. All the tests were performed on the level of statistical significance of 0.05 . Stepwise multivariable linear regression was used to find significant predictors of the quality of life. The following variables were included into the model as independent predictors: age, sex, education, social conditions (lives alone - lives with another person), social activities (social events, visits, telephone contact, time spent alone), hearing and vision impairment, cognition, pain, physical fitness, self-sufficiency in ADL, depression, fear of falling, attitudes to ageing, and dignity. Normality was checked by Shapiro-Wilk test. The independence of residuals was verified by Durbin-Watson test where values close to 2 show the absence 
of autocorrelation. Multicollinearity was checked with the VIF (variance inflation factor) where VIF $>10$ indicates the potential multicollinearity among dependent variables. Data from this study complied with the presumptions of multivariable linear regression. The model quality was evaluated with the coefficient of determination $R^{2}$ and adjusted $R^{2}$. The statistical processing was performed on statistical software IBM SPSS Statistics for Windows, Version 23.0 (IBM Corp., Armonk, NY, USA).

\subsection{Results}

In the first phase of the multicentre longitudinal study, 623 respondents were screened and included into the study. Out of those, 294 were patients who had a diagnosis of any dementia type in its early stage (average age of $79.6 \pm 7.5$ years; 109 [37.1\%] of them were male; MMSE score $=22.7 \pm 1.7$ points) and 329 respondents without dementia (average age $72.7 \pm 7.0$ years; 99 [30.1\%] of them were male; MMSE score $=29.2 \pm 1.3$ points).

Patients diagnosed with dementia in the early stage were significantly older $(p<0.001)$, they had lower education ( $p=0.004)$, participated less in social activities $(p=0.036)$, had a lower frequency of telephone contacts with friends and family members $(p=0.002)$, spent more time alone $(p<0.001)$, and had more occurrence of hearing impairment $(p=0.026)$ and vision impairment $(p<0,001)$. A complete overview of the sociodemographic characteristics of all the respondents participating in the study is shown in Table 18.

\section{Factors affecting the quality of life}

Patients diagnosed with dementia differed a lot from the control group (consisting of older adults without dementia). The factors that affected the quality of life were identified in the first phase of the study.

The results showed that depression was the only common factor affecting the quality of life both in the patients with dementia $(p<0.0001)$ 
Table 18 Demographic and clinical characteristics of the sample

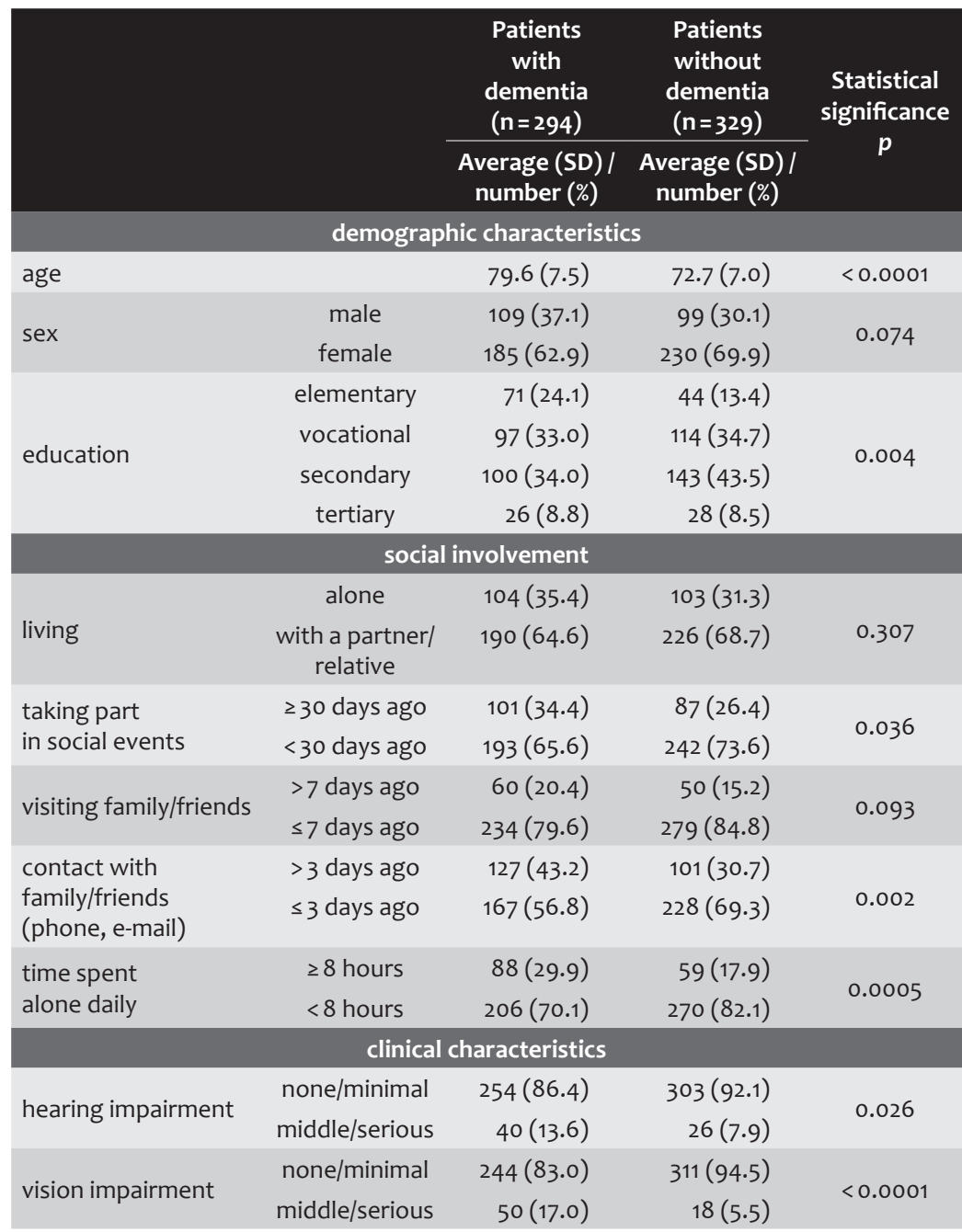

$\mathrm{SD}=$ standard deviation 
and in the respondents without dementia $(p<0.001)$. This result is in compliance with the past findings which confirm that the seriousness of depression negatively affects the quality of life (Gómez-Gallego et al., $2012 \mathrm{~b}$ ). In order to improve the quality of life in older patients, the early diagnosis and depression treatment are key clinical priorities both in the area of primary medical care and in the community nursing care provided to older people in their own social environment.

It was proven in the entry assessment (first research phase) that dignity is one of the factors that affect the quality of life in patients in the early stage of dementia. A higher quality of life was in older adults with dementia who self-rated their dignity in a more positive way $(p<0.0001)$. Dignity is a multidimensional construct that includes perception, cognition, and emotions related both to the feeling of self-esteem and self-respect and to the respect and esteem that others show to the individual. Patients in the early stage of dementia do acknowledge their own deterioration of cognitive abilities and they often consider this to be a stigma lowering their self-esteem (Burgener et al., 2015) and consequently the personal dignity that is negatively reflected in the assessment of their quality of life. Up to now, other studies have not presented a proof that the dignity is a significant factor affecting the quality of life in older patients with dementia living at home.

Another factor was the attitude to ageing. A more positive attitude to ageing was connected with the patients' better quality of life $(p=0.011)$. Older people in the early stage of dementia often connect the negative attitude to ageing with the realisation of their gradual decrease in cognitive abilities (Siebert et al., 2018) which then significantly decreases their quality of life. The study findings also indicate that the quality of life among patients with dementia was affected by the degree of self-sufficiency in ADL. Patients with dementia who demonstrated a higher degree of self-sufficiency assessed their own quality of life better $(p<0.0001)$. This finding is in compliance with other authors' results (Ydstebø et al., 2018; Conde-Sala et al., 2016).

The other (control) group of the research sample consisted of patients without dementia in whom the better quality of life was connected with 
a lower degree of depression ( $p<0.001)$, lower fear of falling $(p<0.001)$, lower intensity of pain $(p=0.009)$, female sex $(p=0.004)$, higher frequency of participation in social events $(p=0.004)$, and a more frequent telephone contact with family and friends $(p=0.019)$. An overview of the individual factors affecting the quality of life in patients with and without dementia is presented in Table 19.

As the study results have shown, the fear of falling has proven to be a factor affecting the quality of life only in older adults without dementia. This can be due to the fact that individuals with cognitive impairment do not always have to be able to acknowledge the deterioration of their physical fitness and the risk of falling related to it. Therefore, their fear of falling is manifested less. Cognitive impairment especially in the area of executive functions can therefore be connected with the absence of fear of falling (Shirooka et al., 2017; Uemura et al., 2012; Uemura et al., 2014). De Borges et al. (2015) confirm similar results in older patients with Alzheimer's disease. Other authors relate the absence of fear of falling in people with cognitive impairment to anosognosia which can be described as the patient's lack of awareness about one's own deterioration of the physical or mental state (Starkstein et al., 2006; Lin et al., 2010).

The fact that the correlation between the intensity of pain and the quality of life has proven only in patients without dementia can be a consequence of a worse ability of the patients with dementia to assess their own pain. The deficit in the ability to assess the present state and the intensity of pain is often connected with impaired communication or with deteriorated short-term memory (Jensen-Dahm et al., 2015).

Social inclusion (frequency of participating in social events and telephone contacts with family and friends) affected the quality of life only in the patients without dementia. These findings are in compliance with the results of an earlier study which also states that the decrease in the quality of life in older people relates to the low frequency of social relationships (de Belvis et al., 2008). 


\section{Changes in the assessment in the course of 24 months}

The measurement results in the individual phases of the project in patients with and without dementia are shown in Table 20. A two-sample $t$-test showed that patients with and without dementia significantly differed in all the examined areas. In all the three measurements, respondents with dementia had lower average values (i. e. worse assessment) in the scales assessing cognition (MMSE), pain (HVAS), physical fitness (SPPB), attitude to ageing (AAQ), quality of life (QOL-AD), and the degree of self-sufficiency (BADL-CZ). On the other hand, they had significantly higher values (i. e. worse assessment) in scales measuring depression (GDS-15), fear of falling (FES-I), and dignity (PDI-CZ).

Comparison of results of the first (entry) and third (24 months later) measurement showed that both the patients diagnosed with dementia and patients without dementia experienced a significant deterioration in the level of cognition, physical fitness, and degree of self-sufficiency (in all cases $p<0.0001$ ). Respondents also experienced an increase in the fear of falling $(p=0.002$ in patients with dementia and $p<0.0001$ in patients without dementia). In patients with dementia there was also a decrease in the quality of life $(p<0.0001)$ and in the assessment of the intensity of pains $(p=0.022)$. Patients without dementia showed a significant deterioration of the attitude to ageing $(p=0.0001)$ and the assessment of dignity $(\mathrm{p}=0.006)$. An overview comparing all the results is shown in Table 21.

\section{Predictors of the change in the assessment of the quality of life}

Twenty-four months after the beginning of the study, the quality of life worsened only in patients with dementia (see Table 21). For that reason, we were looking for predictors that affected the dimensions of the change in the assessment of quality of life in these patients. In the model of multidimensional linear regression, dependent valuables were represented by the difference between the values of the QOL-AD score in the first (entry) and third (24 months later) measurement. The dimensions of the change in the quality of life (i. e. the difference between the first 
and the third measurement) in patients with dementia were affected by age. Men manifested a greater deterioration of the quality of life (average QOL-AD score $=2.8$ ) than did women (average QOL-AD score $=1.8$ ). Another predictor was the time spent alone daily. Patients who spent alone fewer than 8 hours reported a greater worsening of the quality of life (average values $=2.6$ hours vs. 1.1 hours). Another predictor affecting the change in the quality of life in patients with dementia was the social situation (i. e. who the respondent permanently resides with). Patients who lived alone reported a greater worsening of the quality of life (average score values $=3.2$ vs. 1.7). Also the frequency of visiting family or friends was a significant predictor affecting the change in the quality of life. Patients who had a lower frequency of visits had a greater worsening of the quality of life (average values $=3.5$ vs. $1.9 ; p=0.039$ ). Social relationships and social activities constitute the main source of the subjective personal well-being which is composed of both the positive evaluation of the current situation and the balance of positive and negative emotions in patients with dementia (de Belvis et al., 2008). Also Verloo et al. (2018) state that more frequent visits of friends and family have a positive effect on the quality of life in patients with dementia. As opposed to our study, Ydstebø et al. (2018) confirmed just a minor decrease of quality of life in patients with dementia 18 months later. The difference can be explained by a higher heterogeneousness of their research sample in terms of age, cognitive and functional limitation in comparison to the respondents in our study. As the quality of life has a highly subjective nature, it is also possible that the generally positive or generally negative perception of life by some individuals might have had a stronger influence on the assessment of quality of life than that of dementia.

Other predictors were the total scores of the first measurement by QOL-AD and BADLS-CZ. Patients with dementia who had a higher quality of life in the first measurement (a higher QOL-AD score) showed a greater change 24 months later, i. e. their quality of life deteriorated more $(p<0.0001)$. $A$ higher degree of self-sufficiency (BADLS-CZ) in the entry measurement correlated with a smaller change in the quality of life $(p=0.011)$.

The list of all predictors of the change of life quality in respondents with dementia is shown in Table 22. 


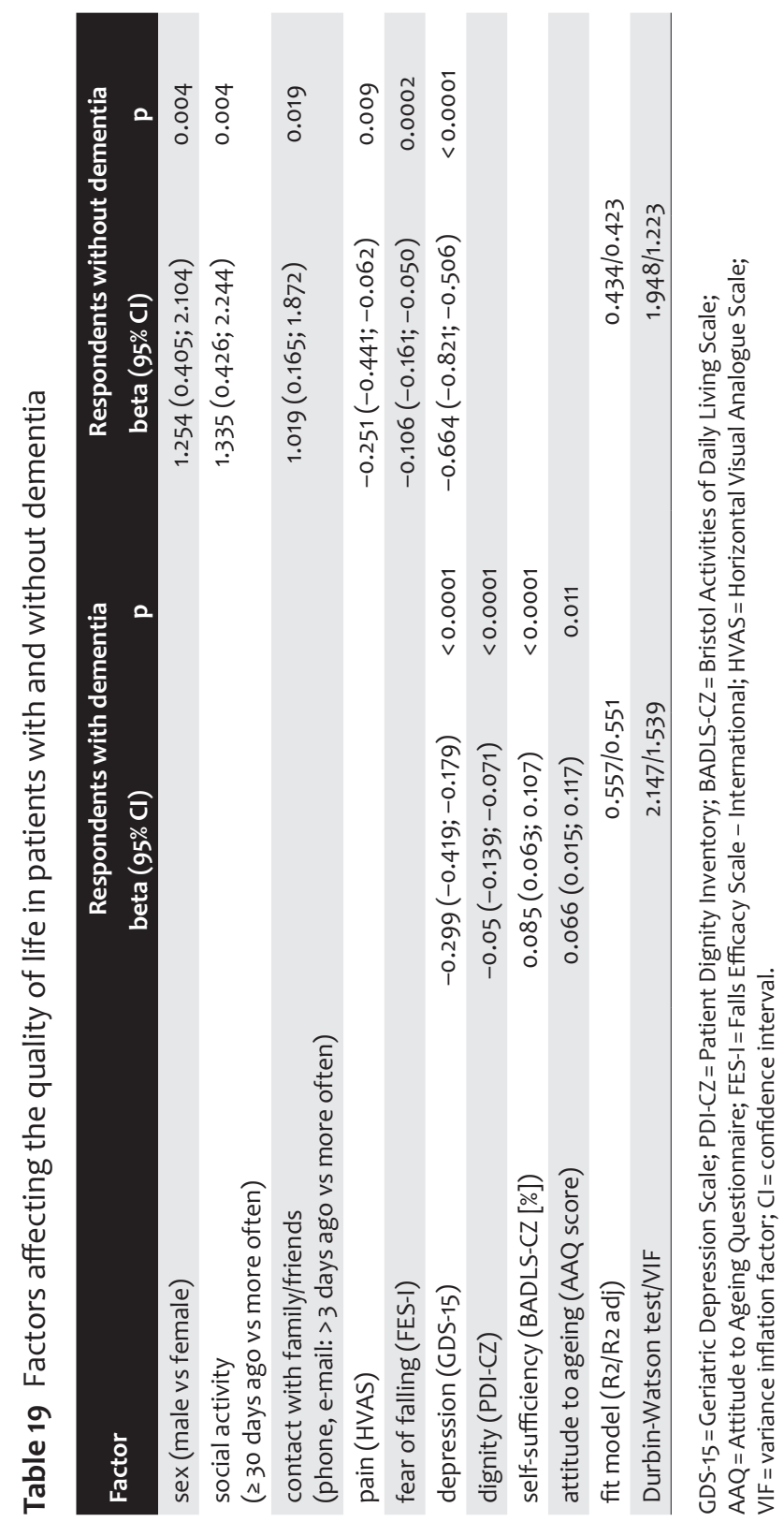




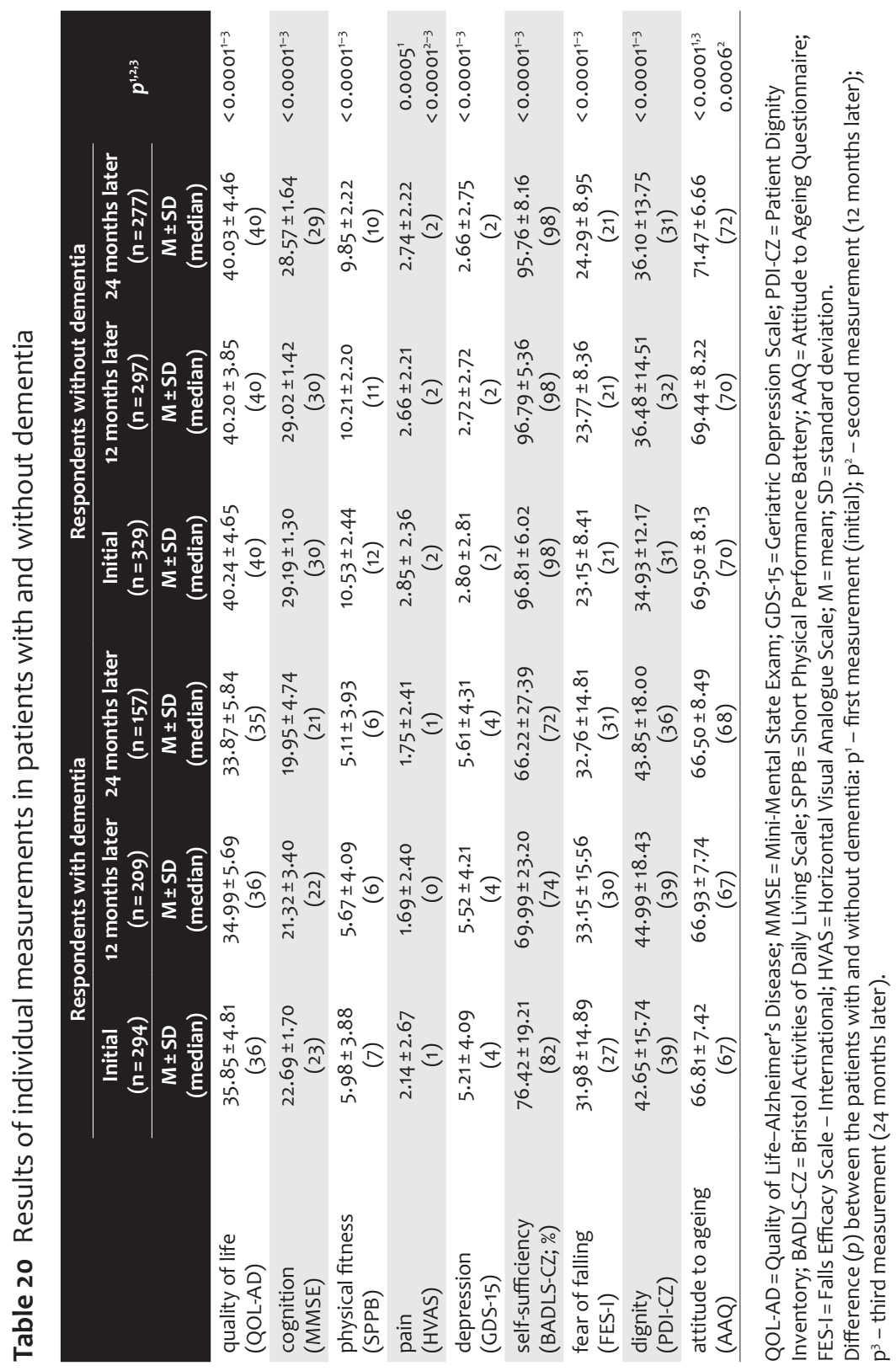




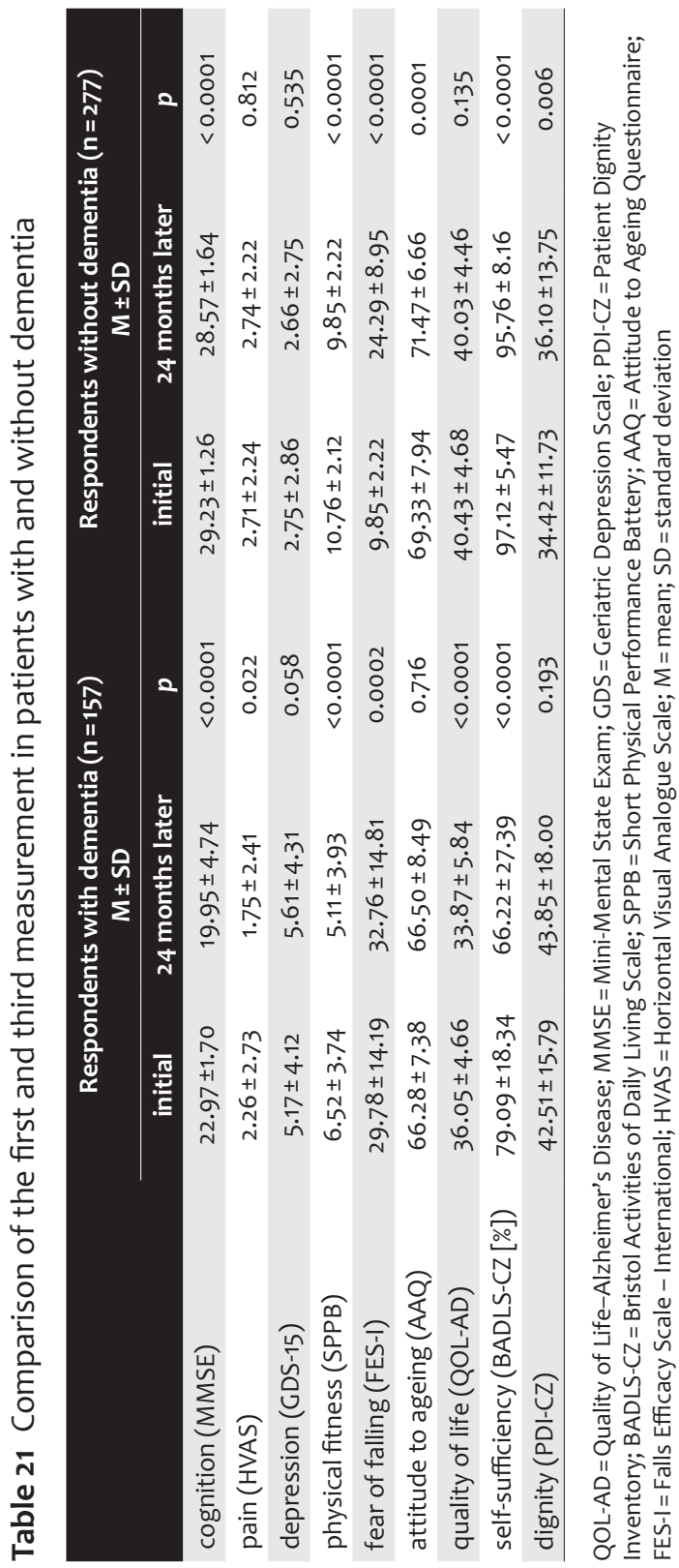




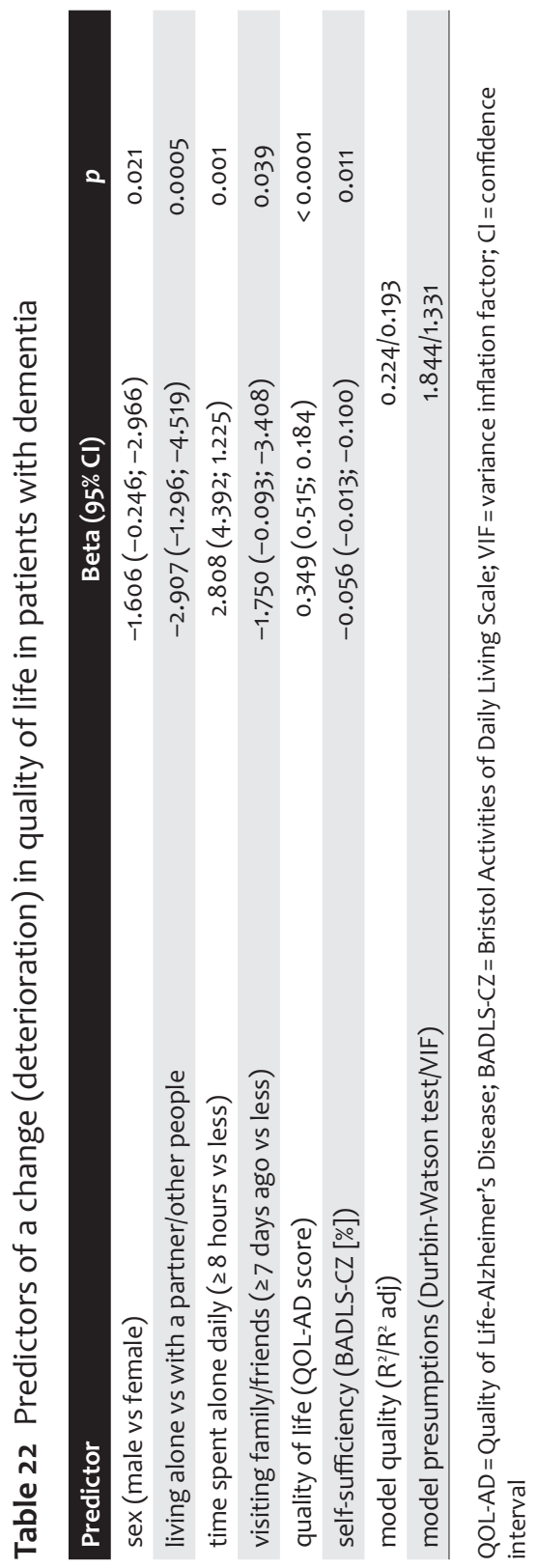




\section{Conclusion}

Current demographic trends leading to the ageing of population affect also the continuing increase in older adults suffering from dementia. The quality of life in these patients and their changes in the individual dementia stages therefore present a challenge that must be researched. However, observing the quality of life in people with dementia in the long run has been a rather rare topic in Czech studies as compared to several foreign studies dealing with this topic.

The results of the first Czech longitudinal multicentre study focusing on the trajectory of quality of life in older adults in the early stage of dementia and its comparison to the control group of older people without any cognitive deficit have shown that patients with dementia evaluated their quality of life as significantly worse than did the individuals without dementia. The set of factors which have influenced the quality of life only in older adults with dementia included dignity, attitude to ageing, and the degree of self-sufficiency in ADL. Depression was then identified as a factor affecting the quality of life in older adults both with and without dementia. It has also been confirmed that the quality of life deteriorated within the two years only in the patients with dementia. The predictors of this change included being male, living without a partner, high number of hours spent alone daily, lower frequency of visiting family or friends, and a higher quality of life (QOL-AD score) and higher self-sufficiency (BADLS-CZ score) in the initial measurement. 
The results therefore demonstrate that relationships and social involvement are crucial for the preservation of the quality of life in older people in the early stage of dementia who are living at home. These findings can be useful when planning medical and social strategies which should concentrate more on the intervention of social support to older adults with dementia in home care. The study results can also serve as a basic source of information for a subsequent longitudinal research specifically dealing with the quality of life in older adults with dementia receiving permanent institutional care in the Czech Republic. 


\section{Summary}

The first chapter of this publication deals with the terminological definitions of dementia, the basic classification according to its causes and the individual stages of dementia. In addition, it introduces risk factors for the development of dementia and the most popular screening tools for assessing cognitive functions. The second chapter focuses on the quality of life, its definition and evaluation for people with dementia. The third chapter describes the basic determinants of the quality of life, which include demographic characteristics and health factors, as well as psychological, emotional, social, and relationship factors. Individual factors related to the basic determinants of the quality of life were used as variables in a longitudinal multicentre prospective study examining the trajectory of quality of life in older adults in the early stage of dementia (Czech Health Research Council; grant no. 16-28628A). Its implementation and results are described in the fourth and final chapter of the publication. The study involved 623 respondents, of whom 294 were diagnosed with early-stage dementia. The results showed that depression was the only common factor that influenced the quality of life in both the patients with and without dementia at baseline (first phase of the project). Among patients with dementia, better quality of life was associated with a lower incidence of depressive symptoms, as well as a more positive assessment of their dignity. It has been confirmed that dignity is one of the factors affecting the quality of life among people with dementia. Positive attitudes to ageing and a higher degree of self-sufficiency 
in ADL were other factors associated with a higher assessment of the quality of life among older adults with dementia. Older adults without dementia had a better quality of life associated with lower fear of falling, less pain, being a female, more frequent partaking in social events, and a higher frequency of phone contacts with relatives and friends. The quality of life within two years only significantly deteriorated among older adults with dementia. The degree of this deterioration was influenced by interactions with being a male, social contacts (daily time spent alone, life without a partner, and frequency of visits), and the level of quality of life plus the degree of self-sufficiency at baseline determined in the first phase of the study. The results of the study thus confirm the fundamental impact of social contacts on maintaining the quality of life among older adults with dementia.

Keywords: quality of life; dementia; older adult; trajectory; depression; dignity; attitude to ageing; social involvement; self-sufficiency 


\section{List of tables}

Table 1

Cognition assessment (Tombaugh, Mclntyre, 1992)

Table 2

MMSE scores for individual dementia stages (Fymat, 2018)

22

Table 3

Cognitive impairment assessment (Jirák, Koukolík, 2004)

Table 4

QOL-AD questionnaire items

Table 5

Demographic characteristics

Table 6

Health factors

48

Table 7

Areas tested in SPPB

Table 8

BADLS-CZ questionnaire items

Table 9

Psychological and emotional factors

Table 10

GDS-15 questionnaire items

56 
Table 11

Domain I

Table 12

Domain II

Table 13

Domain III

Table 14

Correlation of factors (subscales) in PDI-CZ

Table 15

Structure of subscales in PDI-CZ

Table 16

Classification of FES-I items (Kisvetrová et al., 2019b)

Table 17

Social and relationship factors

Table 18

Demographic and clinical characteristics of the sample

Table 19

Factors affecting the quality of life in patients with

and without dementia

Table 20

Results of individual measurements in patients with and without dementia

Table 21

Comparison of the first and third measurement in patients with and without dementia

Table 22

Predictors of a change (deterioration) in quality of life in patients with dementia 


\section{Name index}

B

Boggatz, T. 34, 35

Borson, S. 30

Brown, J. 34, 35

C

Chochinov, H. M. 65

D

Dragomirecká, E. 60

F

Farquhar, M. 33, 34

Folstein, M. F. 21, 26

G

Guralnik, J. M. 48, 49

J

Jacelon, C. S. 60, 64

$\mathbf{L}$

Laidlaw, K. 58, 60

Lawton, M. P. 37, 38, 40, 42, 44, 58

Logsdon, R. 36, 37, 38, 39, 40, 41, 42, 43, 44
M

Mann, J. 62, 63

McIntyre, N. J. 21, 26

Mioshi, E. 29

N

Nasreddine, Z. S. 27,29

Nordenfelt, L. 61, 62

o

Oosterveld-Vlug, M. G. 63

R

Reguli, Z. 72

Reisberg, B. 22

S

Shulman, K. I. 30, 31

Solomon, P. R. 30

Sunderland, T. 30

T

Tombaugh, T. N. 21, 26

Tošnerová, T. 27, 56

Y

Yardley, L. 71, 72

Yesavage, J. A. 55, 56 


\section{Subject index}

A

Activities of Daily Living (ADL) 14, 37, 39, 43, 44, 47, 48, 50, 52, 57, 71, 72, 77, 81, 84, 88, 89, 90, 91, 92

Addenbrooke's Cognitive Examination 29

Affect Rating Scale 40

Alzheimer's disease 15, 16, 18, 20, 21, 23, 30, 41, 42, 44, 76, 81, 85

Alzheimer's Disease-Related Quality of Life (ADRQL) 41

Assessment of cognition 26, 29, 52

Attitude to Ageing Questionnaire (AAQ) 58, 81, 86, 88, 89, 90

Attitude Toward Own Aging (ATOA) 58

Attitudes toward old age and ageing 54 , $57,58,60,78,81,84,86,88,89,90,92$, 94, 95

\section{B}

Biswanger's dementia 20

Bristol Activities of Daily Living Scale

(BADLS) 45, 50, 81, 88, 89, 90, 91

$\checkmark$ BADLS-CZ $51,73,81,87,88,89,90$, 91, 92

\section{C}

Clinic

$\checkmark$ Geriatric 79

$\checkmark$ Neurological 79
Clock Drawing Test (CDT) 30

Cognitive function $13,14,16,17,18,19,20$, $21,23,26,27,28,29,30,37,47,52,56$, 74, 77, 94

\section{D}

Dementia 9, 10, 11, 12, 13, 14, 15, 16, 17, 18, 19, 20, 21, 22, 23, 24, 25, 26, 27, 28, 36, $37,38,39,40,41,42,43,44,45,46,47$, $50,52,53,54,55,56,57,58,59,64,65$, $72,73,74,75,76,77,78,79,80,81,82$, $83,84,85,86,87,88,89,90,91,92,93$, 94, 95

$\checkmark$ Atrophic-degenerative dementia 17

$\checkmark$ Brain trauma-related dementia 16,20

$\checkmark$ Frontotemporal dementia 18,19

$\checkmark$ Huntington's disease-related 19

$\checkmark$ Infectious dementia 20

$\checkmark$ Intoxication-related dementia 20

$\checkmark$ Lewy body dementia 18

$\checkmark$ Metabolic dementia 20

$\checkmark$ Multi-infarct dementia 20

$\checkmark$ Parkinson's disease dementia 16,18

$\checkmark$ Prion disease-related dementia 20

$\checkmark$ Secondary dementia 17, 20

$\checkmark$ Symptomatic dementia 20

$\checkmark$ Tumour-caused dementia 20

$\checkmark$ Vascular dementia 20

Demographic characteristics (factors) 47, 50, 81, 82, 83, 94

Depression 15, 19, 24, 36, 39, 43, 44, 45, $53,54,55,56,71,73,74,77,78,81,82$, $84,85,86,88,89,90,92,94,95$ 
Dignity $24,25,53,54,60,61,62,63,64$, $65,78,79,80,81,84,86,88,89,90$, 92, 94

Dignity category 61,62

Durbin-Watson Test 81, 88, 91

\section{$\mathbf{F}$}

Falls Efficacy Scale-International

(FES-I) 71, 81, 88, 89, 90

Fear of falling $54,71,72,78,81,85,86,88$, $89,90,95$



Health $9,12,13,14,15,28,32,33,35,36$, $42,43,45,46,47,48,55,57,58,59,64$, $67,68,70,94$

Huntington's disease 19

$$
\text { J }
$$

Jacelon Attributed Dignity Scale (JADS) 64

\section{K}

Kaiser-Meyer-Olkin Measure (KMO) 68

$\mathbf{L}$

Lewy bodies 18

Linear regression 81, 82, 86

Longitudinal study $9,45,55,65,78,82$, 92, 94

\section{M}

Mann's taxonomy 62

Mild cognitive impairment 21, 22, 23, 24, $27,29,30,44,53,56,78$
Mini-Cog 26, 30

Mini-Mental State Examination (MMSE) $21,26,52,53,72,79,82,86,89,90$

Model of dignity in illness 63

Montreal Cognitive Assessment (MoCA) 26, 27, 29

Multicentre study 9, 45, 65, 79, 82, 92, 94

$\mathbf{P}$

Pain $47,48,52,53,70,78,81,85,86,88$, 89, 90, 95

Parkinson's disease 16, 18

Patient Dignity Inventory (PDI) 64, 65, 66, 81

$\checkmark$ PDI-CZ (Czech version) 65, 67, 68, $69,70,81,86,88,89,90$

Physical fitness $45,48,49,73,77,81,85$, $86,89,90$

Pick's disease 19

Predictor 10, 12, 54, 55, 79, 81, 86, 87, 91, 92

Q

Quality of life 12, 23, 24, 25, 32, 33, 34, 35, $36,41,42,43,44,45,46,47,49,50,52$, $53,54,57,64,65,66,71,73,74,75,76$, $77,78,79,80,81,82,84,85,86,87,88$, $89,90,91,92,93,94,95$

Quality of Life - Alzheimer's Disease Questionnaire (QOL-AD) 41, 42, 43, 44, 45, 73, 80, 81, 86, 87, 89, 90, 91, 92

$\checkmark$ QOL-AD (Czech version) 43, 44, 45

Questionnaire battery 48,81

$\mathbf{R}$

Research 12, 26, 28, 32, 33, 36, 37, 39, 40, $44,45,46,47,54,55,66,67,71,72,76$, 77, 79, 80, 84, 87, 93

Respondents $67,68,72,77,80,81,82,84$, $86,87,88,89,90,94$

Risk factors 14, 15, 16, 17, 55, 94 
S

Seven-minute Screening Test (7MST) 30

Shapiro-Wilk test 81

Social situation 81,87

Social involvement $83,93,95$

Stages of dementia 20, 21, 22, 84, 92, 93

$\checkmark$ Early stage of dementia 22, 24, 38, 41,45

$\checkmark$ Middle dementia 22, 24, 27, 53

$\checkmark$ Severe dementia 25, 36, 38, 52, 53

Steele-Richardson-Olszewski syndrome 19

Strategically placed infarct 20

Subjective impairment of cognitive functions 23
T

Trajectory of quality of life $9,41,45,55$, $65,76,77,78,92,94$

V

Validation

$\checkmark$ Linguistic (language) 65

$\checkmark$ Psychometric 44, 45, 60, 64, 65, 68, 72

W

Wernicke-Korsakoff syndrome 16, 20

Wilson's disease 20 


\section{References}

AARSLAND, D., CREESE, B., POLITIS, M. et al. Cognitive decline in Parkinson disease. Nature reviews. Neurology. 2017; 13(4): 217-231. ISSN 1759-4758.

AKOSILE, C. O., ANUKAM, G., JOHNSON, O. et al. Fear of Falling and Quality of Life of Apparently-Healthy Elderly Individuals from a Nigerian Population. Journal of cross-cultural gerontology. 2014; 29(2): 201-209. ISSN 0169-3816.

AKPINAR, B., KÜÇÜKGÜÇLÜ, Ö. The validity and Reliability of The Turkish Version of The Quality of Life Scale for Patients with Alzheimer's Disease (QOL-AD). Journal of Neurological Sciences-Turkish. 2012; 29(3): 554-565. ISSN 1302-1664.

ALBERT, S. M., CASTILLO-CASTANADA, C., JACOBS, D. M. et al. Proxy-reported quality of life in Alzheimer's patients: comparison of clinical and population based samples. Journal of Mental Health and Aging. 1999; 5(1): 49-58. ISSN 1078-4470.

ALBERT, S. M., DEL CASTILLO-CASTANEDA, C., SANO, M. et al. Quality of life in patients with Alzheimer's disease as reported by patient proxies. Journal of the American Geriatrics Society. 1996; 44(11): 1342-1347. ISSN 0002-8614.

ÁLVARO GONZÁLEZ, L. C. The neurologist facing pain in dementia. Neurologia. 2015; 30(9): 574-585. ISSN 0213-4853.

ALZHEIMER EUROPE. Dementia in Europe Yearbook 2019. Luxembourg: Alzheimer Europe; 2019. 106 pp. ISBN 978-99959-995-9-9.

ALZHEIMER'S DISEASE INTERNATIONAL (ADI). World Alzheimer Report 2015. The Global Impact of Dementia. An analysis of prevalence, incidence, cost and trends. Accessible at: https://www.alz.co.uk/research/WorldAlzheimerReport2015.pdf 
ALZHEIMER'S DISEASE INTERNATIONAL (ADI). World Alzheimer Report 2016. Improving health care for people living with dementia. Accessible at: https://www. alz.co.uk/research/WorldAlzheimerReport2016.pdf

ALZHEIMER'S DISEASE INTERNATIONAL (ADI). World Alzheimer Report 2018. The state of the art of dementia research: New frontiers. Accessible at: https:// www.alz.co.uk/research/WorldAlzheimerReport2018.pdf

ALZHEIMER'S DISEASE INTERNATIONAL (ADI). World Alzheimer Report 2019. Attitudes to dementia. Accessible at: https://www.alz.co.uk/research/WorldAlzheimerReport2019.pdf

AMODEO, S., MAINLAND, B. J., HERRMANN, N., SHULMAN, K. I. The times they are a-changin': Clock drawing and prediction of dementia. Journal of Geriatric Psychiatry and Neurology. 2015; 28(2): 145-155. ISSN 0891-9887.

ARLT, S., HORNUNG, J., EICHENLAUB, M. et al. The patient with dementia, the caregiver and the doctor: cognition, depression and quality of life from three perspectives. International Journal of Geriatric Psychiatry. 2008; 23(6): 604-610. ISSN 0885-6230.

AUAIS, M., ALVARADO, B., GUERRA, R. et al. Fear of falling and its association with lifespace mobility of older adults: a cross-sectional analysis using data from five international sites. Age and Ageing. 2017; 46(3): 459-465. ISSN 0002-0729.

AUSTIN, N., DEVINE, A., DICK, I., PRINCE, R., BRUCE, D. Fear of falling in older women: a longitudinal study of incidence, persistence, and predictors. Journal of the American Geriatrics Society. 2007; 5(10): 1598-1603. ISSN 0002-8614.

BAHARLOUEI, H., SALAVATI, M., AKHBARI, B. et al. Cross-cultural validation of the Falls Efficacy Scale International (FES-I) using self-report and interview-based questionnaires among Persian-speaking elderly adults. Archives of gerontology and geriatrics. 2013; 57(3): 339-344. ISSN 0167-4943.

BANERJEE, S., SAMSI, K., PETRIE, C. D. et al. What do we know about quality of life in dementia? A review of the emerging evidence on predictive and explanatory value of disease specific measures of health related quality of life in people with dementia. International Journal of Geriatric Psychiatry. 2009; 24(1): 15-24. ISSN 0885-6230.

BANERJEE, S., SMITH, S., LAMPING, D. et al. Quality of life in dementia: more than just cognition. An analysis of associations with quality of life in dementia. Journal of Neurology, Neurosurgery \& Psychiatry. 2006; 77(2): 146-148. ISSN 0022-3050. 
BANG, J., SPINA, S., MILLER, B. L. Frontotemporal dementia. Lancet. 2015; 386(10004): 1672-1682. ISSN 0140-6736.

BARBE, C., MORRONE, I., WOLAK-THIERRY, A. et al. Impact of functional alterations on quality of life in patients with Alzheimer's disease. Aging and mental health. 2017; 21(5): 571-576. ISSN 1360-7863.

BARCA, L., ENGEDAL, K., LAKS, J., SELBAEK, G. Quality of life among elderly patients with dementia in institutions. Dementia and Geriatric Cognitive Disorders. 2011; 31(6): 435-442. ISSN 1420-8008.

BARCA, M. L., ENGEDAL, K., LAKS, J., SELBAEK. G. A 12 months follow-up study of depression among nursing-home patients in Norway. Journal of affective disorders. 2010; 120(1-3): 141-148. ISSN 0165-0327.

BARCA, M. L., PERSSON, K., ELDHOLM, R. et al. Trajectories of depressive symptoms and their relationship to the progression of dementia. Journal of affective disorders. 2017; 222: 146-152. ISSN 1573-2517.

BÁRRIOS, H., VERDELHO, A., NARCISO, S. et al. Quality of life in patients with cognitive impairment: validation of the quality of life-Alzheimer's disease scale in Portugal. International psychogeriatrics. 2013; 25(7): 1085-1096. ISSN 1041-6102.

BARTOŠ, A. Dvě původní české zkoušky k vyšetření paměti za tři minuty - Amnesia Light and Brief Assessment (ALBA). Česká a slovenská neurologie a neurochirurgie. 2019; 82(4): 420-429. ISSN 1210-7859.

BARTOŠ, A., HASALÍKOVÁ, M. Poznejte demenci správně a včas - příručka pro klinickou praxi. 2010. Praha: Mladá fronta a. s. ISBN 978-80-204-2282-8.

BARTOŠ, A., MARTÍNEK, P., ŘíPOVÁ, D. Dotazník Bristolská škála aktivit denního života BADLS-CZ pro hodnocení pacientů s demencí. Česká a slovenská neurologie a neurochirurgie. 2010; 73/106(6): 673-677. ISSN 1210-7859.

BARTOŠ, A., RAISOVÁ, M. The Mini-Mental State Examination: Czech Norms and Cutoffs for Mild Dementia and Mild Cognitive Impairment due to Alzheimer's Disease. Dementia and Geriatric Cognitive Disorders. 2016; 42(1-2): 50-57. ISSN 1420-8008.

BEATON, D. E., BOMBARDIER, C., GUILLEMIN, F., FERRAZ, M. B. Guidelines for the proces of cross-cultural adaptation of self-report measures. Spine. 2000; 25(24): 3186-3191. ISSN 0362-2436

BEATON, D. E., BOMBARDIER, C., GUILLEMIN, F., FERRAZ, M. B. Recommendations for the Cross-Cultural Adaptation of the DASH \& Quick DASH Outcome Meas- 
ures. 1st. ed. Institute for Work \& Health. 2007, 45 pp. Accessible at: http://www. dash.iwh.on.ca/sites/dash/files/downloads/cross_cultural_adaptation_2007.pdf

BECK, A. T., STEER, R. A., BROWN, G. K. Manual for the Beck Depression Inventory-II. San Antonio, TX: Psychological Corporation. 1996.

BEER, C., FLICKER, L., HORNER, B. et al. Factors associated with self and informant ratings of the quality of life of people with dementia living in care facilities: a cross sectional study. PLoS One. 2010; 5(12): e15621. ISSN 1932-6203.

BEERENS, H. C., DE BOER, B., ZWAKHALEN, S. M. et al. The association between aspects of daily life and quality of life of people with dementia living in long-term care facilities: a momentary assessment study. International psychogeriatrics. 2016; 28(8): 1323-1331. ISSN 1041-6102.

BEERENS, H., ZWAKHALEN, S., VERBEEK, H. et al. Change in quality of life of people with dementia recently admitted to long-term care facilities. Journal of Advanced Nursing. 2015; 71(6): 1435-1447. ISSN 0309-2402.

BEERENS, H., ZWAKHALEN, S., VERBEEK, H., RUWAARD, D., HAMERS, J. Factors associated with quality of life of people with dementia in long-term care facilities: a systematic review. International Journal of Nursing Studies. 2013; 50(9): 1259-1270. ISSN 0020-7489.

BERKOVÁ, M., TOPINKOVÁ, E., MÁDLOVÁ, P. et al. „Krátká baterie pro testování fyzické zdatnosti seniorů“ - pilotní studie a validizace testu u starších osob v České republice. Vnitřní lékařství. 2013; 59(4): 256-263. ISSN 0042-773X.

BEYER, A. K., WOLFF, J. K., WARNER, L. M., SCHÜZ, B., WURM, S. The role of physical activity in the relationship between self-perceptions of ageing and self-rated health in older adults. Psychology \& Health. 2015; 30(6): 671-685. ISSN $0887-0446$.

BILGILI, N., ARPACI, F. Quality of life of older adults in Turkey. Archives of gerontology and geriatrics. 2014; 59(2): 415-421. ISSN 0167-4943.

BILLIS, E., STRIMPAKOS, N., KAPRELI, E. et al. Cross-cultural validation of the Falls Efficacy Scale International (FES-I) in Greek community-dwelling older adults. Disability and rehabilitation. 2011; 33(19-20): 1776-1784. ISSN 0963-8288.

BIRREN, J., DIECKERMANN, L. Concepts and content of quality of life in later years: an overview. In: Birren, J., Lubben, J., Rowe, J. C., Deutchman, G. E. (eds.). The Concept and Measurement of Quality of Life in the Frail Elderly. New York: Academic Press, 1991, pp. 344-360. 
BLACK, B., JOHNSTON, D., MORRISON, A. et al. Quality of life of communityresiding persons with dementia based on self-rated and caregiver-rated measures. Quality of Life Research. 2012; 21(8): 1379-1389. ISSN 0962-9343.

BOGGATZ, T. Quality of life in old age - a concept analysis. International journal of older people nursing. 2016; 11(1): 55-69. ISSN 1748-3735.

BORSON, S., SCANLAN, J., BRUSH, M., VITALIANO, P., DOKMAK, A. The Mini-cog: a cognitive 'vital signs' measure for dementia screening in multi-lingual elderly. International journal of geriatric psychiatry. 2000; 15(11): 1021-1027. ISSN 0885-6230.

BOSBOOM, P. R., ALFONSO, H., EATON, J., ALMEIDA, O. P. Quality of life in Alzheimer's disease: different factors associated with complementary ratings by patients and family carers. International psychogeriatrics. 2012; 24(5): 708-721. ISSN 1041-6102.

BOWLING, A., GABRIEL, Z., DYKES, J. et al. Let's ask them: a national survey of definitions of quality of life and its enhancement among people aged 65 and over. International Journal of Aging and Human Development. 2003; 56(4): 269-306. ISSN $0091-4150$.

BOWLING, A., ROWE, G., ADAMS, S. et al. Quality of life in dementia: a systematically conducted narrative review of dementia-specific measurement scales. Aging and Mental Health. 2015; 19(1): 13-31. ISSN 1360-7863.

BOYD, R., STEVENS, J. A. Falls and fear of falling: burden, beliefs and behaviours. Age and Ageing. 2009; 38(4): 423-428. ISSN 0002-0729.

BRÁZDIL, M., RUTA, V., SOBOTKA, M. Česka verze Mini-Mental State testu. Česká a slovenská neurologie a neurochirurgie. 1995; 58/91(5): 244-245. ISSN 1210-7859.

BROD, M., STEWARD, A. L., SANDS, L., WALTON, P. Conceptualization and measurement of quality of life in dementia: The Dementia Quality of Life instrument (DQoL). The Gerontologist. 1999; 39(1): 25-35. ISSN 0016-9013.

BROWN, J., BOWLING, A., FLYN, T. Models of quality of life: a taxonomy, overview and systematic review of the literature. (Project Report) European Forum on Population Ageing Research. 2004. 113 pp. Accessible at: https://pdfs.semanticscholar.org/8673/606b4e14603eafbdf91b09318fc59da70159.pdf?_ga=2.50050278. $1795708186.1585687763-421637127.1566846328$

BRUNO, D., SCHURMANN VIGNAGA, S. Addenbrooke's cognitive examination III in the diagnosis of dementia: a critical review. Neuropsychiatric Disease and Treatment. 2019; 15: 441-447. ISSN 1176-6328. 
BRUVIK, F. K., ULSTEIN, I. D., RANHOFF, A. H., ENGEDAL, K. The Quality of Life of People with Dementia and Their Family Carers. Dementia and Geriatric Cognitive Disorders. 2012; 34(1): 7-14. ISSN 1420-8008.

BRYANT, C., BEI, B., GILSON, K. et al. The relationship between attitudes to aging and physical and mental health in older adults. International psychogeriatrics. 2012; 24(10): 1674-1683. ISSN 1041-6102.

BUASI, N., PERMSUWAN, U. Validation of the Thai QOL-AD version in Alzheimer's patients and caregivers. The Australasian medical journal. 2014; 7(6): 251-259. ISSN 1836-1935.

BUCKLEY, T., FAUTH, E. B., MORRISON, A. et al. Predictors of quality of life ratings for persons with dementia simultaneously reported by patients and their caregivers: The Cache County (Utah) Study. International Psychogeriatrics. 2012; 24(7): 1094-1102. ISSN 1041-6102.

BUCKS, R. S., HAWORTH, J. Bristol Activities of Daily Living Scale: a critical evaluation. Expert review of neurotherapeutics. 2002; 2(5): 669-676. ISSN 1473-7175.

BUCKS, R., ASHWORTH, D., WILCOCK, G., SIEGFRIED, K. Assessment of activities of daily living in dementia: development of the Bristol Activities of Daily Living Scale. Age and Ageing. 1996; 25(2): 113-120. ISSN 0002-0729.

BULLOCK, L., BEDSON, J., JORDAN, J. L. et al. Pain assessment and pain treatment for community-dwelling people with dementia: A systematic review and narrative synthesis. International journal of geriatric psychiatry. 2019; 34(6): 807-821. ISSN 0885-6230.

BURGENER, S. C., BUCKWALTER, K., PERKHOUNKOVA, Y. et al. The effects of perceived stigma on quality of life outcomes in persons with early-stage dementia: Longitudinal findings: Part 2. Dementia (London). 2015; 14(5): 609-632. ISSN $1471-3012$.

BURGENER, S., TWIGG, P. Relationships Among Caregiver Factors and Quality of Life in Care Recipients with Irreversible Dementia. Alzheimer disease and associated disorders. 2002; 16(2): 88-102. ISSN 0893-0341.

BYRNE, L. M., WILSON, P. M., BUCK, R. S., HUGHES, A. O., WILCOCK, G. K. The sensitivity to change over time of the Bristol Activities of daily Living Scale in Alzheimer's disease. International journal of geriatric psychiatry. 2000; 15(7): 656-661. ISSN 0885-6230. 
BYRNE-DAVIS, L. M., BENNETT, P., WILCOCK, G. How are quality of life ratings made toward a model of quality of life in people with dementia. Quality of Life Research. 2006; 15(5): 855-865. ISSN 0962-9343.

CAHILL, S., BEGLEY, E., TOPO, P. et al. 'I know where this is going and I know it won't go back': hearing the individual's voice in dementia quality of life assessments. Dementia. 2004; 3(3), 313-330. ISSN 1471-3012.

CAHILL, S., DIAZ-PONCE, A. 'I hate having nobody here. I'd like to know where they all are': Can qualitative research detect differences in quality of life among nursing home residents with different levels of cognitive impairment? Aging and Mental Health. 2011; 15(5): 562-572. ISSN 1360-7863.

CAMARGOS, F. F., DIAS, R. C., DIAS, J. M., FREIRE, M. T. Cross-cultural adaptation and evaluation of the psychometric properties of the Falls Efficacy Scale-International Among Elderly Brazilians (FES-I-BRAZIL). Revista brasileira de fisioterapia. 2010; 14(3): 237-243. ISSN 1413-3555.

CASTILLO, C., WOODS, B., GALBODA, K. et al. Unmet needs, quality of life and support networks of people with dementia living at home. Health and Quality of Life Outcomes. 2010; 8: 132. ISSN 1477-7525.

CHACHAMOVICH, E., FLECK, M. P., TRENTINI, C. M., LAIDLAW, K., POW$E R, M$. J. Development and validation of the Brazilian version of the Attitudes to Aging Questionnaire (AAQ): An example of merging classical psychometric theory and the Rasch measurement model. Health and Quality of Life Outcomes. 2008b; 6:5. ISSN 1477-7525.

CHACHAMOVICH, E., FLECK, M., LAIDLAW, K., POWER, M. Impact of major depression and subsyndromal symptoms on quality of life and attitudes toward aging in an international sample of older adults. Gerontologist. 2008a; 48(5): 593-602. ISSN 0016-9013.

CHOCHINOV, H. M., HASSARD, T., MCCLEMENT, S. et al. The patient dignity inventory: a novel way of measuring dignity-related distress in palliative care. Journal of Pain and Symptom Management. 2008; 36(6): 559-571. ISSN 0885-3924.

CIESIELSKA, N., SOKOŁOWSKI, R., MAZUR, E. et al. Is the Montreal Cognitive Assessment (MoCA) test better suited than the Mini-Mental State Examination (MMSE) in mild cognitive impairment $(\mathrm{MCl})$ detection among people aged over 60? Meta-analysis. Psychiatria polska. 2016, 50(5): 1039-1052. ISSN 0033-2674.

CLARE, L., QUINN, C., HOARE, Z., WHITAKER, R., WOODS, R. Care staff and family member perspectives on quality of life in people with very severe demen- 
tia in long-term care: a cross-sectional study. Health and Quality of Life Outcomes. 2014; 12: 175. ISSN 1477-7525.

CLARE, L., WOODS, R., NELIS, S. et al. Trajectories of quality of life in early-stage dementia: individual variations and predictors of change. International journal of geriatric psychiatry. 2014; 29(6): 616-623. ISSN 0885-6230.

CONDE-SALA, J. L., GARRE-OLMO, J., TURRO-GARRIGA, O., LOPEZ-POUSA, S., VILALTA-FRANCH, J. Factors related to perceived quality of life in patients with Alzheimer's disease: the patient's perception compared with that of caregivers. International journal of geriatric psychiatry. 2009; 24(6): 585-594. ISSN 0885-6230.

CONDE-SALA, J. L., TURRO-GARRIGA, O., PORTELLANO-ORTIZ, C. et al. Self Perceived quality of life among patients with Alzheimer's disease: two longitudinal models of analysis. Journal of Alzheimer's disease. 2016; 52(3): 999-1012. ISSN 1387-2877.

CONRADSSON, M., ROSENDAHL, E., LITTBRAND, H. et al. Usefulness of the Geriatric Depression Scale 15-item version among very old people with and without cognitive impairment. Aging and Mental Health. 2013; 17(5): 638-665. ISSN 1360-7863.

CORBETT, A., HUSEBO, B., MALCANGIO, M. et al. Assessment and treatment of pain in people with dementia. Nature Reviews. Neurology. 2012; 8(5): 264-274. ISSN 1759-4758.

CORDNER, Z., BLASS, D. M., RABINS, P. V., BLACK, B. S. Quality of life in nursing home residents with advanced dementia. Journal of the American Geriatrics Society. 2010; 58(12): 2394-2400. ISSN 0002-8614.

CRAVELLO, L., DI SANTO, S., VARRASSI, G. et al. Chronic Pain in the Elderly with Cognitive Decline: A Narrative Review. Pain and therapy. 2019; 8(1): 53-65. ISSN 2193-651X.

CREAVIN, S. T., WISNIEWSKI, S., NOEL-STORR, A. H. et al. Mini-Mental State Examination (MMSE) for the detection of dementia in clinically unevaluated people aged 65 and over in community and primary care populations. Cochrane Database of Systematic Reviews. 2016; 13(1): CD011145. ISSN 1469-493X.

CRESPO, M., BERNALDO DE QUIROS, M., GOMEZ, M., HORNILLOS, C. Quality of life of nursing home residents with dementia: a comparison of perspectives of residents, family, and staff. Gerontologist. 2011; 52(1): 56-65. ISSN 0016-9013. 
CROWNE, D., MARLOWE, D. A new scale of social desirability independent of psychopathology. Journal of Consulting Psychology. 1960; 24(4): 349-354. ISSN 0095-8891.

CZECH STATISTICAL OFFICE (CZSO). Aktuální populační vývoj v kostce. 2018. Accessible at: https://www.czso.cz/csu/czso/aktualni-populacni-vyvoj-v-kostce

DAMIAN, A. M., JACOBSON, S. A., HENTZ, J. G. et al. The Montreal Cognitive Assessment and the Mini-Mental State Examination as screening instruments for cognitive impairment: item analyses and threshold scores. Dementia and Geriatric Cognitive Disorders. 2011; 31(2): 126-131. ISSN 1420-8008.

DE BELVIS, A. G., AVOLIO, M., SPAGNOLO, A. et al. Factors associated with health-related quality of life: the role of social relationships among the elderly in an Italian region. Public Health. 2008; 122(8): 784-793. ISSN 0033-350.

DE BORGES, S. M., RADANOVIC, M., FORLENZA O. V. Fear of falling and falls in older adults with mild cognitive impairment and Alzheimer's disease. Neuropsychology, development, and cognition. Section B, Aging, neuropsychology and cognition. 2015; 22(3): 312-321. ISSN 1382-5585.

DECARLI, C. Mild cognitive impairment: prevalence, prognosis, aetiology, and treatment. Lancet. Neurology. 2003; 2(1): 15-21. ISSN 1474-4422.

DECKERS, K., VAN BOXTEL, M. P., SCHIEPERS, O. J. et al. Target risk factors for dementia prevention: a systematic review and Delphi consensus study on the evidence from observational studies. International Journal of Geriatric Psychiatry. 2015; 30(3): 234-246. ISSN 0885-6230.

DELBAERE, K., CLOSE, J. C., MIKOLAIZAK, A. S. et al. The Falls Efficacy Scale International (FES-I). A comprehensive longitudinal validation study. Age and Ageing. 2010; 39(2): 210-216. ISSN 0002-0729.

DENKINGER, M. D., IGL, W., COLL-PLANAS, L. et al. Practicality, validity and sensitivity to change of fear of falling self-report in hospitalised elderly - a comparison of four instruments. Age and Ageing. 2009; 38(1): 108-112. ISSN 0002-0729.

DEPARTMENT OF HEALTH. Living well with dementia: a national dementia strategy good practice compendium - an assets approach. Leeds: Department of Health (Great Britain). 2011. $141 \mathrm{pp.}$

DIAS, R. C., FREIRE, M. T., SANTOS, E. G. et al. Characteristics associated with activity restriction induced by fear of falling in community-dwelling elderly. Revista brasileira de fisioterapia. 2011; 15(5): 406-413. ISSN 1413-3555. 
DICHTER, M. N., QUASDORF, T., SCHWAB, C. G. et al. Dementia care mapping: effects on residents' quality of life and challenging behavior in German nursing homes. A quasi-experimental trial. International Psychogeriatrics. 2015; 27(11): 1875-1892. ISSN 1041-6102.

DIJKSTRA, K., BOURGEOIS, M. S., ALLEN, R. S., BURGIO, L. D. Conversational coherence: discourse analysis of older adults with and without dementia. Journal of Neurolinguistics. 2004; 17(4): 263-283. ISSN 0911-6044.

DINIZ, B. S., BUTTERS, M. A., ALBERT, S. M., DEW, M. A., REYNOLDS, C. F., 3RD. Late-life depression and risk of vascular dementia and Alzheimer's disease: systematic review and meta-analysis of community-based cohort studies. The British journal of psychiatry: the journal of mental science. 2013; 202(5): 329-335. ISSN 0007-1250.

DISHMAN, R. K., BERTHOUD, H. R., BOOTH, F. W. et al. Neurobiology of exercise. Obesity. 2006; 14(3): 345-356. ISSN 1930-7381.

DONOGHUE, O. A., CRONIN, H., SAVVA, G. M., O'REGAN, C., KENNY, R. A. Effects of fear of falling and activity restriction on normal and dual task walking in community dwelling older adults. Gait Posture. 2013; 38(1): 120-124. ISSN $0966-6362$.

DRAGOMIRECKÁ, E., PRAJSOVÁ, J. Příručka pro uživatele české verze dotazníků Světové zdravotnické organizace pro měření kvality života ve vyšším věku WHOQOL-OLD. Praha: Psychiatrické centrum, 2009. 72 s. ISBN 978-80-87142-05-9.

EDELMAN, P., FULTON, B. R., KUHN, D., CHANG, CH. A comparison of three methods of measuring dementia-specific quality of life: perspectives of residents, staff, and observers. Gerontologist. 2005; Spec No 1(1): 27-36. ISSN 0016-9013.

EDLUND, M., LINDWALL, L., VON POST, I., LINDSTRÖM, U. Å. Concept determination of human dignity. Nursing Ethics. 2013; 20(8): 851-860. ISSN 0969-7330.

ESBRÍ-VÍCTOR, M., HUEDO-RODENAS, I., LÓPEZ-UTIEL M. et al. Frailty and Fear of Falling: The FISTAC Study. The Journal of frailty \& aging. 2017; 6(3): 136-140. ISSN 2260-1341.

ETTEMA, T. P., DROES, R-M., DE LANGE, J. et al. The concept of quality of life in dementia in the different stages of the disease. International Psychogeriatrics. 2005; 17(3): 353-370. ISSN 1041-6102.

FALK, N., COLE, A., MEREDITH, T. J. Evaluation of Suspected Dementia. American family physician. 2018; 97(6): 398-405. ISSN 0002-838X. 
FARQUHAR, M. Definitions of quality of life: a taxonomy. Journal of Advanced Nursing. 1995b; 22(3): 502-508. ISSN 0309-2402.

FARQUHAR, M. Elderly people's definitions of quality of life. Social Science \& Medicine. 1995a; 41(10): 1439-1446. ISSN 0277-9536.

FAUDZI, F. N. M., ARMITAGE, C. J., BRYANT, C., BROWN, L. J. E. Moderating effects of age on relationships between attitudes to aging and well-being outcomes. Aging and Mental Health. 2019, May 17: 1-7. doi: 10.1080/13607863.2019.1619167. [Epub ahead of print]

FAYERS, P. M., MACHIN, D. Quality of life. The Assessment, Analysis and Reporting of Patient-reported Outcomes. 3rd edition. Chichester, UK: Wiley Blaskwell, 2016. 626 pp. ISBN 978-1-444-33795-2.

FERNANDEZ-BALLESTEROS, R. (ed.). GeroPsychology. European Perspectives for an Aging World. Cambridge, MA: Hogrefe \& Huber Pub., 2007. 254 pp. ISSN 978-088937-340-2.

FIGUEIREDO, D., NEVES, M. Falls Efficacy Scale-International: exploring psychometric properties with adult day care users. Archives of gerontology and geriatrics. 2018; 79: 145-150. ISSN 0167-4943.

FIGUEIREDO, D., SANTOS, S. Cross-cultural validation of the Falls Efficacy ScaleInternational (FES-I) in Portuguese community-dwelling older adults. Archives of gerontology and geriatrics. 2017; 68: 168-173. ISSN 0167-4943.

FILIP, V. Praktický manuál psychiatrických posuzovacích stupnic. 1. vyd. Praha: Psychiatrické centrum, 1997. 213 s. ISBN 80-85121-06-9.

FOLSTEIN, M. F., FOLSTEIN, S. E., MCHUGH, P. R. “Mini-mental state”. A practical method for grading the cognitive state of patients for the clinician. Journal of psychiatric research. 1975; 12(3): 189-198. ISSN 0022-3956.

FOLSTEIN, M. F., FOLSTEIN, S. E., MCHUGH, P. R., FANJIANG, G. M. MMSE: Mini-Mental State Examination: User's Guide. Odessa, FL: Psychological Assessment Resources, 2001.

FOLSTEIN, M. F., ROBINS, L. N., HELZER, J. E. The Mini-Mental State Examination. Archives of general psychiatry. 1983; 40(7): 812. ISSN 0003-990X.

FRIEDMAN, S. M., MUNOZ, B., WEST, S. K., RUBIN, G. S., FRIED, L. P. Falls and fear of falling: which comes first? A longitudinal prediction model suggests strategies for primary and secondary prevention. Journal of the American Geriatrics Society. 2002; 50(8): 1329-1335. ISSN 0002-8614. 
FUKUSHIMA, T., NAGAHATA, K., ISHIBASHI, N., TAKAHASHI, Y., MORIYAMA, M. Quality of life from the viewpoint of patients with dementia in Japan: nurturing through an acceptance of dementia by patients: their families and care professionals. Health \& Social Care in the Community. 2005; 13(1): 30-37. ISSN 0966-0410.

FYMAT, A. L. Dementia: A review. Journal of Clinical Psychiatry and Neuroscience. 2018; 1(3): 27-34. ISSN 1488-2434.

GALE, C. R., COOPER, C. Attitudes to ageing and change in frailty status: The English Longitudinal Study of Ageing. Gerontology. 2018; 64(1): 58-66. ISSN 0304-324X.

GALLAGHER, A. Dignity and Respect for Dignity - Two Key Health Professional Values: Implications for Nursing Practice. Nursing Ethics. 2004; 11(6): 587-599. ISSN 0969-7330.

GALVIN, J. E., SADOWSKY, CH.; NINCDS-ADRDA. Practical guidelines for the recognition and diagnosis of dementia. Journal of the American Board of Family Medicine. 2012; 25(3): 367-382. ISSN 1557-2625.

GARRE-OLMO, J., LÓPEZ-POUSA, S., TURON-ESTRADA, A. et al. Environmental determinants of quality of life in nursing home residents with severe dementia. Journal of The American Geriatrics Society. 2012; 60(7): 1230-1236. ISSN 0002-8614.

GARRIDO-ABEJAR, M., SERRANO-PARRA, M. D., BARTOLOMÉ-GUTIÉRREZ, R., MARTÍNEZ-VIZCAINO, V. Factors associated with health-related quality of life in the institutionalised elderly: differences between men and women. Enfermería clínica. 2012; 22(1): 27-34. ISSN 1130-8621.

GEORGE, R. Intergenerational volunteering and quality of life: mixed methods evaluation of a randomized control trial involving persons with mild to moderate dementia. Quality of Life Research. 2010; 20(7): 987-993. ISSN 0962-9343.

GIEBEL, C. M., SUTCLIFFE, C., CHALLIS, D. Activities of daily living and quality of life across different stages of dementia: a UK study. Aging and Mental Health. 2015; 19(1): 63-71. ISSN 1360-7863.

GOBBENS, R., VAN ASSEN, M. The prediction of quality of life by physical, psychological and social components of frailty in community-dwelling older people. Quality of Life Research. 2014; 23(8): 2289-2300. ISSN 0962-9343.

GÓMEZ-GALLEGO, M., GOMEZ-AMOR, J., GOMEZ-GARCIA, J. Determinants of quality of life in Alzheimer's disease perspective of patients, informal caregivers, and professional caregivers. International Psychogeriatrics. 2012b; 24(11): 1805-1815. ISSN 1041-6102. 
GÓMEZ-GALLEGO, M., GÓMEZ-AMOR, J., GÓMEZ-GARCÍA, J. Validation of the Spanish version of the QoL-AD Scale in Alzheimer disease patients, their carers, and health professionals. Neurologia. 2012a; 27(1): 4-10. ISSN 0213-4853.

GONZÁLEZ-SALVADOR, L., LYKETSOS, C., BAKER, A. et al. Quality of life in dementia patients in long-term care. International Journal of Geriatric Psychiatry. 2000; 15(2): 181-189. ISSN 0885-6230.

GOYAL, A. R., BERGH, S., ENGEDAL, K., KIRKEVOLD, M., KIRKEVOLD, Ø. Trajectories of quality of life and their association with anxiety in people with dementia in nursing homes: A 12-month follow-up study. PLoS One. 2018; 13(9): e0203773. ISSN 1932-6203.

GRÄSKE, J., MEYER, S., WORCH, A., WOLF-OSTERMANN, K. Family visits in shared-housing arrangements for residents with dementia - a cross-sectional study on the impact on residents' quality of life. BMC Geriatrics. 2015; 15:14. ISSN 1471-2318.

GUILLEMIN, F., BOMBARDIER, C., BEATON, D. Cross-Cultural Adaptation of Health-Related Quality-of-Life Measures - Literature-Review and Proposed Guidelines. Journal of Clinical Epidemiology. 1993; 46(12): 1417-1432. ISSN 0895-4356.

GURALNIK, J. M., FERRUCCI, L., SIMONSICK, E. M., SALIVE, M. E., WALLACE, R. B. Lower-extremity function in persons over the age of 70 years as a predictor of subsequent disability. The New England journal of medicine. 1995; 332(9): 556-560. ISSN 0028-4793.

GURALNIK, J., SIMONSICK, E., FERRUCCI, L. et al. A short physical performance battery assessing lower extremity function: association with self-reported disability and prediction of mortality and nursing home admission. Journal of Gerontology. 1994; 49(2): M85-94. ISSN 0022-1422.

HALAWEH, H., SVANTESSON, U., ROSBERG, S., WILLEN, C. Cross-Cultural Adaptation, Validity and Reliability of the Arabic Version of the Falls Efficacy ScaleInternational (FES-I). Medical principles and practice: international journal of the Kuwait University, Health Science Centre. 2016; 25(1): 1-7. ISSN 1011-7571.

HALVORSRUD, L., KALFOSS, M. The conceptualization and measurement of quality of life in older adults: a review of empirical studies published during 1994-2006. European Journal of Ageing. 2007; 4(4): 229-246. ISSN 1613-9372.

HAMILTON, M. A. A rating scale for depression. Journal of neurology, neurosurgery, and psychiatry. 1960; 23: 56-62. ISSN 0022-3050. 
HANYU, H. Prevention of Dementia-with Special Reference to Lifestyle and Vascular Risk Factors. Brain and nerve. 2018; 70(3): 191-198. ISSN 1881-6096.

HAUER, K. A., KEMPEN, G. I., SCHWENK, M. et al. Validity and sensitivity to change of the falls efficacy scales international to assess fear of falling in older adults with and without cognitive impairment. Gerontology. 2011; 57(5): 462-472. ISSN 0304-324X.

HAUER, K., YARDLEY, L., BEYER, N. et al. Validation of the Falls Efficacy Scale and Falls Efficacy Scale International in Geriatric Patients with and without Cognitive Impairment: Results of Self-Report and Interview-Based Questionnaires. Gerontology. 2010; 56(2): 190-199. ISSN 0304-324X.

HEGGIE, M., MORGAN, D., CROSSLEY, M. et al. Quality of life in early dementia: comparison of rural patient and caregiver ratings at baseline and one year. Dementia. 2011; 11(4): 521-541. ISSN 1471-3012.

HENDRIKS, S., SMALBRUGGE, M., HERTOGH, C., VAN DER STEEN, J. Dying with dementia: symptoms, treatment, and quality of life in the last week of life. Journal of Pain and Symptom Management. 2014; 47(4): 710-720. ISSN 0885-3924.

HERR, K. Pain assessment strategies in older patients. The journal of pain: official journal of the American Pain Society. 2011; 12 (3 Suppl 1): S3-S13. ISSN 1526-5900.

HODGSON, N., GITLIN, L., HUANG, J. Department: the influence of sleep disruption and pain perception on indicators of quality of life in individuals living with dementia at home. Geriatric Nursing. 2014; 35(5): 394-398. ISSN 0197-4572.

HOE, J., HANCOCK, G., LIVINGSTON, G. et al. Changes in the quality of life of people with dementia living in care homes. Alzheimer's Disease and Associated Disorders. 2009; 23(3): 285-290. ISSN 0893-0341.

HOE, J., HANCOCK, G., LIVINGSTON, G., ORRELL, M. Quality of life of people with dementia in residential care homes. The British journal of psychiatry: the journal of mental science. 2006; 188: 460-464. ISSN 0007-1250.

HOUTJES, W., VAN MEIJEL, B., DEEG, D. J., BEEKMAN, A. T. Unmet needs of outpatients with late-life depression: A comparison of patient, staff and carer perceptions. Journal of Affective Disorders. 2011; 134(1-3): 242-248. ISSN 0165-0327.

HSIEH, S., SCHUBERT, S., HOON, C., MIOSHI, E., HODGES, J. R. Validation of the Addenbrooke's cognitive examination III in frontotemporal dementia and Alzheimer's disease. Dementia and Geriatric Cognitive Disorders. 2013; 36(3-4): 242-50. ISSN 1420-8008. 
HUBER, M., KNOTTNERUS, J. A., GREEN, L. et al. How should we define health? BMJ: British medical journal / British Medical Association. 2011; 343: d4163. ISSN 0959-8138.

HURT, C., BHATTACHARYYA, S., BURNS, A. et al. Patient and caregiver perspectives of quality of life in dementia. Dementia and Geriatric Cognitive Disorders. 2008; 26(2): 138-146. ISSN 1420-8008.

HYLLA, J., SCHWAB, C., ISFORT, M., HALEK, M., DICHTER, M. N. Internal consistency and construct validity of the quality of life in Alzheimer's disease (QoLAD) proxy - a secondary data analysis. Pflege. 2016; 29(4): 183-191. ISSN 1012-5302.

IBRAHIM, C. N., BAYEN, U. J. Attitudes toward aging and older adults in Arab culture: A literature review. Zeitschrift für Gerontologie und Geriatrie. 2019; 52(Suppl 3): 180-187. ISSN 0948-6704.

JACELON, C. S., CONNELLY, T. W., BROWN, R., PROULX, K., VO, T. A concept analysis of dignity for older adults. Journal of advanced nursing. 2004; 48(1): 76-83. ISSN 0309-2402.

JACELON, C. S., DIXON, J., KNAFL, K. A. Development of the Attributed Dignity Scale. Research in gerontological nursing. 2009; 2(3): 202-213. ISSN 1940-4921.

JACELON, C. S., CHOI, J. Evaluating the psychometric properties of the Jacelon Attributed Dignity Scale. Journal of advanced nursing. 2014; 70(9): 2149-2161. ISSN 0309-2402.

JACOBSON, N. A taxonomy of dignity: a grounded theory study. BMC International Health and Human Rights. 2009; 9:3. ISSN 1472-698X.

JACOBSON, N. Dignity and health: a review. Social science \& medicine. 2007; 64(2): 292-302. ISSN 0277-9536.

JENKINS, A., TALES, A., TREE, J., BAYER, A. Are we ready? The construct of subjective cognitive impairment and its utilization in clinical practice: a preliminary UK-based service evaluation. Journal of Alzheimer's disease. 2015; 48(Suppl 1): S25-31. ISSN 1387-2877.

JENSEN-DAHM, C., WERNER, M. U., DAHL, J. B. et al. Quantitative sensory testing and pain tolerance in patients with mild to moderate Alzheimer disease compared to healthy control subjects. Pain. 2014; 155(8): 1439-1445. ISSN 0304-3959.

JESSEN, F., AMARIGLIO, R. E., VAN BOXTEL, M. et al. A conceptual framework for research on subjective cognitive decline in preclinical Alzheimer's disease. 
Alzheimer's \& dementia: the journal of the Alzheimer's Association. 2014; 10(6): 844-852. ISSN 1552-5260.

JIRÁK, R. Duševní poruchy ve stárí. Psychiatria pre prax. 2004; 6: 318-320. ISSN 1213-0508.

JIRÁK, R., HOLMEROVÁ, I., BORZOVÁ, C. et al. Demence a jiné poruchy. Komunikace a každodenní péče. Praha: Grada Publishing a.s., 2009. 164 s. ISBN 978-80-247-2454-6.

JIRÁK, R., KOUKOLÍK, F. Demence; neurobiologie, klinický obraz, terapie. Praha: Galén, 2004. 335 s. ISBN 80-7262-268-85.

JOANOVIČ, E., KISVETROVÁ, H., NEMČEK, D. et al. Gender differences in improvement of older-person-specific quality of life after hearing-aid fitting. Disability and Health Journal. 2019; 12(2): 209-213. ISSN 1936-6574.

JOHNSTON, B., LAWTON, S., MCCAW, C. et al. Living well with dementia: enhancing dignity and quality of life, using a novel intervention, Dignity Therapy. International journal of older people nursing. 2016; 11(2): 107-120. ISSN 1748-3735.

KALFOSS, M. H., LOW, G., MOLZAHN, A. E. Reliability and validity of the attitudes to ageing questionnaire for Canadian and Norwegian older adults. Scandinavian Journal of Caring Sciences. 2010; 24 (s1): 75-85. ISSN 1471-6712.

KALVACH, Z., ČELEDOVÁ, L., HOLMEROVÁ, I. a kol. Křehký pacient a primární péče. Praha: Grada, 2011. 399 s. ISBN 978-80-247-4026-3.

KANE, R. A. Long-term care and a good quality of life: bringing them closer together. Gerontologist. 2001; 41(3): 293-304. ISSN 0016-9013.

KASPER, J. D., BLACK, B. S., SHORE, A. D., RABINS, P. V. Evaluation of the validity and reliability of the Alzheimer Disease-related Quality of Life Assessment Instrument. Alzheimer disease and associated disorders. 2009; 23(3): 275-284. ISSN 0893-0341.

KATSUMATA, Y., ARAI, A., TOMIMORI, M. et al. Fear of falling and falls selfefficacy and their relationship to higher-level competence among communitydwelling senior men and women in Japan. Geriatrics \& gerontology international. 2011; 11(3): 282-289. ISSN 1444-1586.

KATZ, N. The impact of pain management on quality of life. Journal of pain and symptom management. 2002; 24 (suppl 1): S38-47. ISSN 0885-3924.

KEMPEN, G. I., TODD, C. J., VAN HAASTREGT, J. C. et al. Falls Efficacy Scale International (FES-I) in older people: results from Germany, the Netherlands 
and the UK were satisfactory. Disability and rehabilitation. 2007; 29(2): 155-162. ISSN $0963-8288$.

$\mathrm{KICKBUSCH}$, I. Action on global health: addressing global health governance challenges. Public Health. 2005; 119(11): 969-973. ISSN 0033-3506.

$\mathrm{KIM}, \mathrm{H}$., CHEY, J. Effects of education, literacy and dementia on the clock drawing test performance. Journal of the International Neuropsychological Society. 2010; 16(6): 1138-1146. ISSN 1355-6177.

KISVETROVÁ, H., HERZIG, R., BRETŠNAJDROVÁ, M. et al. Predictors of Quality of Life and Attitude to Ageing in Older Adults with and without Dementia. Aging and Mental Health. 2019a; doi: 10.1080/13607863.2019.1705758 [Epub ahead of print]. ISSN 1364-6915.

KISVETROVÁ, H., ŠKOLOUdíK, D., DANIELOVÁ, L. et al. Czech Version of the Patient Dignity Inventory: Translation and Validation in Incurable Patients. Journal of Pain and Symptom Management. 2018b; 55(2): 444-450. ISSN 0885-3924.

KISVETROVÁ, H., ŠKOLOUdíK, D., HERZIG, R. et al. Psychometric Properties of the Czech Version of the Falls Efficacy Scale-International in Patients with Early-Stage Dementia. Dementia and Geriatric Cognitive Disorders Extra. 2019b; 29;9(2): 319-329. ISSN 1664-5464.

KISVETROVÁ, H., ŠKOLOUDÍK, D., HERZIG, R. et al. Psychometric Validation of the Czech Version of the Quality of Life - Alzheimer's Disease Scale in Patients with Early-Stage Dementia. Dementia and Geriatric Cognitive Disorders. 2018a; 46(1-2): 109-118. ISSN 1420-8008.

KISVETROVÁ, H., ŠKOLOUDÍK, D., HERZIG, R. et al. Vliv demence na trajektorie kvality života seniorů. Česká a slovenská neurologie a neurochirurgie. 2020 (in process). ISSN 1210-7859.

KLAPWIJK, M., CALJOUW, M., PIEPER, M., VAN DER STEEN, J., ACHTERBERG, W. Characteristics Associated with Quality of Life in Long-Term Care Residents with Dementia: A Cross-Sectional Study. Dementia and Geriatric Cognitive Disorders. 2016; 42(3-4): 186-197. ISSN 1420-8008.

KORKMAZ ASLAN, G., KARTAL, A., ÖZEN ÇINAR, I., KOŞTU, N. The relationship between attitudes toward aging and health-promoting behaviors in older adults. International journal of nursing practice. 2017; 23(6): e12594. ISSN 1322-7114.

KØRNER, A., LAURITZEN, L., ABELSKOV, K. et al. The Geriatric Depression Scale and the Cornell Scale for Depression in Dementia. A validity study. Nordic Journal of Psychiatry. 2006; 60(5): 360-364. ISSN 0803-9488. 
KOVÁCS, E., ROZS, F., PETRIDISZ, A., ERDÖS, R., MAJERCSIK, E. Cross-cultural validation of the Falls Efficacy Scale-International to assess concerns about falls among Hungarian community-living older people. Disability and rehabilitation. 2017; 40(25): 3070-3075. ISSN 0963-8288.

KOŽENÝ, J., TIŠANSKÁ, L., BEDNAŘíK, J., HÖSCHL, C. A Rasch analysis of the Q-LES-Q-SF questionnaire in a cohort of patients with neuropathic pain. Česká a slovenská neurologie a neurochirurgie. 2019; 82(1): 60-67. ISSN 1210-7859.

KROMBHOLZ, R. Nejčastější demence a jejich léčba. Neurologie pro praxi. 2011; 12(3): 196-200. ISSN 1213-1814.

KUIPER, J. S., ZUIDERSMA, M., OUDE VOSHAAR, R. C. et al. Social relationships and risk of dementia: a systematic review and meta-analysis of longitudinal cohort studies. Ageing research reviews. 2015; 22: 39-57. ISSN 1568-1637.

KUMAR, A., CARPENTER, H., MORRIS, R., ILIFFE, S., KENDRICK, D. Which factors are associated with fear of falling in community-dwelling older people? Age and Ageing. 2014; 43(1): 76-84. ISSN 0002-0729.

KUO, Y., LAN, C., CHEN, L., LAN, V. Dementia care costs and the patient's quality of life (QoL) in Taiwan: home versus institutional care services. Archives of Gerontology and Geriatrics. 2010; 51(2): 159-163. ISSN 0167-4943.

KURKOVÁ, P., KISVETROVÁ, H., HORVÁTHOVÁ, M. et al. Fear of falling and physical performance among older Czech adults. Family Medicine \& Primary Care Review. 2020; 22(1): 32-35. ISSN 1734-3402.

KWAN, M. M., TSANG, W. W., CLOSE, J. C., LORD, S. R. Development and validation of a Chinese version of the Falls Efficacy Scale International. Archives of gerontology and geriatrics. 2013; 56(1): 169-174. ISSN 0167-4943.

LAIDLAW, K., POWER, M. J., SCHMIDT, S., \& WHOQOL-OLD Group. The Attitudes to Ageing Questionnaire (AAQ): development and psychometric properties. International Journal of Geriatric Psychiatry. 2007; 22(4): 367-379. ISSN 0885-6230.

LAVEDÁN, A., VILADROSA, M., JÜRSCHIK, P. et al. Fear of falling in communitydwelling older adults: A cause of falls, a consequence, or both? PLoS One. 2018; 13(3): e0194967. ISSN 1932-6203.

LAWTON, M. P. A multidimensional view of quality of life in frail elders. In: Birren, J., Lubben J., Rowe J. C., Deutchman, G. E. (eds.). The Concept and Measurement of Quality of Life in the Frail Elderly. New York: Academic Press, 1991, pp. 3-27. ISBN 978-01-21012-75-5. 
LAWTON, M. P. Assessing quality of life in Alzheimer disease research. Alzheimer's Disease and Associated Disorders. 1997; 11 (Suppl 6): 91-99. ISSN 0893-0341. LAWTON, M. P. The Philadelphia Geriatric Center Morale Scale: A revision. Journal of gerontology. 1975; 30(1): 85-89. ISSN 0022-1422.

LAWTON, M. P. The varieties of wellbeing. Experimental Aging Research. 1983; $9(2): 65-72$.

LAWTON, M. P., VAN HAITSMA, K. S., KLAPPER, J. A. Observed affect in nursing home residents with Alzheimer's disease. The journals of gerontology. Series $B$, Psychological sciences and social sciences. 1996; 51(1): P3-P14. ISSN 1079-5014.

LAWTON, M. P., VAN HAITSMA, K., PERKINSON, M., RUCKDESCHEL, K. Observed affect and quality of life in dementia: further affirmations and problems. Journal of Mental Health and Aging. 1999; 5(1): 69-81. ISSN 1078-4470.

LE BOUTHILliER, D. M., THIBODEAU, M. A., ASMUNDSON, G. J. Severity of fall-based injuries, fear of falling, and activity restriction: sex differences in a population-based sample of older Canadian adults. Journal of aging and health. 2013; 25(8): 1378-1387. ISSN 0898-2643.

LECKIE, R. L., OBERLIN, L. E., VOSS, M. W. et al. BDNF mediates improvements in executive function following a 1-year exercise intervention. Frontiers in human neuroscience. 2014; 8: 985. ISSN 1662-5161.

LEÓN-SALAS, B., AVILA-VILLANUEVA, M., AYALA, A. et al. Quality of life across three groups of older adults differing in cognitive status and place of residence. Geriatrics and Gerontology International. 2015; 15(5): 627-635. ISSN 1444-1586.

LÉON-SALAS, B., LOGSDON, R., OLAZARÁN, J., MARTÍNEZ-MARTÍN, P. Psychometric properties of the Spanish QOL-AD with institutionalized dementia patients and their family caregivers in Spain. Aging and Mental Health. 2011; 15(6): 775-783. ISSN 1360-7863.

LEZAK, M. D., HOWIESON, D. B., BIGLER, E. D., TRANEL, D. (eds.). Neuropsychological assessment. 5th ed. New York: Oxford University Press, 2012. 1200 pp. ISBN 978-01-95395-52-5.

LI, C. L., CHANG, H. Y., STANAWAY, F. F. Combined effects of frailty status and cognitive impairment on health-related quality of life among community dwelling older adults. Archives of gerontology and geriatrics. 2020; 87: 103999. ISSN 0167-4943. 
LI, X., SUISHU, C., HATTORI, S. et al. The comparison of dementia patient's quality of life and influencing factors in two cities. Journal of Clinical Nursing. 2012; 22(15-16): 2132-2140. ISSN 0962-1067.

LIANG, J., BOLLEN, K. A. The structure of the Philadelphia Geriatric Center Morale scale: a reinterpretation. Journal of Gerontology. 1983; 38(2): 181-189. ISSN 0022-1422.

LIN, F., WHARTON, W., DOWLING, N. M. et al. Awareness of memory abilities in community-dwelling older adults with suspected dementia and mild cognitive impairment. Dementia and geriatric cognitive disorders. 2010; 30(1): 83-92. ISSN $1420-8008$.

LIN, J. S., O'CONNOR, E., ROSSOM, R. C. et al. Screening for cognitive impairment in older adults: an evidence update for the U. S. Preventive Services Task Force. Evidence syntheses, No. 107. Rockville, Md.: Agency for Healthcare Research and Quality; 2013. Report No.: 14-05198-EF-1.

LIN, Y., SHAN, P. Y., JIANG, W. J., SHENG, C., MA, L. Subjective Cognitive Decline: Preclinical Manifestation of Alzheimer's Disease. Neurological sciences: official journal of the Italian Neurological Society and of the Italian Society of Clinical Neurophysiology. 2019; 40(1): 41-49. ISSN 1590-1874.

LIU, J. Y. Fear of falling in robust community-dwelling older people: results of a cross-sectional study. Journal of clinical nursing. 2015; 24(3-4): 393-405. ISSN 0962-1067.

LIVINGSTON, G., SOMMERLAD, A., ORGETA, V. et al. Dementia prevention, intervention, and care. Lancet. 2017; 390(10113): 2673-2734. ISSN 0140-6736.

LOGSDON, R. G., TERI, L. The Pleasant Events Schedule-AD: psychometric properties and relationship to depression and cognition in Alzheimer's disease patients. Gerontologist. 1997; 37(1): 40-45. ISSN 0016-9013.

LOGSDON, R., GIBBONS, L., MCCURRY, S., TERI, L. Assessing quality of life in older adults with cognitive impairment. Psychosomatic Medicine. 2002; 64(3): 510-519. ISSN 0033-3174.

LOGSDON, R., GIBBONS, L., MCCURRY, S., TERI, L. Quality of life in Alzheimer's disease: Patient and caregiver reports. Journal of Mental Health and Aging. 1999; 5(1): 21-32. ISSN 1078-4470.

LOGSDON, R., MCCURRY, S. M. TERI, L. Evidence-based interventions to improve quality of life for individuals with dementia. Alzheimer's care today. 2007; 8: 309-318. 
LOW, G., MOLZAHN, A. E., SCHOFLOCHER, D. Attitudes to aging mediate the relationship between older people's subjective health and quality of life in 20 countries. Health and quality of life outcomes. 2013; 11: 146. ISSN 1477-7525.

LU, L., KAO, S., HSIEH, Y. H. Positive attitudes toward older people and wellbeing among Chinese community older adults. Journal of Applied Gerontology. 2010; 29(5): 622-639. ISSN 0733-4648.

LUCAS-CARRASCO, R., LAIDLAW, K., GOMEZ-BENITO, J., POWER, M. J. The suitability of the Attitudes Ageing Questionnaire (AAQ) for Spanish older adults. International Psychogeriatrics. 2013; 25(3): 490-499. ISSN 1041-6102.

LUŽNÝ, J. Kvalita života u pacientů s demencí. Česká a slovenská neurologie a neurochirurgie. 2013; 76/109(1): 90-95. ISSN 1210-7859.

MACHADO, A., BAETA, É., PIMENTEL, P., PEIXOTO, B. Psychometric and normative indicators of the Portuguese version of the Addenbrooke's cognitive examination-III. Preliminary study on a sample of healthy subjects. Acta Neuropsychologica. 2015; 13(2): 127-136. ISSN 1730-7503.

MAINLAND, B. J., AMODEO, S., SHULMAN, K. I. Multiple clock drawing scoring systems: Simpler is better. International Journal of Geriatric Psychiatry. 2014; 29(2): 127-136. ISSN 0885-6230.

MAJ, M., SARTORIUS, N. Dementia. Chichester: Wiley, 2 edition, 2003. 416 pp. ISBN 978-04-70849-63-7.

MALINI, F. M., LOURENÇO, R. A., LOPES, C. S. Prevalence of fear of falling in older adults, and its associations with clinical, functional and psychosocial factors: the Frailty in Brazilian Older People-Rio de Janeiro study. Geriatrics \& gerontology international. 2016; 16(3): 336-344. ISSN 1444-1586.

MANN, J. Dignity and Health: The UDHR's Revolutionary First Article. Health and human rights. 1998; 3(2): 31-38. ISSN 1079-0969.

MANTHORPE, J., ILIFFE, S., SAMSI, K. et al. Dementia, dignity and quality of life: nursing practice and its dilemmas. International Journal of Older People Nursing. 2010; 5(3), 235-244. ISSN 1748-3735.

MARVENTANO, S., PRIETO-FLORES, M., SANZ-BARBERO, B. et al. Quality of life in older people with dementia: a multilevel study of individual attributes and residential care center characteristics. Geriatrics \& Gerontology International. 2015; 15(1): 104-110. ISSN 1444-1586. 
MATHURANATH, P. S., NESTOR, P. J., BERRIOS, G. E., RAKOWICZ, W., HODG$E S$, J. R. A brief cognitive test battery to differentiate Alzheimer's disease and frontotemporal dementia. Neurology. 2000; 55(11): 1613-1620. ISSN 1759-4758.

MATIAS-GUIU, J. A., FERNÁNDEZ DE BOBADILLA, R., ESCUDERO, G. et al. Validation of the Spanish version of Addenbrooke's cognitive examination III for diagnosing dementia. Neurologia. 2015; 30(9): 545-551. ISSN 0213-4853.

MÁTL, O., MÁTLOVÁ, M., HOLMEROVÁ, I. Zpráva o stavu demence 2016. Praha: Česká alzheimerovská společnost. 2016, 43 s. ISBN 978-80-86541-50-1.

MATSUI, T., NAKAAKI, S., MURATA, Y. et al. Determinants of quality of life in Alzheimer's disease patients as assessed by Japanese version of the quality of life - Alzheimer's disease scale. Dementia and Geriatric Cognitive Disorders. 2006; 21(3): 182-191. ISSN 1420-8008.

MCNAMARA, P. The motivational origins of religious practices. Zygon. 2002; 37(1): 143-160. ISSN 1467-9744.

MEULEN, E. F., SCHMAND, B., VAN CAMPEN, J. P., et al. The seven minute screen: a neurocognitive screening test highly sensitive to various types of dementia. Journal of neurology, neurosurgery, and psychiatry. 2004; 75(5): 700-705. ISSN 0022-3050.

MHAOLÁIN, A. M., GALLAGHER, D., CROSBY, L. et al. Frailty and Quality of Life for People with Alzheimer's Dementia and Mild Cognitive Impairment. American journal of Alzheimer's disease and other dementias. 2012; 27(1): 48-54. ISSN $1533-3175$.

MIOSHI, E., DAWSON, K., MITCHELL, J., ARNOLD, R., HODGES, J. R. The Addenbrooke's Cognitive Examination Revised (ACE-R): a brief cognitive test battery for dementia screening. International Journal of Geriatric Psychiatry. 2006; 21(11): 1078-1085. ISSN 0885-6230.

MIRZA, N., PANAGIOTI, M., WAHEED, M. W., WAHEED, W. Reporting of the translation and cultural adaptation procedures of the Addenbrooke's cognitive examination version III (ACE-III) and its predecessors: a systematic review. BMC medical research methodology. 2017; 17(1): 141. ISSN 1471-2288.

MISSOTTEN, P., YLIEFF, M., DI NOTTE, D. et al. Quality of life in dementia: A 2-year follow-up study. International Journal of Geriatric Psychiatry. 2007; 22(12): 1201-1207. ISSN 0885-6230. 
MITCHELL, A. J. A meta-analysis of the accuracy of the mini-mental state examination in the detection of dementia and mild cognitive impairment. Journal of psychiatric research. 2009; 43(4): 411-431. ISSN 0022-3956.

MJØRUD, M., KIRKEVOLD, M., RØSVIK, J., SELBÆK, G., ENGEDAL, K. Variables associated to quality of life among nursing home patients with dementia. Aging and Mental Health. 2014; 18(8): 1013-1021. ISSN 1360-7863.

MKN-10: Mezinárodní klasifikace nemocí a přidružených zdravotních problémů: desátá revize. ÚZIS ČR. Updated on 1 January, 2020. Accessible at: https://www.uzis.cz/ index.php?pg=registry-sber-dat--klasifikace--mezinarodni-klasifikace-nemoci

MOBERG, D. O. Research in spirituality, religion and ageing. Journal of gerontological social work. 2005; 45(1-2): 11-40. ISSN 0163-4372.

MOLINUEVO, J. L., RABIN, L. A., AMARIGLIO, R. et al. Implementation of subjective cognitive decline criteria in research studies. Alzheimer's \& dementia: the journal of the Alzheimer's Association. 2017; 13(3): 296-311. ISSN 1552-5260.

MONIZ-COOK, E., VERNOOIJ-DASSEN, M., WOODS, R. et al. A European consensus on outcome measures for psychosocial intervention research in dementia care. Aging and Mental Health. 2008; 12(1): 14-29. ISSN 1360-7863.

MOSER, C., SPAGNOLI, J., SANTOS-EGGIMANN, B. Self-perception of aging and vulnerability to adverse outcomes at the age of 65-70 years. The Journals of Gerontology Series B: Psychological Sciences and Social Sciences. 2011; 66(6): 675-680. ISSN 1079-5014.

MOYLE, W., FETHERSTONHAUGH, D., BEATTIE, E., GREBEN, M. Influencers on quality of life as reported by people living with dementia in long-term care: a descriptive exploratory approach. BMC Geriatrics. 2015; 15: 50. ISSN 1471-2318. MOYLE, W., KELLETT, U., BALLANTYNE, A., GRACIA, N. Dementia and loneliness: an Australian perspective. Journal of clinical nursing. 2011b; 20(9-10): 1445-1453. ISSN 0962-1067.

MOYLE, W., MURFIELD, J. E., GRIFFITHS, S. G., VENTURATO, L. Assessing quality of life of older people with dementia: a comparison of quantitative selfreport and proxy accounts. Journal of advanced nursing. 2012; 68(10): 2237-2246. ISSN 0309-2402.

MOYLE, W., MURFIELD, J., VENTURTO, L. al. Dementia and its influence on quality of life and what it means to be valued: family members' perceptions. Dementia. 2014; 13(3): 412-425. ISSN 1471-3012. 
MOYLE, W., VENTURTO, L., GRIFFITHS, S. et al. Factors influencing quality of life for people with dementia: a qualitative perspective. Aging and Mental Health. 2011a; 15(8): 970-977. ISSN 1360-7863.

NAGLIE, G. Quality of life in dementia. Canadian Journal of Neurological Sciences. 2007; 34 (Suppl 1): S57-S61. ISSN 0317-1671.

NAGLIE, G., HOGAN, D. B., KRAHN, M. et al. Predictors of patient self-ratings of quality of life in Alzheimer's disease: Cross-sectional results from the Canadian Alzheimer's Disease Quality of Life (CADQOL) Study. The American Journal of Geriatric Psychiatry. 2011; 19(10): 891-901. ISSN 1064-7481.

NAISMITH, S. L., NORRIE, L. M., MOWSZOWSKI, L., HICKIE, I. B. The neurobiology of depression in later-life: clinical, neuropsychological, neuroimaging and pathophysiological features. Progress in neurobiology. 2012; 98(1): 99-143. ISSN $0301-0082$.

NASREDDINE, Z. S., PHILLIPS, N. A., BEDIRIAN, V. et al. The Montreal Cognitive Assessment, MoCA: a brief screening tool for mild cognitive impairment. Journal of the American Geriatrics Society. 2005; 53(4): 695-699. ISSN 0002-8614.

NATIONAL ACADEMIES OF SCIENCES, ENGINEERING, AND MEDICINE; HEALTH AND MEDICINE DIVISION; BOARD ON HEALTH SCIENCES POLICY; COMMITTEE ON PREVENTING DEMENTIA AND COGNITIVE IMPAIRMENT; DOWNEY, A., STROUD, C., LANDIS, S. et al. (eds.). Preventing Cognitive Decline and Dementia: A Way Forward. Washington (DC): National Academies Press (US); 2017. ISBN 978-0309459594.

NATIONAL INSTITUTES OF HEALTH. The Dementias. Hope Through Research. $\mathrm{NIH}, 2017$. Accessible at: https://catalog.ninds.nih.gov/pubstatic//17-NS-2252/ 17-NS-2252.pdf

NEWMAN, J. C. Copyright and bedside cognitive testing why we need alternatives to the Mini-Mental State Examination. JAMA internal medicine. 2015; 175(9): 1459-1460. ISSN 2168-6106.

NICE. Dementia, disability and frailty in later life - mid-life approaches to delay or prevent onset. London: National Institute for Health and Care Excellence, 2015. Accessible at: https://www.nice.org.uk/guidance/ng16/resources/dementiadisability-and-frailty-in-later-life-midlife-approaches-to-delay-or-prevent-onsetpdf-1837274790085

NIELSEN, A. B., SIERSMA, V., WALDEMAR, G., WALDORFF, F. B. Poor selfrated health did not increase risk of permanent nursing placement or mortality in people with mild Alzheimer's disease. BMC geriatrics. 2016; 16: 87. ISSN 1471-2318. 
NIKMAT, A., HAWTHORNE, G., AL-MASHOOR, S. The comparison of quality of life among people with mild dementia in nursing home and home care - a preliminary report. Dementia. 2015; 14(1): 114-125. ISSN 1471-3012.

NORDENFELT, L. The varieties of dignity. Health Care Analysis. 2004; 2(2): 69-81. ISSN $1065-3058$.

NOVELLI, M. M., NITRINI, R., CARAMELLI, P. Validation of the Brazilian version of the quality of life scale for patients with Alzheimer's disease and their caregivers (QOL-AD). Aging and Mental Health. 2010; 14(5): 624-631. ISSN 1360-7863.

O'ROURKE, H., DUGGLEBY, W., FRASER, K., JERKE, L. Factors that affect quality of life from the perspective of people with dementia: a metasynthesis. Journal of The American Geriatrics Society. 2015; 63(1): 24-38. ISSN 0002-8614.

O'BRIEN, J. T., THOMAS, A. Vascular dementia. Lancet. 2015;386(10004):1698-16706. ISSN 0140-6736.

OLNEY, N. T., SPINA, S., MILLER, B. L. Frontotemporal dementia. Neurologic clinics. 2017; 35(2): 339-374. ISSN 0733-8619.

OOSTERVELD-VLUG, M. G., PASMAN, H. R., VAN GENNIP, I. E. et al. Dignity and the factors that influence it according to nursing home residents: a qualitative interview study. Journal of Advanced Nursing. 2014; 70(1): 97-106. ISSN 0309-2402.

ORGETA, V., ORELL, M., HOUNSOME, B. et al. Self and carer perspectives of quality of life in dementia using the QoL-AD. International journal of geriatric psychiatry. 2014; 30(1): 97-104. ISSN 0885-6230.

ORPWOOD, R., SIXSMITH, A., TORRINGTON, J. et al. Designing technology to support quality of life of people with dementia. Technology \& Disability. 2007; 19(2-3): 103-112. ISSN 1055-4181.

ORRELL, M., HANCOCK, G., GALBODA LIYANAGE, K. C. et al. The needs of people with dementia in care homes: the perspectives of users, staff and family caregivers. International Psychogeriatrics. 2008; 20(5): 941-951. ISSN 1041-6102.

OUDMAN, E., VEURINK, B. Quality of life in nursing home residents with advanced dementia: a 2-year follow-up. Psychogeriatrics. 2014; 14(4): 235-240. ISSN 1346-3500.

PARK, J., JEONG, E., SEOMUN, G. The clock drawing test: A systematic review and meta-analysis of diagnostic accuracy. Journal of Advanced Nursing. 2018; 74(12): 2742-2754. ISSN 0309-2402. 
PAUTEX, S., HERRMANN, F., LE LOUS, P. et al. Feasibility and reliability of four pain self-assessment scales and correlation with an observational rating scale in hospitalized elderly demented patients. The journals of gerontology. Series A, Biological sciences and medical sciences. 2005; 60(4): 524-529. ISSN 1079-5006.

PEREIRA, A., FERREIRA, A., MARTINS, J. People with Dementia in the Community: Satisfaction with Life and Health-related Quality of Life. European Researcher. 2015; 92(3): 222-229. ISSN 2219-8229.

PIDRMAN, V. Demence. Vyd. 1. Praha: Grada, 2007. 183 s. ISBN 978-80-247-1490-5.

PITKÄLÄ, K., PÖYSTI, M., LAAKKONEN, M. et al. Effects of the Finnish Alzheimer Disease Exercise Trial (FINALEX). A Randomized Controlled Trial. Journal of the American Medical Association internal medicine. 2013; 173(10): 894-901. ISSN 2168-6106.

POTTER, R., ELLARD, D., REES, K., THOROGOOD, M. A systematic review of the effects of physical activity on physical functioning: quality of life and depression in older people with dementia. International Journal of Geriatric Psychiatry. 2011; 26(10): 1000-1011. ISSN 0885-6230.

PREISS, M., VACíŘ, K. Beckova sebeposuzovací škála depresivity pro dospělé: BDI-II. Príručka. Brno: Psychodiagnostika, 1999.

QUANTE M. Quality of life assessment and human dignity: Against the incompatibility- assumption. Poiesis \& Praxis. 2005; 3(3): 168-180. ISSN 1615-6617.

RABIN, L. A., SMART, C. M., AMARIGLIO, R. E. Subjective Cognitive Decline in Preclinical Alzheimer's Disease. Annual review of clinical psychology. 2017; 8(13): 369-396. ISSN 1548-5943.

RABINS, P. V. Measuring quality of life in persons with dementia. International Psychogeriatrics. 2000; 12(51): 47-49. ISSN 1041-6102.

RABINS, P. V., KASPER, J. D., KLEINMAN, L. et al. Concepts and methods in the development of the ADRQL: an instrument for assessing health-related quality of life in persons with Alzheimer's disease. Journal of Mental Health and Aging. 1999; 5(1): 33-48. ISSN 1078-4470.

RABINS, V., BLACK, S. Measuring quality of life in dementia: purposes, goals, challenges and progress. International Psychogeriatrics. 2007; 19(3): 401-407. ISSN 1041-6102.

RABOCH, J. et al. Klinická psychiatrie v denní praxi. 1. vyd. Praha: Galén, 2008. 158 p. ISBN 978-80-7262-586-4. 
READY, R. E., OTT, B. R., GRACE, J. Insight and cognitive impairment: effects on quality-of-life reports from mild cognitive impairment and Alzheimer's disease patients. American Journal of Alzheimer's Disease Other Dementias. 2006; 21(4): 242-248. ISSN 1533-3175.

REGULI, Z., SVOBODOVÁ, L. Česká verze diagnostiky strachu z pádů u seniorů FES-I (Falls Efficacy Scale International) [Czech version of the diagnosis of fear of falls in seniors - FES-I (Falls Efficacy Scale International)]. Studia sportive. 2011; 5(2): 5-12. ISSN 2570-8783.

REISBERG, B., FERRIS, S., DE LEON, M., CROOK, T. The Global Deterioration Scale for assessment of primary degenerative dementia. The American journal of psychiatry. 1982; 139(9): 1136-1139. ISSN 0002-953X.

REJEH, N., HERAVI-KARIMOOI, M., VAISMORADI, M. et al. Psychometric properties of the Farsi version of Attitudes to Aging Questionnaire in Iranian older adults. Clinical interventions in aging. 2017; 12: 1531-1542. ISSN 1176-9092.

REKTOROVÁ, I. Screeningové škály pro hodnocení demence. Neurologie pro praxi. 2011; 12 (Suppl. G): 37-45. ISSN 1213-1814.

RICCI, M., PIGLIAUTILE, M., D'AMBROSIO, V. et al. The clock drawing test as a screening tool in mild cognitive impairment and very mild dementia: A new brief method of scoring and normative data in the elderly. Neurological sciences: official journal of the Italian Neurological Society and of the Italian Society of Clinical Neurophysiology. 2016; 37(6): 867-873. ISSN 1590-1874.

RITTER-RAUCH, R. Život s demencí. 2016. Accessible at: http://www.apsscr.cz/ files/files/\%C5\%BDivot\%20s\%20demenc\%C3\%AD_Tipy\%20pro\%2orodinn\%C3\%A9\%20 p\%C5\%99\%C3\%ADslu\%C5\%A1n\%C3\%ADky.pdf

ROBERTSON, D. A., KING-KALLIMANIS, B. L., KENNY, R. A. Negative perceptions of aging predict longitudinal decline in cognitive function. Psychology and Aging. 2016; 31(1): 71-81. ISSN 0882-797.

ROBERTSON, D., SAVVA, G., KENNY, R. Frailty and cognitive impairment - A review of the evidence and causal mechanisms. Ageing research reviews. 2013; 12(4): 840-851. ISSN 1568-1637.

ROCKWOOD, K., MIDDLETON, L. Physical activity and the maintenance of cognitive function. Alzheimer's \& dementia: the journal of the Alzheimer's Association. 2007; 3(2 Suppl): 38-44. ISSN 1552-5260.

RODAKOWSKI, J., SKIDMORE, E. R., REYNOLDS, C. F. et al. Can performance on daily activities discriminate between older adults with normal cognitive func- 
tion and those with mild cognitive impairment? Journal of the American Geriatrics Society. 2014; 62(7): 1347-1352. ISSN 0002-8614.

ROKNE, B., WAHL, A. K. Quality of life assessment in health sciences. In: Reuschenbach B., Mahler C. (eds.). Pflegebezogene Assessmentinstrumente: Internationales Handbuch für Pflegeforschung und-praxis. Bern: Huber, 2011, pp. 401-416. ISBN 978-34-56844-98-5.

ROSENBERG, M. Society and the Adolescent Self-Image. Princeton, NJ: Princeton University Press, 1965.

ROSENBERG, R. Health-related quality of life between naturalism and hermeneutics. Social Science \& Medicine. 1995; 41(10): 1411-1415. ISSN 0277-9536.

RUGGIERO, C., MARIANI, T., GUGLIOTTA, R. et al. Validation of the Italian version of the Falls Efficacy Scale International (FES-I) and the Short FES-I in community-dwelling older persons. Archives of gerontology and geriatrics. 2009; 49(Suppl 1): 211-219. ISSN 0167-4943.

RUSSELL, C. Passion and heretics: meaning in life and quality of life of persons with dementia. Journal of the American Geriatrics Society. 1996; 44(11): 1400-1402. ISSN 0002-8614.

RUSSELL, C., MIDDLETON, H., SHANLEY, C. Dying with dementia: the views of family caregivers about quality of life. Australasian Journal on Ageing. 2008; 27(2): 89-92. ISSN 1440-6381.

SABIA, S., DUGRAVOT, A., DARTIGUES, J. F. et al. Physical activity, cognitive decline, and risk of dementia: 28 year follow-up of Whitehall II cohort study. BMJ: British medical journal. 2017; 357: j2709. ISSN 0959-8138.

SAMUS, Q., ROSENBLATT, A., STEELE, C. et al. The association of neuropsychiatric symptoms and environment with quality of life in assisted living residents with dementia. The Gerontologist. 2005; 45 Spec No 1(1): 19-26. ISSN 0016-9013. SANFORD, A. M. Lewy Body Dementia. Clinics in geriatric medicine. 2018; 34(4): 603-615. ISSN 0749-0690.

SELAI, C., TRIMBLE, M. R. Assessing quality of life in dementia. Aging and Mental Health. 1999; 3(2): 101-111. ISSN 1360-7863.

SELAI, C., VAUGHAN, A., HARVEY, R. J., LOGSDON, R. Using the QoL-AD in the UK. International Journal of Geriatric Psychiatry. 2001; 16(5): 537-538. ISSN 0885-6230. 
SELWOOD, A., THORGRIMSEN, L., ORRELL, M. Quality of life in dementia a one-year follow-up study. International Journal of Geriatric Psychiatry. 2005; 20(3): 232-237. ISSN 0885-6230.

SESHADRI, M., MAZI-KOTWAL, N. A copyright-free alternative to the MiniMental State Examination is needed. BMJ. 2012; 345: e8589. ISSN 1756-1833.

SETIATI, S., HARIMURTI, K., DEWIASTY, E., ISTANTI, R. Predictors and Scoring System for Health-related Quality of life in an Indonesian Community-dwelling elderly Population. Acta medica Indonesiana. 2011; 43(4): 237-242. ISSN 0125-9326.

SHAH, H., ALBANESE, E., DUGGAN, C. et al. Research priorities to reduce the global burden of dementia by 2025. The Lancet Neurology. 2016; 15(2): 1285-1294. ISSN 1474-4422.

SHEEHAN, B. D., LALL, R., STINTON, C. et al. Patient and proxy measurement of quality of life among general hospital in-patients with dementia. Aging and Mental Health. 2012; 16(5): 603-607. ISSN 1360-7863.

SHEIKH, J. I., YESAVAGE, J. A. Geriatric Depression Scale (GDS). Recent evidence and development of a shorter version. In: Brink, T. L. (ed.). Clinical Gerontology: A Guide to Assessment and Intervention (pp. 165-173). NY: The Haworth Press, Inc., 1986. ISBN 9780866565363.

SHENKIN, S. D., WATSON, R., LAIDLAW, K., STARR, J. M., DEARY, I. J. The attitudes to the Attitudes to Ageing Questionnaire: Mokken Scaling Analysis. PLoS One. 2014; 9(6): e99100. ISSN 1932-6203.

SHIROOKA, H., NISHIGUCHI, S., FUKUTANI, N. et al. Cognitive impairment is associated with the absence of fear of falling in community-dwelling frail older adults. Geriatrics and Gerontology International. 2017; 17(2): 232-238. ISSN 1444-1586.

SHULMAN, K. I. Clock-drawing: Is it the ideal cognitive screening test? International Journal of Geriatric Psychiatry. 2000; 15(6): 548-561. ISSN 0885-6230.

SHULMAN, K. I., HERRMANN, N., BRODATY, H. et al. IPA survey of brief cognitive screening instruments. International Psychogeriatrics. 2006; 18(2): 281-294. ISSN 1041-6102.

SCHEFFER, A. C., SCHUURMANS, M. J., VAN DIJK, N., VAN DER HOOFT, T., DE ROOIJ, S. E. Fear of falling: measurement strategy, prevalence, risk factors and consequences among older persons. Age and Ageing. 2008; 37(1): 19-24. ISSN 0002-0729. 
SCHERDER, E., HERR, K., PICKERING, G., GIBSON, S., BENEDETTI, F., LAUTENBACHER, S. Pain in dementia. Pain. 2009; 145(3): 276-278. ISSN 0304-3959.

SCHÖLZEL-DORENBOS, C. J., ETTEMA, T. P., BOS, J. et al. Evaluating the outcome of interventions on quality of life in dementia: selection of the appropriate scale. International Journal of Geriatric Psychiatry. 2007; 22(6): 511-519. ISSN 0885-6230.

SIEBERT, J. S., WAHL, H. W., DEGEN, C., SCHRÖDER, J. Attitude toward own aging as a risk factor for cognitive disorder in old age: 12-year evidence from the ILSE study. Psychology and Aging. 2018; 33(3): 461-472. ISSN 0882-797.

SIKKES, S. A., DE LANGE-DE KLERK, E. S., PIJNENBURG, Y. A., SCHELTENS, P., UITDEHAAG, B. M. A systematic review of instrumental Activities of Daily Living scales in dementia: room for improvement. Journal of neurology, neurosurgery, and psychiatry. 2009; 80(1): 7-12. ISSN 0022-3050.

SILBERFELD, M., SERGIO, R., KRAHN, M., NAGLIE, G. Content validity for dementia of three generic preference based health related quality of life instruments. Quality of Life Research. 2002; 11(1): 71-78. ISSN 0962-9343.

SIRGY, M. J., MICHALOS, A. C., FERRISS, A. L. et al. The quality of life (QoL) research movement: past, present and future. Social Indicators Research. 2006; 76(3): 343-462. ISSN 0303-830.

SIVERTSEN, H., BJØRKLØF, G. H., ENGEDAL, K., SELBÆK, G., HELVIK, A. S. Depression and Quality of Life in Older Persons: A Review. Dementia and Geriatric Cognitive Disorders. 2015; 40(5-6): 311-139. ISSN 1420-8008.

SLOANE, P., ZIMMERMAN, S., WILLIAMS, C. et al. Evaluating the quality of life of long-term care residents with dementia. The Gerontologist. 2005; 45 Spec No 1(1): 37-49. ISSN 0016-9013.

SOLOMON, P. R., HIRSCHOFF, A., KELLY, B. et al. A 7-minute neurocognitive screening battery highly sensitive to Alzheimer's disease. Archives of neurology. 1998; 55(3): 349-355. ISSN 0003-9942.

SONG, D., YU, D. S., LI, P. W., HE, G., SUN, Q. Correlates of Health-Related Quality of Life Among Chinese Older Adults with Mild Cognitive Impairment. Clinical interventions in aging. 2019; 14: 2205-2212. ISSN 1176-9092.

SORRELL, J. M. Listening in thin places: Ethics in the care of persons with Alzheimer's disease. Advances in nursing science. 2006; 29(2): 152-160. ISSN 0161-9268.

SOUILLARD-MANDAR, W., DAVIS, R., RUDIN, C. et al. Learning classification models of cognitive conditions from subtle behaviors in the digital clock drawing test. Machine Learning. 2016; 102(3): 393-441. ISSN 0885-6125. 
ST JOHN, P., MONTGOMERY, P. Cognitive impairment and life satisfaction in older adults. Internatiol Journal of Geriatric Psychiatry. 2010; 25(8): 814-821. ISSN 0885-6230.

STARKSTEIN, S. E., JORGE, R., MIZRAHI, R., ROBINSON, R. G. A diagnostic formulation for anosognosia in Alzheimer's disease. Journal of neurology, neurosurgery, and psychiatry. 2006; 77(6): 719-725. ISSN 0022-3050.

SUGAWARA, N., YASUI-FURUKORI, N., UMEDA, T. et al. Clock drawing performance in a community-dwelling population: Normative data for Japanese subjects. Aging and Mental Health. 2010; 14(5): 587-592. ISSN 1360-7863.

SUNDERLAND, T., HILL, J. L., MELLOW, A. M. et al. Clock drawing in Alzheimer's disease. A novel measure of dementia severity. Journal of the American Geriatrics Society. 1989; 37(8): 725-729. ISSN 0002-8614.

ŠTĚPÁNKOVÁ, H., NIKOLAI, T., LUKAVSKY, J. et al. M. Mini-Mental State Examination - česká normativní studie. Česká a slovenská neurologie a neurochirurgie. 2015; 78/111(1): 57-63. ISSN 1210-7859.

TAKENOSHITA, S., TERADA, S., YOSHIDA, H. et al. Validation of Addenbrooke's cognitive examination III for detecting mild cognitive impairment and dementia in Japan. BMC Geriatric. 2019; 19(1): 123. ISSN 1471-2318.

TAN, E., VISVANATHAN, R., HILMER, S. et al. Analgesic use and pain in residents with and without dementia in aged care facilities: A cross-sectional study. Australasian journal on ageing. 2016; 35(3): 180-187. ISSN 1440-6381.

TAN, E., VISVANATHAN, R., HILMER, S. et al. Analgesic use, pain and daytime sedation in people with and without dementia in aged care facilities: a cross-sectional, multisite, epidemiological study protocol. BMJ Open. 2014; 4(6): e005757. ISSN 2044-6055.

TANGALOS, E. G., PETERSEN, R. C. Mild Cognitive Impairment in Geriatrics. Clinics in geriatric medicine. 2018; 34(4):563-589. ISSN 0749-0690.

TATSUMI, H., NAKAAKI, S., TORII, K. et al. Neuropsychiatric symptoms predict change in quality of life of Alzheimer disease patients: A two-year follow-up study. Psychiatry and Clinical Neurosciences. 2009; 63(3): 374-384. ISSN 1323-1316.

TENG, E., TASSNIYON, K., LU, P. Reduced quality-of-life ratings in Mild Cognitive Impairment: analyses of subject and informant ratings. American Journal of Geriatric Psychiatry. 2012; 20(12): 1016-1025. ISSN 1064-7481. 
TERI, L., LOGSDON, R. G. Identifying pleasant activities for Alzheimer's disease patients: the Pleasant Events Schedule-AD. Gerontologist. 1991; 31(1): 124-7. ISSN 0016-9013.

THE INSTITUTE OF HEALTH INFORMATION AND STATISTICS OF THE CZECH REPUBLIC (IHIS CR). Aktuální informace č. 57/2013. Accessible at: https://www. uzis.cz/sites/default/files/knihovna/ai_2013_57.pdf

THE INSTITUTE OF HEALTH INFORMATION AND STATISTICS OF THE CZECH REPUBLIC (IHIS CR). Demence: priorita pro systém zdravotnictví (zpráva WHO). 2012. Accessible at: https://www.uzis.cz/index.php?pg=record\&id=5725

The WHOQOL Group. Study protocol for the World Health Organization Project to develop a quality of life assessment instrument (WHOQOL). Quality of Life Research. 1993; 2(2): 153-159. ISSN 0962-9343.

The WHOQOL Group. The World Health Organization Quality of life Assessment (WHOQOL): position paper from the World Health Organization. Social Science and Medicine. 1995; 41(10): 1403-1409. ISSN 0277-9536.

THE WORLD HEALTH ORGANIZATION. Dementia: A Public Health Priority. 2012, Geneva: WHO Press.

THE WORLD HEALTH ORGANIZATION. Global action plan on the public health response to dementia 2017-2025. 2017, Geneva, Switzerland: WHO. ISBN 978-92-4-151348-7

THORGRIMSEN, L., SELWOOD, A., SPECTOR, A. et al. Whose quality of life is it anyway? The validity and reliability of the Quality of Life-Alzheimer's Disease (QoL-AD) Scale. Alzheimer's Disease and Associated Disorders. 2003; 17(4): 201-208. ISSN 0893-0341.

TINETTI, M. E., POWELL, L. Fear of falling and low self-efficacy: a case of dependence in elderly persons. Journal of Gerontology. 1993; 48(Spec No): 35-38. ISSN 0022-1422.

TOMBAUGH, T. N., McINTYRE, N. J. The Mini-Mental State Examination: a comprehensive review. Journal of the American Geriatrics Society. 1992; 40(9): 922- 935. ISSN 0002-8614.

TOP, M., DIKMETAS, E. Quality of life and attitudes to ageing in Turkish older adults at old people's homes. Health expectations: an international journal of public participation in health care and health policy. 2015; 18(2): 288-300. ISSN 1369-6513. 
TOP, M., ERIS, H., KABALCIOGLU, F. Quality of life (QOL) and attitudes toward aging in older adults in Şanlıurfa, Turkey. Research on Aging. 2012; 35(5): 533-562. ISSN 0164-0275.

TOŠNEROVÁ, T., BAHBOUH, R. Mini-mental state - rychlé orientační vyšetření kognitivního stavu [Mini-Mental State Examination: A quick cognitive state test]. Československá Psychologie: Časopis Pro Psychologickou Teorii a Praxi. 1998; 42(4): 328-333. ISSN 0009-062X.

TOŠNEROVÁ, T., BAHBOUH, R. Orientační škála deprese: Geriatric Depression Scale dle Yesavage (shortened version). 1999. Praha: Ambulance pro poruchy paměti FNKV.

TRANVAG, O., PETERSEN, K. A., NÅDEN, D. Crucial dimensions constituting dignity experience in persons living with dementia. Dementia. 2016; 15(4): 578-595. ISSN 1471-3012.

TRANVAG, O., PETERSEN, K. A., NÅDEN, D. Relational interactions preserving dignity experience: Perceptions of persons living with dementia. Nursing Ethics. 2015; 22(5): 577-593. ISSN 0969-7330.

TRIGG, R., JONES, R. W., SKEVINGTON, S. M. Can people with mild to moderate dementia provide reliable answers about their quality of life? Age and Ageing. 2007; 36(6): 663-669. ISSN 0002-0729.

TRIGG, R., WATTS, S., JONES, R. et al. Self-reported quality of life rating of people with dementia: the role of attitudes to aging. International Psychogeriatrics. 2012; 24(7): 1085-1093. ISSN 1041-6102.

TROMBETTI, A., REID, K. F., HARS, M. et al. Age-associated declines in muscle mass, strength, power, and physical performance: impact on fear of falling and quality of life. Osteoporosis international: a journal established as result of cooperation between the European Foundation for Osteoporosis and the National Osteoporosis Foundation of the USA. 2016; 27(2): 463-471. ISSN 0937-941X.

UEMURA, K., SHIMADA, H., MAKIZAKO, H. et al. A lower prevalence of selfreported fear of falling is associated with memory decline among older adults. Gerontology. 2012; 58(5): 413-418. ISSN 0304-324X.

UEMURA, K., SHIMADA, H., MAKIZAKO, H. et al. Effects of mild and global cognitive impairment on the prevalence of fear of falling in community-dwelling older adults. Maturitas. 2014; 78(1): 62-66. ISSN 0378-5122.

ULUS, Y., DURMUS, D., AKYOL, Y. et al. Reliability and validity of the Turkish version of the Falls Efficacy Scale International (FES-I) in community-dwelling 
older persons. Archives of gerontology and geriatrics. 2012; 54(3): 429-433. ISSN 0167-4943.

UNITED NATIONS (UN). World Population Ageing 2017. 2017. New York, NY: UN. Accessible at: https://www.un.org/en/development/desa/population/publications/pdf/ageing/WPA2017_Report.pdf

UNITED NATIONS POPULATION FUND (UNPF) and HelpAge International. Ageing in the twenty-first century: a celebration and a challenge. 2012. New York, accessible at: https://www.unfpa.org/sites/default/files/pub-pdf/Ageing\%2oreport.pdf

VALENZUELA, M. J. Brain reserve and the prevention of dementia. Current opinion in psychiatry. 2008; 21(3): 296-302. ISSN 0951-7367.

VALENZUELA, M. J., SACHDE, V. P. Brain reserve and dementia: a systematic review. Psychological medicine. 2006; 36(4): 441-454. ISSN 0033-2917.

VAN DE BEEK, M., VAN STEENOVEN, I., RAMAKERS, I. H. G. B. et al. Trajectories and Determinants of Quality of Life in Dementia with Lewy Bodies and Alzheimer's Disease. Journal of Alzheimer's disease. 2019; 70(2): 389-397. ISSN 1387-2877.

VAN DE VIJVER, F., TANZER, N. K. Bias and equivalence in cross-cultural assessment: an overview. European Review of Applied Psychology-Revue Europeenne De Psychologie Appliquee. 2004; 54(2): 119-135. ISSN 1162-9088.

VAUGHAN, S., WALLIS, M., POLIT, D. et al. The effects of multimodal exercise on cognitive and physical functioning and brain-derived neurotrophic factor in older women: a randomised controlled trial. Age and Ageing. 2014; 43(5): 623-629. ISSN 0002-0729.

VELAYUDHAN, L., RYU, S. H., RACZEK, M. et al. Review of brief cognitive tests for patients with suspected dementia. International Psychogeriatrics. 2014; 26(8): 1247-1262. ISSN 1041-6102.

VENTURATO, L. Dignity: dining and dialogue: reviewing the literature on quality of life for people with dementia. International Journal of Older People Nursing. 2010; 5(3): 228-234. ISSN 1748-3735.

VERLOO, H., SALINA, A., FIORENTINO, A., COHEN, C. Factors influencing the quality of life perceptions of cognitively impaired older adults in a nursing home and their informal and professional caregivers: a mixed methods study. Clinical interventions in aging. 2018; 13: 2135-47. ISSN 1176-9092. 
VOGEL, A., BHATTACHARYA, S., WALDORFF, F. B., WALDEMAR, G. Proxy-rated quality of life in Alzheimer's disease: A three-year longitudinal study. International Psychogeriatrics. 2012; 24(1): 82-89. ISSN 1041-6102.

VOGEL, A., MORTENSEN, E. L., HASSELBALCH, S. G., ANDERSEN, B. B., WALDEMAR, G. Patient versus informant reported quality of life in the earliest phases of Alzheimer's disease. International Journal of Geriatric Psychiatry. 2006; 21(12): 1132-1138. ISSN 0885-6230.

VYHNÁLEK, M. Frontotemporální demence. Psychiatrie pro praxi. 2017; 18(3): 140-142. ISSN 1213-0508.

WALKER, A. A European perspective on quality of life in old age. European Journal of Ageing. 2005; 2(1): 2-12. ISSN 1613-9372.

WALKER, A. Ageing and quality of life in Europe. In: Phillipson, C., Dannefe, D. (eds.). The SAGE Handbook of Social Gerontology. 2010. London: Sage, pp. 573-586. ISBN 9781446248393.

WALKER, M. D., SALEK, S., BAYER, A. J. A review of quality of life in Alzheimer's disease. Pharmacoeconomics. 1998; 14(5): 499-530. ISSN 1170-7690.

WANG, B. R., OU, Z., GU, X. H. et al. Validation of the Chinese version of Addenbrooke's cognitive examination III for diagnosing dementia. International Journal of Geriatric Psychiatry. 2017; 32(12): e173-e179. ISSN 1099-1166.

WETZELS, B., ZUIDEMA, U., JONGHE, F., VERHEY, R., KOOPMANS, T. Determinants of quality of life in nursing home residents with dementia. Dementia and Geriatric Cognitive Disorders. 2010; 29(3): 189-197. ISSN 1420-8008.

WHITEHOUSE, P. J., ORGOGOZO, J. M., BECKER, R. E. Quality-of-life assessment in dementia drug development. Position paper from the International Working Group on Harmonization of Dementia Drug Guidelines. Alzheimer's Disease and Associated Disorders. 1997; 11 (Suppl 3): 56-60. ISSN 0893-0341.

WHITEHOUSE, P. J., RABINS, P. V. Quality of life and dementia. Alzheimer's Disease and Associated Disorders. 1992; 6(3): 135-137. ISSN 0893-0341.

WILLIAMS, D. R., HOLTON, J. L., STRAND, K., REVESZ, T., LEES, A. J. Pure Akinesia with gait freezing: a third clinical phenotype of progressive supranuclear palsy. Movement disorders: official journal of the Movement Disorder Society. 2007; 22(15): 2235-2241.

WIND, A. W., SCHELLEVIS, F. G., VAN STAVEREN, G. et al. Limitations of the Mini-Mental State Examination in diagnosing dementia in general practice. International journal of geriatric psychiatry. 1997; 12(1): 101-108. ISSN 0885-6230. 
WINZELBERG, G., WILLIAMS, C., PREISSER, J., ZIMMERMAN, S., SLOANE, P. Factors associated with nursing assistant quality-of-life ratings for residents with dementia in long-term care facilities. The Gerontologist. 2005; 45 Spec No 1 (1): 106-114. ISSN 0016-9013.

WOLAK, A., NOVELLA, J. L., DRAME, M. et al. Transcultural adaptation and psychometric validation of a French-language version of the QoL-AD. Aging and Mental Health. 2009; 13(4): 593-600. ISSN 1360-7863.

WOLF-OSTERMANN, K., WORCH, A., MEYER, S., GRÄSKE, J. Original article: quality of care and its impact on quality of life for care-dependent persons with dementia in shared-housing arrangements: results of the Berlin WGQual-study. Applied Nursing Research. 2014; 27(1): 33-40. ISSN 0897-1897.

WOODS, R. T., NELIS, S. M., MARTYR, A. et al. What contributes to a good quality of life in early dementia? Awareness and the QoL-AD: a cross-sectional study. Health and Quality of Life Outcomes. 2014; 12:94. ISSN 1477-7525.

WRÓBLEWSKA, I., TALARSKA, D., WRÓBLEWSKA, Z., SUSŁO, R., DROBNIK, J. Pain and symptoms of depression: international comparative study on selected factors affecting the quality of life of elderly people residing in institutions in Europe. BMC Geriatrics. 2019; 19(1): 147. ISSN 1471-2318.

WYANT, K. J., RIDDER, A. J., DAYALU, P. Huntington's Disease-Update on Treatments. Current neurology and neuroscience reports. 2017; 17(4): 33. ISSN 1528-4042.

YAMADA, Y., MERZ, L., KISVETROVA, H. Quality of life and comorbidity among older home care clients: role of positive attitudes toward aging. Quality of Life Research. 2015; 24(7): 1661-1667. ISSN 0962-9343.

YARDLEY, L., BEYER, N., HAUER, K. et al. Development and initial validation of the Falls Efficacy Scale International (FES-I). Age and Ageing. 2005; 34(6): 614-619. ISSN 0002-0729.

YARDLEY, L., SMITH, H. A prospective study of the relationship between feared consequences of falling and avoidance of activity in community-living older people. Gerontologist. 2002; 42(1): 17-23. ISSN 0016-9013.

YDSTEB $\varnothing$, A. E., BERGH, S., SELBÆE, G. et al. Longitudinal changes in quality of life among elderly people with and without dementia. International Psychogeriatrics. 2018; 30(11): 1607-1618. ISSN 1041-6102.

YESAVAGE, J. A., BRINK, T. L., ROSE, T. L. et al. Development and validation of a geriatric depression screening scale: A preliminary report. Journal of Psychiatric Research. 1983; 17(1): 37-49. ISSN 0022-3956. 
YESAVAGE, J. A., SHEIKH, J. I. 9/Geriatric Depression Scale (GDS) Recent evidence and development of a shorter. Clinical Gerontologist. 1986; 5(1-2): 165-173. ISSN 0731-7115.

YOUNG, T., MANTHORP, C., HOWELLS, D., TULLO, E. Developing a carer communication intervention to support personhood and quality of life in dementia. Ageing and Society. 2011; 31(6): 1003-1008. ISSN 0144-686X.

ZIJLSTRA, G. A., VAN HAASTREGT, J. C., VAN EIJK, J. T. et al. Prevalence and correlates of fear of falling, and associated avoidance of activity in the general population of community-living older people. Age and Ageing. 2007a; 36(3): 304-309. ISSN 0002-0729.

ZIJLSTRA, G. A., VAN HAASTREGT, J. C., VAN ROSSUM, E. et al. Interventions to reduce fear of falling in community-living older people: a systematic review. Journal of the American Geriatrics Society. 2007b; 55(4): 603-615. ISSN 0002-8614. 
Kisvetrová, Helena

Dementia and quality of life / Helena Kisvetrová; translation Helena Tylšarová. -First edition. -- Olomouc: Palacký University Olomouc, 2020. -- 1 online zdroj

Nad názvem: Palacký University Olomouc, Faculty of Health Sciences. -Obsahuje bibliografii a rejstř́ky

ISBN 978-80-244-5778-9 (online ; pdf)

* 616-053.9*616.892/.894*616.892/.894-052 *316.346.32-053.9*316.728-021.465 * $001.891-028.46 * 614.2: 001.891 *(437.3) *(048.8)$

- 2016-2019

- 21. století

- geriatrie

- demence

- pacienti s demencí

- senioři

- kvalita života

- empirický výzkum -- Česko -- 21. století

- zdravotnický výzkum -- Česko -- 21. století

- monografie

616-053.9 - Geriatrie [14] 
Helena Kisvetrová

\title{
Dementia and quality of life
}

\author{
Executive editor Šárka Vévodová \\ Translation Helena Tylšarová \\ In-house editor Tereza Vintrová \\ Layout Jitka Bednaříková \\ Cover Ivana Perůtková \\ Published by Palacký University Olomouc \\ Kř́žkovského 8, 77147 Olomouc \\ www.vydavatelstvi.upol.cz \\ www.e-shop.upol.cz \\ vup@upol.cz
}

The publication has not been subjected to any language editing review by the publishing house.

First edition

Olomouc 2020

DOI: $10.5507 / f z v .20 .24457772$

ISBN 978-80-244-5777-2 (print)

ISBN 978-80-244-5778-9 (online: PDF)

VUP 2020/0272

VUP 2020/0273 